\title{
WestVirginiaUniversity
}

THE RESEARCH REPOSITORY @ WVU

Graduate Theses, Dissertations, and Problem Reports

2004

\section{Constraint-based facilities planning}

Tafazzul Ahmed Khan

West Virginia University

Follow this and additional works at: https://researchrepository.wvu.edu/etd

\section{Recommended Citation}

Khan, Tafazzul Ahmed, "Constraint-based facilities planning" (2004). Graduate Theses, Dissertations, and Problem Reports. 1545.

https://researchrepository.wvu.edu/etd/1545

This Thesis is protected by copyright and/or related rights. It has been brought to you by the The Research Repository @ WVU with permission from the rights-holder(s). You are free to use this Thesis in any way that is permitted by the copyright and related rights legislation that applies to your use. For other uses you must obtain permission from the rights-holder(s) directly, unless additional rights are indicated by a Creative Commons license in the record and/ or on the work itself. This Thesis has been accepted for inclusion in WVU Graduate Theses, Dissertations, and Problem Reports collection by an authorized administrator of The Research Repository @ WVU. For more information, please contact researchrepository@mail.wvu.edu. 


\title{
Constraint Based Facilities Planning
}

\author{
Tafazzul Ahmed Khan
}

Thesis submitted to the

College of Engineering and Mineral Resources

at West Virginia University

in partial fulfillment of the requirements

for the degree of

\author{
Master of Science \\ in \\ Industrial Engineering
}

B. Gopalakrishnan, Ph.D., Chair

Ralph Plummer, Ph.D.

Robert Creese, Ph.D.

Department of Industrial Engineering

Morgantown, West Virginia

2004

Keywords: Facilities Planning, Facility Layout, Facility Design, Manufacturing Parameters, Layout Effectiveness, M-CRAFT 


\section{ABSTRACT \\ Constraint Based Facilities Planning \\ Tafazzul Ahmed Khan}

In recent years a large variation of production volume for the mass-production products happens frequently due to the changes in technology and market. Those changes cause introduction of new products having shorter life cycles, thus enforcing modification and renewal of production facilities much earlier than their lifetime. A model was built to assess the impact of manufacturing parameters on the effectiveness of the layout and the material handling system. A relationship was developed between variations in production oriented parameters and its impact on the facility size and final cost of the product being manufactured exclusively in terms of machine time, operator time and material handling duration. A job shop manufacturing scenario was considered for this analysis and a "Powerarm" [22] was considered as the product being manufactured. The various manufacturing parameters involved are considered one at a time and varied keeping the other parameters constant and their impact on the facility layout effectiveness is determined. 


\section{ACKNOWLEDGEMENTS}

I would like to wholeheartedly thank my advisor Dr. B. Gopalakrishnan for his continued support, guidance and encouragement during the course of this research work. I also wish to thank Dr. Ralph Plummer and Dr. Robert Creese, my committee members, for their advice and support. Above all, I wish to thank God, my family for being there for me always and supporting me and my friends for their constant support and help in all my endeavors. 


\section{TABLE OF CONTENTS}

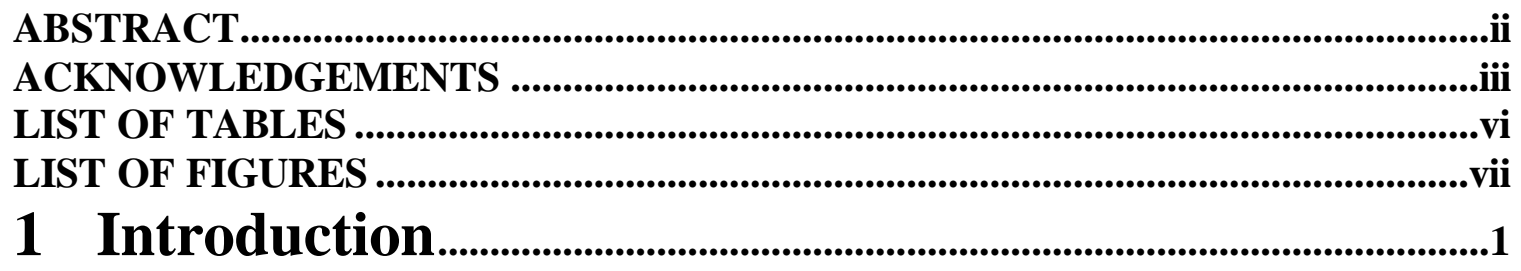

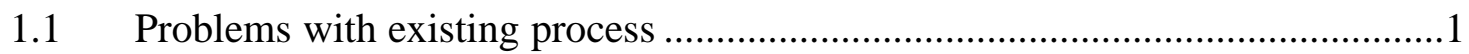

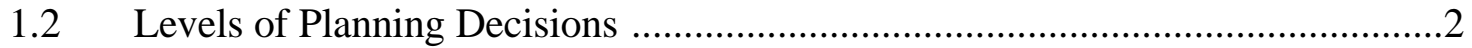

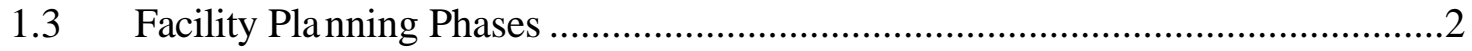

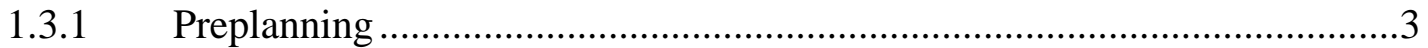

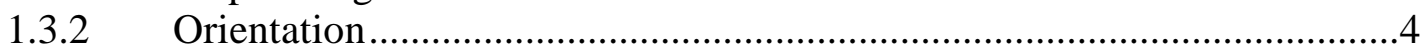

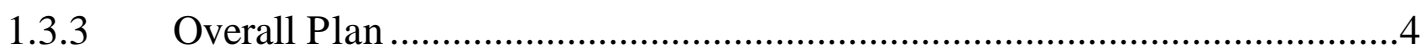

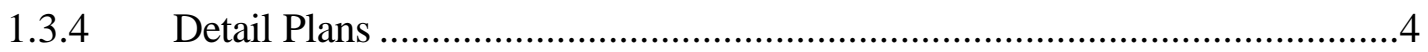

1.3.5 Implementation...............................................................................

1.3.6 Construction, Renovation and/or Installation..........................................

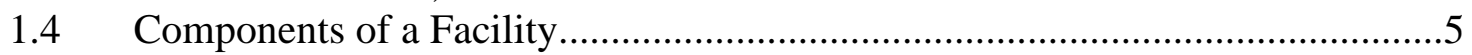

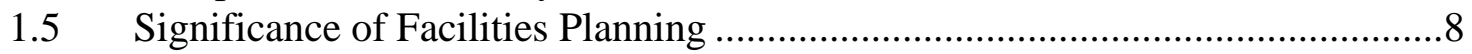

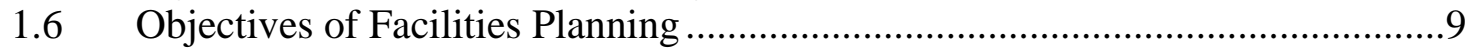

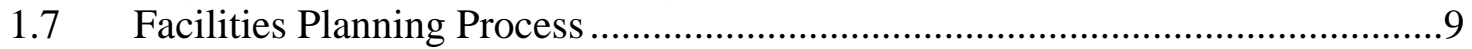

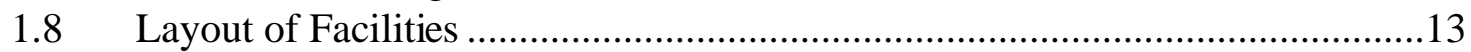

1.9 Approaches to Layout Problems.....................................................................14

1.9.1 Nadler's Ideal Systems Approach ..........................................................14

1.9.2 Immer's Basic Steps ……………………….....................................15

1.9.3 Apple's Plant Layout Procedure .................................................................15

1.9.4 Reed's Plant Layout Procedure .................................................................16

1.9.5 Muther's Systematic Layout Planning (SLP) Procedure ………................16

1.9.6 Algorithmic Approaches.....................................................................17

1.10 Computer Aided Layout Planning ..................................................................18

1.11 Economic Consequences of Facilities Planning .............................................18

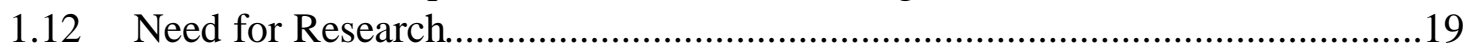

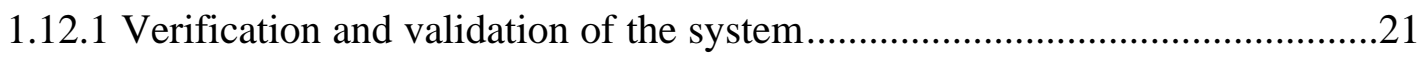

1.12.2 Sensitivity Analysis ...............................................................................21

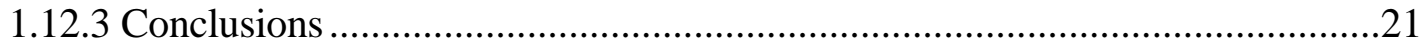

1.12.4 Research Objectives..............................................................................22

2 LITERATURE REVIEW .......................................................................23

$2.1 \quad$ Computer Aided Layout Planning .................................................................25

2.1.1 CRAFT (Computerized Relative Allocation of Facilities Technique)[1] .25

2.1.2 MCRAFT (MicroCRAFT) [1] ..........................................................26

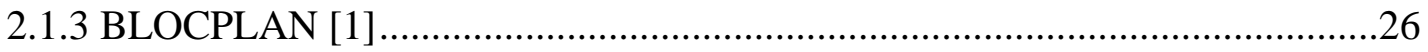

2.1.4 LOGIC (Layout Optimization with Guillotine Induced Cuts)[1] .....................27

2.1.5 MULTIPLE (MULTI-floor Plant Layout Evaluation)[1] ...............................2.

2.1.6 CORELAP (Computerized Relationship Layout Planning)[1] ........................27

2.1.7 ALDEP (Automated Layout Design Program)[1] ……...................................28

2.2 Advanced Computer based Technologies for Facility Design ...........................28

2.2.1 Integration of Simulation and Graphics for Flow visualization .................29

2.2.2 Databases and Computer Aided Drafting ....................................................30 
2.2.3 Artificial Intelligence in Facility Design ..................................................30

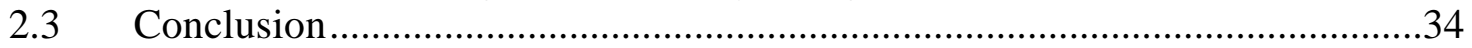

3 RESEARCH APPROACH ................................................................35

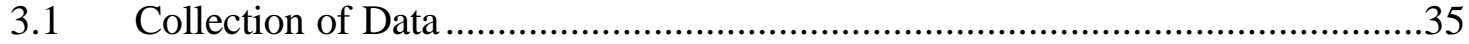

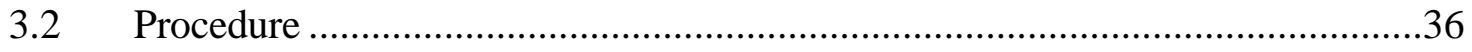

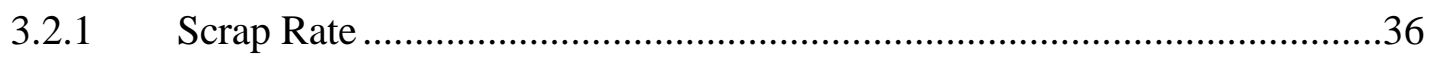

3.2.2 Equipment Fractions ................................................................................

3.2.3 Employee Requirements ....................................................................

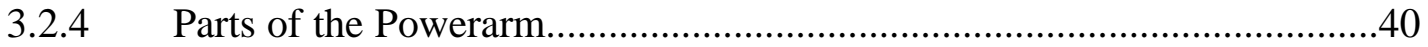

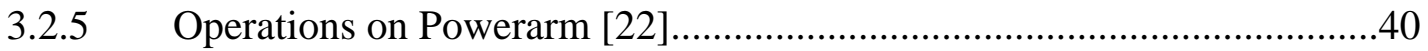

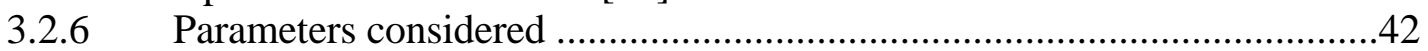

3.3 Operations Process Chart for the Powerarm [22] …………............................44

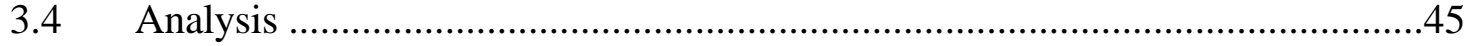

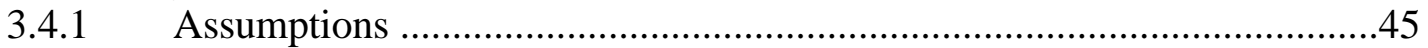

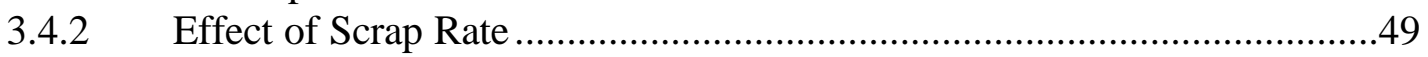

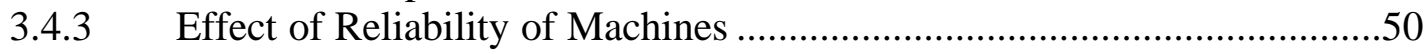

3.4.4 Effect of Availability of Machines ......................................................51

3.4.5 Effect of Loading and Unloading Time ..................................................52

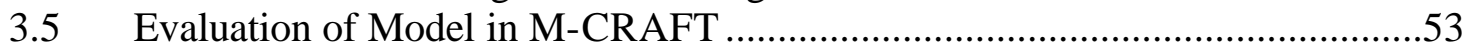

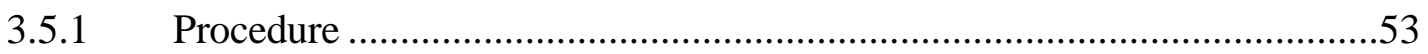

3.5.2 M-CRAFT Analysis with Scrap Rate ......................................................55

3.5.3 M-CRAFT Analysis with Reliability of Machines.....................................56

3.5.4 M-CRAFT Analysis with Availability of Machines …………………......57

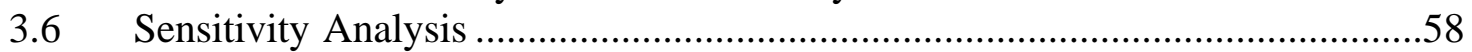

3.6.1 Sensitivity Analysis with Scrap rate ……………..................................58

3.6.2 Sensitivity Analysis with Reliability of Machines .....................................62

3.6.3 Sensitivity Analysis with Availability of Machines ....................................65

3.6.4 Sensitivity Analysis with Loading/Unloading Time ……………...............67

3.6.5 Sensitivity Analysis with M-CRAFT Results...........................................70

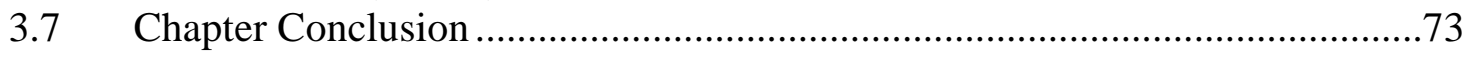

4 Conclusion and Future Work .............................................................74

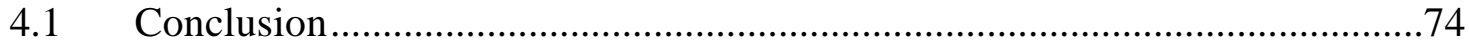

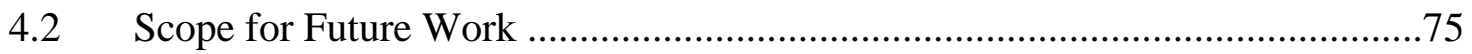

Bibliography ………...........................................................................................................................76

Appendix....................................................................................................................................78

A1. MCRAFT Results after Scrap Rate was reduced by 50\% ...................................87

A2. MCRAFT Results after Scrap Rate was increased by $50 \%$.....................................8

A3. M-CRAFT Results after Reliability of Machines was reduced by $25 \%$..................89

A4. M-CRAFT Results after Availability of Machines was reduced by $25 \%$...............90 


\section{LIST OF TABLES}

Table 1.1Percentage of the Gross National Product (GNP) typically expended on New

Facilities between 1955 and Today(2003) by Industry Grouping [1] ...................... 8

Table 2.1 Development of computer aided facility design methods .............................29

Table 3.1 Manufacturing Times for individual machines ..........................................42

Table 3.2 Scrap rates of different operations .............................................................43

Table 3.3 Loading and Unloading times for different machine operations .....................43

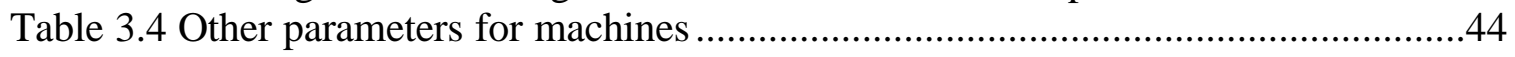

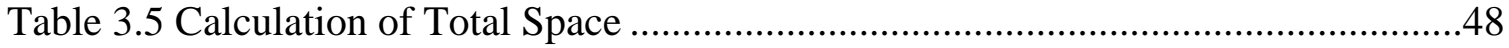

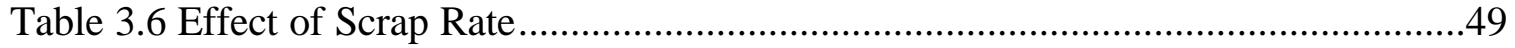

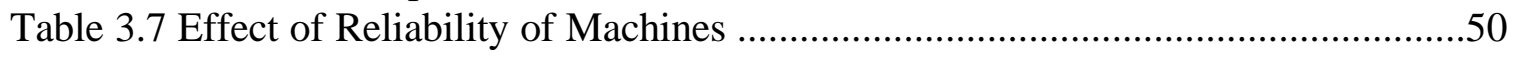

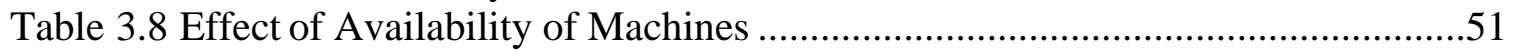

Table 3.9 Effect of Loading and Unloading time ....................................................52

Table 3.10 M-CRAFT Results on Change of Scrap Rate ............................................56

Table 3.11 M-CRAFT Results on Reliability Values of Machines ..................................56

Table 3.12 M-CRAFT Analysis with Availability of Machines ....................................57

Table 0.1 Model Excel Spreadsheet ........................................................................ 79

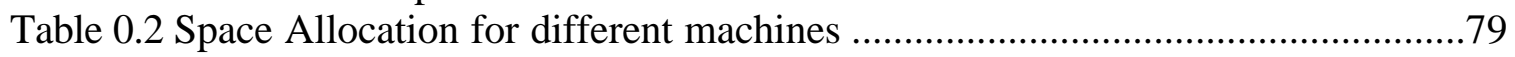

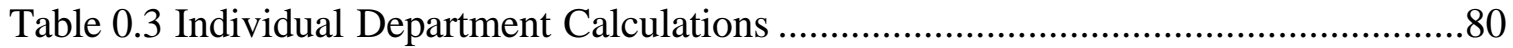




\section{LIST OF FIGURES}

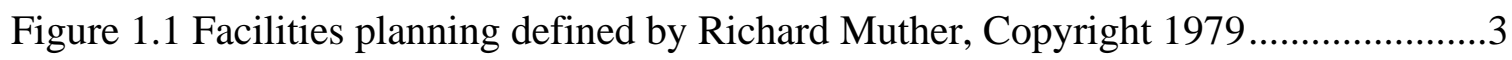

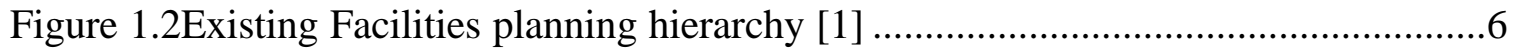

Figure 1.3 Proposed Facilities planning hierarchy …...............................................

Figure 1.4 Continuous improvement facilities planning cycle [1] ...............................10

Figure 1.5 Winning facilities planning process. Source Tompkins [1] ............................12

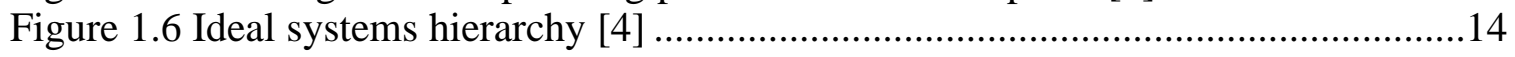

Figure 1.7 Systematic layout planning (SLP) procedure [1] ........................................

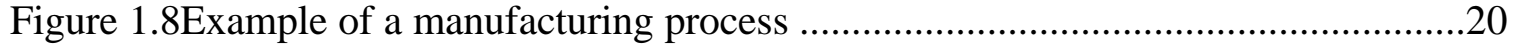

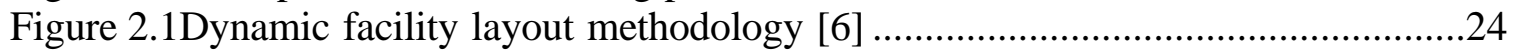

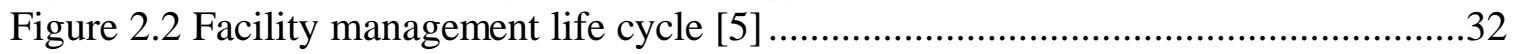

Figure 3.1 Operations Process Chart for the Powerarm ..............................................45

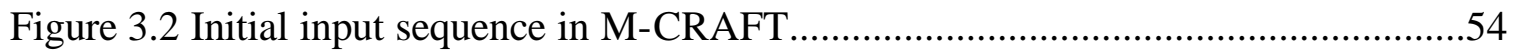

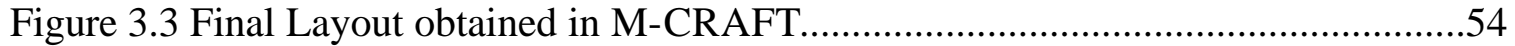

Figure 3.4 Number of Machines Vs \% Change in Scrap Rate .......................................58

Figure 3.5 Number of Operators Vs \% Change in Scrap Rate ........................................59

Figure 3.6 Area of the Facility Vs \% Change in Scrap Rate ........................................60

Figure 3.7 Machine and Operator Activity Cost Vs \% Change in Scrap Rate .................61

Figure 3.8 Number of Machines Vs \% Change in Reliability of Machines .....................62

Figure 3.9 Number of Operators Vs \% Change in Reliability of Machines ......................63

Figure 3.10 Area of the Facility Vs \% Change in Reliability of Machines ......................63

Figure 3.11Cost of the Product Vs \% Change in the Reliability of Machines ..................64

Figure 3.12 Number of Machines Vs \% Change in Availability of Machines .................65

Figure 3.13Number of Operators Vs \% Change in Availability of Machines...................65

Figure 3.14 Area of the Facility Vs\% Change in Availability of Machine ......................66

Figure 3.15 Cost of the Product Vs \% Change in Availability of Machines ....................67

Figure 3.16 Area Vs \% Change in Loading/Unloading Time of Machines ......................68

Figure 3.17Number of Machines Vs\% Change in Loading/Unloading Time ...................68

Figure 3.18 Loading/Unloading time Vs Number of Operators ......................................69

Figure 3.19 Cost of Product Vs \% Change in Loading/Unloading Time ..........................70

Figure 3.20 Material Handling Costs (\$) by M-CRAFT Vs \% Change in Scrap Rate......71

Figure 3.21 Material Handling Costs $(\$)$ by M-CRAFT Vs \% Change in Reliability

Values of Machines

Figure 3.22 Material Handling Costs (\$) by M-CRAFT Vs \% Change in Availability of

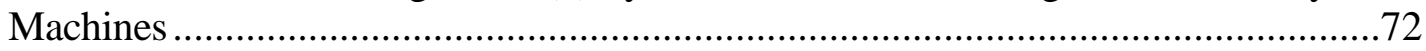

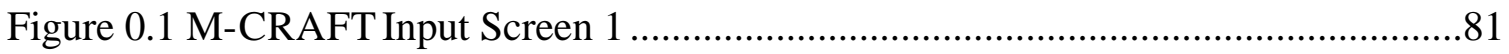

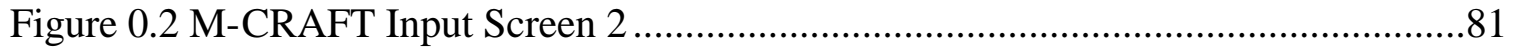

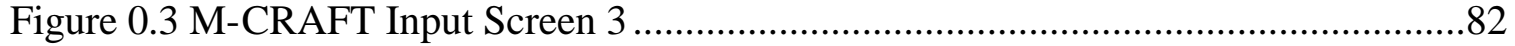

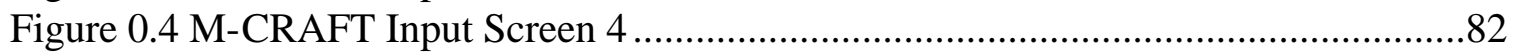

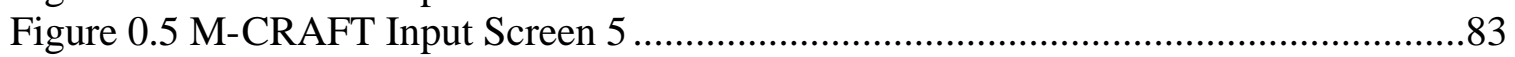

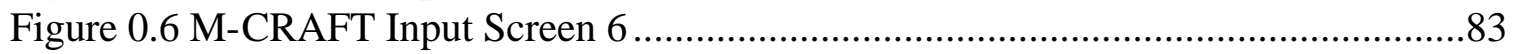

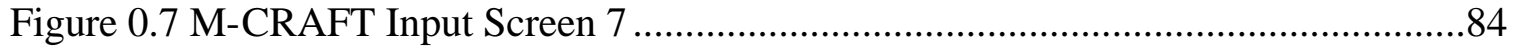

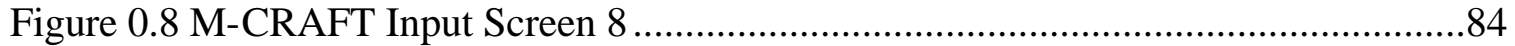

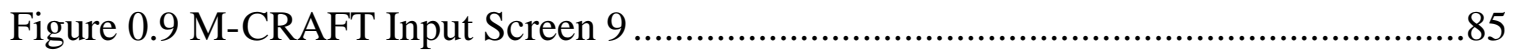




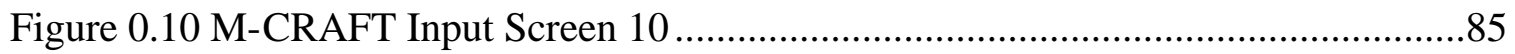

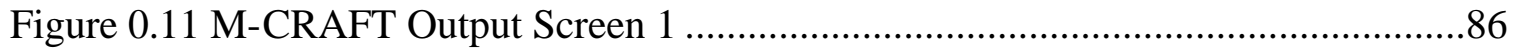

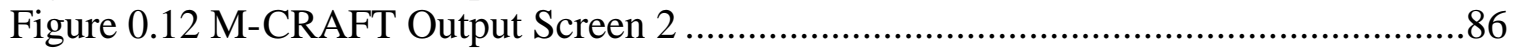

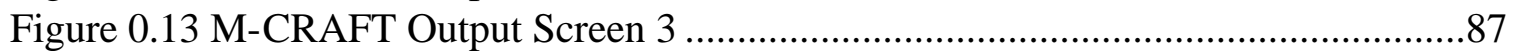

Figure 0.14 M-CRAFT Output Screen 1 when Scrap Rate was reduced by $50 \%$.............87

Figure 0.15 M-CRAFT Output Screen 2 when Scrap Rate was reduced by $50 \%$.............88

Figure 0.16 M-CRAFT Output Screen 1 when Scrap Rate was increased by 50\% .........88

Figure 0.17 M-CRAFT Output Screen 2 when Scrap Rate was increased by $50 \%$..........89

Figure 0.18 M-CRAFT Output Screen 1 when Reliability of Machines was reduced by $25 \%$

Figure 0.19 M-CRAFT Output Screen 2 when Reliability of Machines was reduced by $25 \%$

Figure 0.20 M-CRAFT Output Screen 1 when Availability of Machines was reduced by $25 \%$

Figure 0.21 M-CRAFT Output Screen 2 when Availability of Machines was reduced by $25 \%$ 


\section{Introduction}

Facilities planning is a complex and broad subject spanning a wide range of disciplines such as engineering, real estate, insurance, ergonomics, architecture, law and management. Infact, the actual breadth of information needed to successfully carry out a major facilities planning and design project would require the expertise of not one but many experts in a host of disparate fields. For example, within the engineering profession, civil, electrical, industrial and mechanical engineers are all involved with facility planning. Also involved are architects, consultants, general contractors, managers, real estate brokers and urban planners. Hence it is very difficult to address it from a single viewpoint as so many entities are involved. Also, the design of facilities has become relevant to business success.

Facilities planning determines how an activity's tangible fixed assets best support achieving the activity's objective [1]. For a manufacturing firm, facilities planning involves the determination of how the manufacturing facility best supports production. In the case of an airport, facilities planning involves how the airport facility is to support the passenger-airplane interface. Similarly, facilities planning for a hospital determines how the hospital facility supports providing medical care to its patients.

\subsection{Problems with existing process}

Before looking at the various aspects of facilities planning and design, I looked at some of the questions which when answered would give us better results. Some of the questions which need to be answered are:

- What happens if people are not sensitive to the manufacturing operations in the facility being designed?

- What would happen if the layout is designed first and then the equipment placed in it?

- What is the impact on the facility layout if there is a change in any of the parameters involved in the manufacturing process? 
It is very important to look into the answers for the above questions before planning any facility. Any facility which is constructed is for the particular product that is to be manufactured in it and also for the equipment which is used in its manufacture. Hence, details of the processes required for the manufacture and the equipment needed, the space requirements and their location is important at the facility planning stage. It is difficult and expensive to install the processes and equipment after the facility is designed without considering the above parameters. It would be very difficult to identify the key parameters which are important and whose variation might bring about changes in the facility layout. It is always desired that a new facility be designed in such a way that it can incorporate any small changes or modifications required in future. In order to design such a facility, it is important to have knowledge of the manufacturing processes, the equipment required, their location or orientation inside the facility and the effects of the parameter changes on the facility layout.

\subsection{Levels of Planning Decisions}

Facilities planning and design decisions are made at different levels. The highest decision level is capacity planning that provides enough productive capacity of all kinds to meet the requirement of the organization. This might be related to specific conditions and quantities of floor space, land, building and equipment. The next level is location, the geographic placement of capacity. At this level, site planning decisions are made that are followed by building decisions where the interior and exterior structure is designed. The next level is the department level where the decisions are taken with concerned groups of people and equipment and their day to day activities. Once this level is set, the planner considers workplace design. Then, plans are made to implement these decisions. It is not necessary that these levels need to occur in a sequence. In a practical environment, these levels overlap. It is always desirable to proceed in rigorous top-down order. The decisions made at any level must be compatible with those at other levels.

\subsection{Facility Planning Phases}

After considering the levels of facilities planning, it is important to analyze the different phases involved in facilities planning. Every planning project involves a move from the 
existing condition to some future stage of development or desired condition. The project is accomplished by following the sequence of the planning phases. Each phase addresses a different level of planning and decision. However, as in the case of planning levels, these phases overlap in order to integrate the decisions made at different levels of planning. Figure 1.1 illustrates the concept of planning phases:

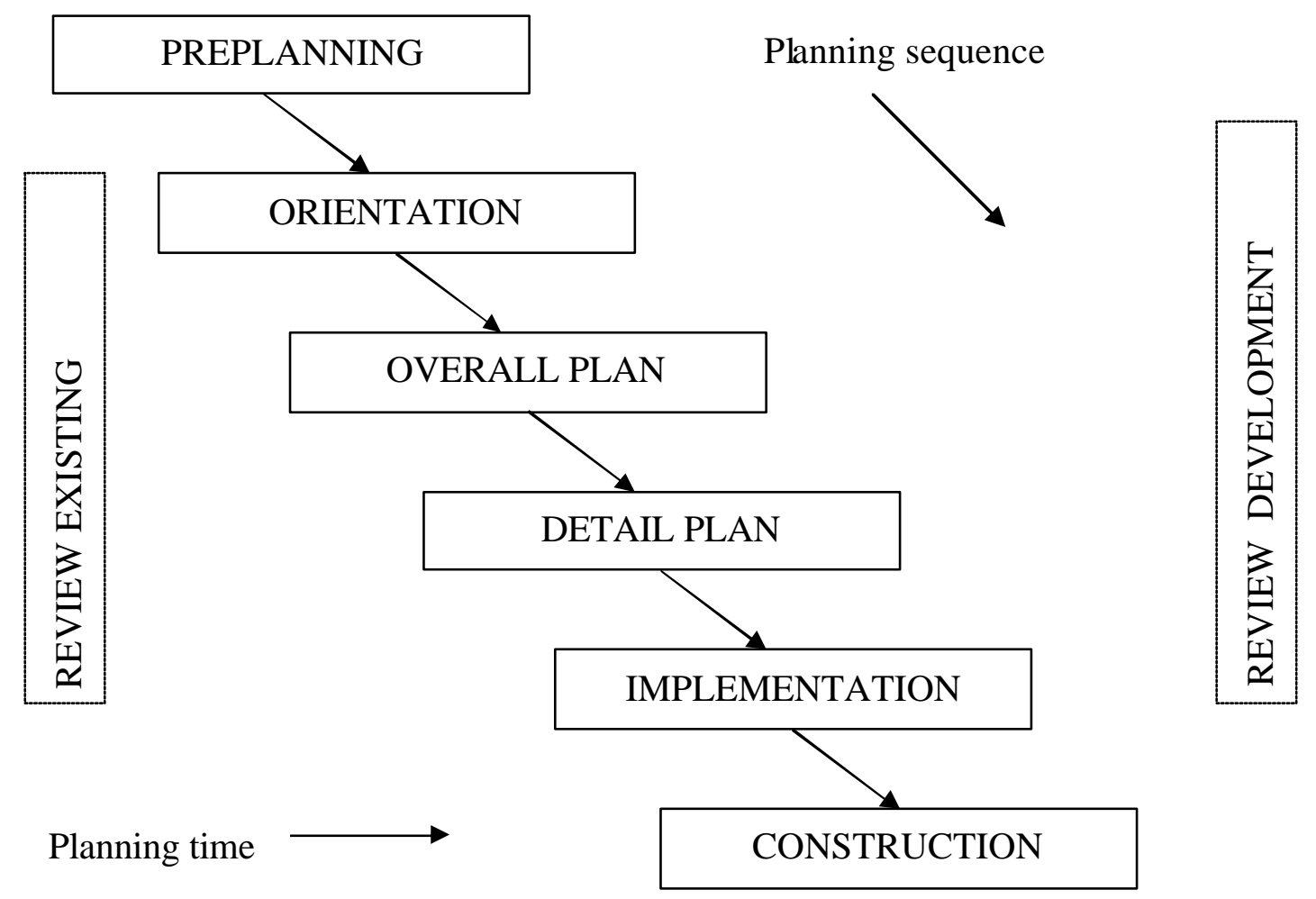

Figure 1.1 Facilities planning defined by Richard Muther, Copyright 1979

\subsubsection{Preplanning}

During this phase, the basic needs of the facility such as company policy, business plans and general goals are complied. The existing facilities are evaluated and their requirements are determined. Another important analysis done is the determination of the capacity requirement. It is estimated as to what size of plant is required and a rough plan is made. Feasibility analysis is carried out and a project plan is made where the different phases are broken in steps and responsibilities and schedule is decided. 


\subsubsection{Orientation}

In this phase, the non-facility objectives and existing conditions are converted to physical facility requirements. The site location, the current facilities in the site or the department in the plant are evaluated. Also considered are the external opportunities available and the constraints if there are any.

\subsubsection{Overall Plan}

During this phase, the physical requirements are converted into an overall plan of the facility. The overall block layout, handling plan, basic communications plan, primary utilities distribution plan and preliminary building plans are developed. In general, in this phase, the actual solution is determined in order to reach the objective.

\subsubsection{Detail Plans}

In this phase, the physical requirements and constraints identified in the earlier phase are further subdivided into areas and components so that a more detailed plan of the facilities is obtained. The detailed machinery and equipment layouts, detailed handling plans, detailed communication plans, secondary utilities distribution plans and the detailed building documents are developed. The major features of the different components and areas are studied and the solutions are developed.

\subsubsection{Implementation}

This is the phase in which the evaluated plans and strategies are streamlined and an action plan is made for the construction, renovation and installation. Preparation of installation documents, handling equipment procurement, and training is done.

\subsubsection{Construction, Renovation and/or Installation}

This phase involves the actual implementation of the plans made in the earlier phases. It involves follow-up of the planning process and monitoring of the implementation of the above made plans. Communications equipment installation, utilities installation and building construction and rehabilitation is done in this phase. 


\subsection{Components of a Facility}

There are five components in any facility must be discussed in order to organize the planning approach. They are:

1. Layout: This is the arrangement of activities, features and spaces around the relationships that exist between them.

2. Handling: This component deals with evaluating the methods to move products, materials, people and equipment between the various points in the facility. Material handling is the art of moving, storing, protecting and controlling material. This is a means by which manufacturing quality is improved by reducing inventory and damage through improved handling practices.

3. Communication: This is the means of transmitting information between various points in the facility. It is very important to have a good communication system in place for the successful transfer of information from different stages of the manufacturing process thereby reducing the defects in products and improving the quality.

4. Utilities: This is one of the most important components in any type of facility being planned. Every facility needs to have the resources for generation and distribution of substances like water, waste, gas, air and power, though the importance of each of these may vary depending upon the type of facility.

5. Building: Finally, in order to incorporate all the components mentioned above, we need to have a building or structure. The form, type of material used for construction and the design depends on the requirement of the components which constitute it and also based on the product being manufactured.

Facilities planning is further divided into its location and design components. It is very important to identify facilities planning as a broad area which incorporates related terms such as facilities location, facilities design and facilities layout. Figure 1.2 gives the existing division in the form of a diagram. 


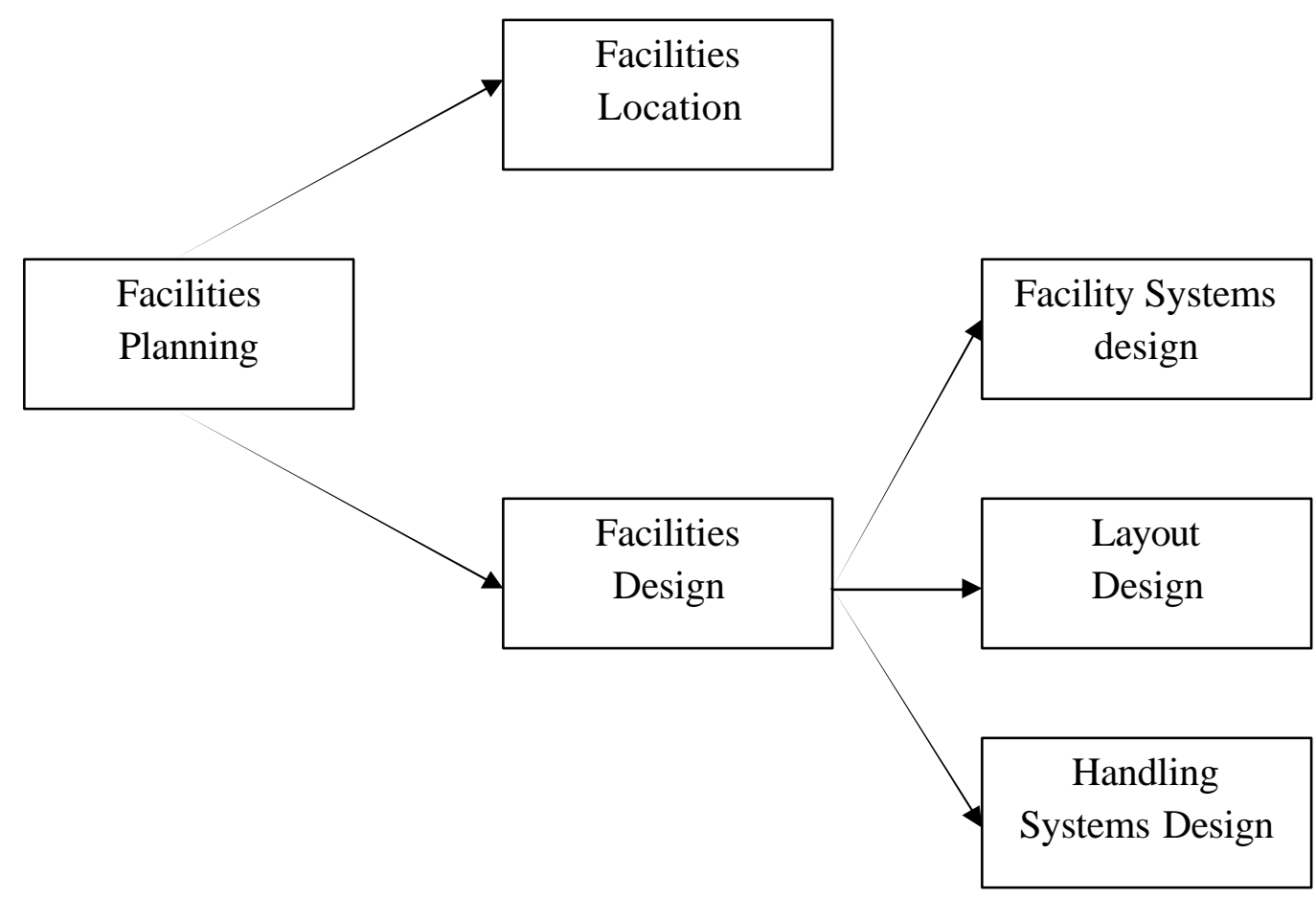

Figure 1.2Existing Facilities planning hierarchy [1]

The location of the facility refers to its placement with respect to its customers, vendors or suppliers and other facilities with which it interacts. The location of the facility also includes its placement and the way it is oriented on a given area. Hence, facilities location is often defined as the determination of how the location of a facility helps meeting the facility's objective.

Facilities design consists of the facility systems, the facility layout and the handling system. The facility system consists of the structural systems, the atmospheric systems, the enclosure systems, the lighting, electrical, communication systems, the life safety systems and the sanitation systems. The facility systems may also include the structure and enclosure elements, power, light, gas, ventilation, air conditioning, water and sewage needs. The layout primarily consists of the equipment, machinery and the furnishings within the building enclosure. It consists of the production areas, support areas and personnel areas within the building. The handling systems consist of having a mechanism to move products, people, information and equipment within the facility in order to support production. On the whole, facilities design can be defined as the determination of how the design components mentioned above support the facility in 
meeting its objectives. Facilities location addresses the macro or major issues of facility planning and facilities design addresses the micro or finer elements of facility planning.

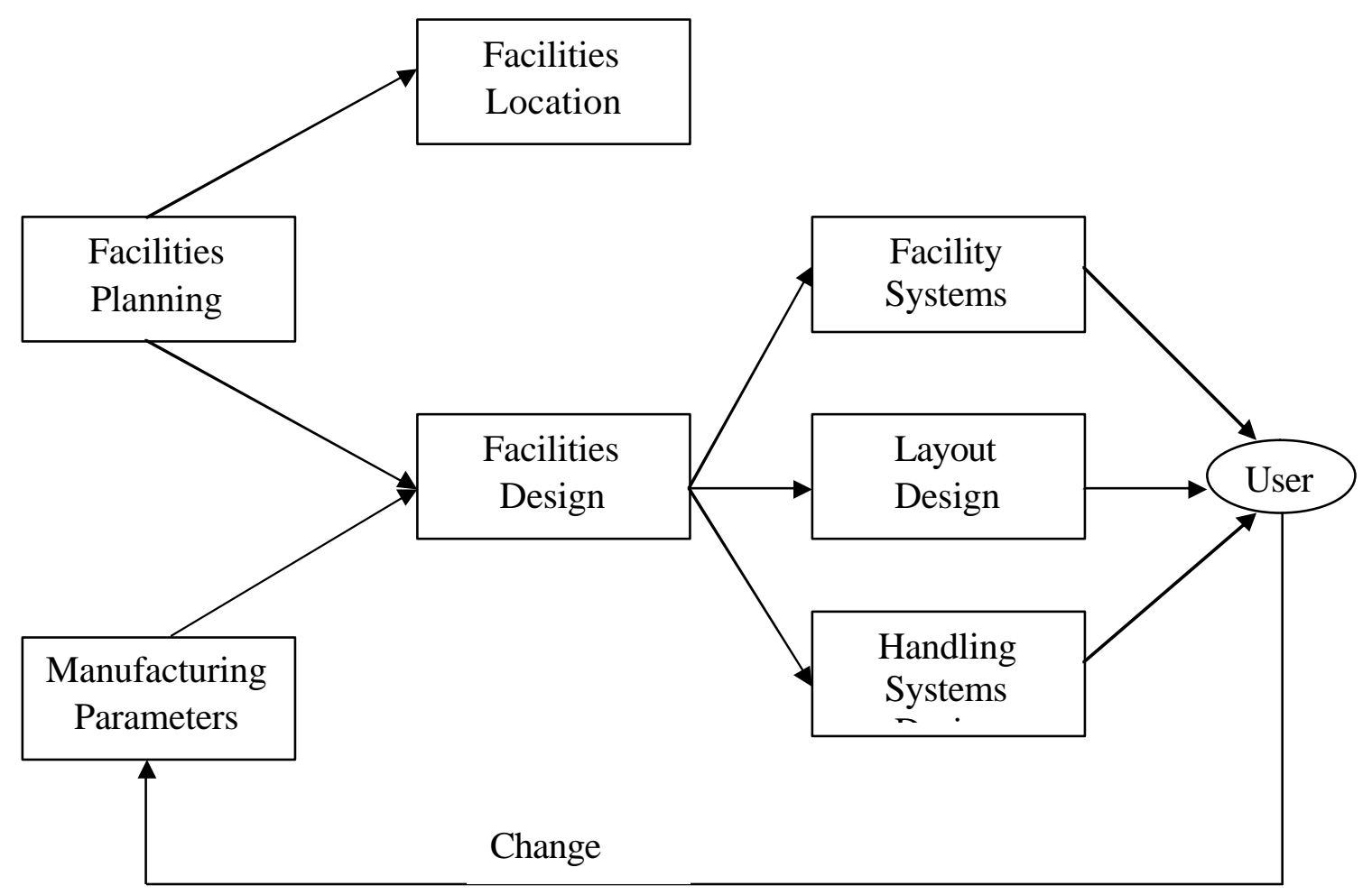

Figure 1.3 Proposed Facilities planning hierarchy

Figure 1.3 shows the proposed facilities planning hierarchy. The focus of the research starts from the facility design stage, the input for which comes from facility planning and location. A user interface is proposed which provides the user with the information about the facility systems design, layout design and the handling systems design. Information is also provided about the manufacturing parameters. Thus any changes in the manufacturing parameters resulting in changes in facility layout are reflected in the facility design. This approach helps in determining the manufacturing parameters which are important and the effect of their changes on the facility systems, layout and material handling system. It also helps the user to establish the important parameters which have the largest impact on the facility. 


\subsection{Significance of Facilities Planning}

According to the U.S. Bureau of Census, since 1955, approximately $8 \%$ of the Gross National Product (GNP) has been spent annually on new facilities in the United States. Table 1.1 indicates the typical expenditures on facilities planning in percentage of GNP, for major industry groupings.

\begin{tabular}{lc}
\hline Industry & GNP Percentage \\
\hline Manufacturing & 3.2 \\
Mining & 0.2 \\
Railroad & 0.2 \\
Air and other transportation & 0.3 \\
Public utilities & 1.6 \\
Communication & 1.0 \\
Commercial and other & 1.5 \\
All industry & 8.0 \\
\hline
\end{tabular}

Source: US Bureau of Census

Table 1.1Percentage of the Gross National Product (GNP) typically expended on New Facilities between 1955 and Today(2003) by Industry Grouping [1]

The size of investment in the new facilities and modifications in the existing facilities make study of facilities planning important. The manufacturing industry spent the maximum amount of money on facility redesigning because of frequent changes in product demand and changes in process designs. This process design changes resulted in changes in facility design resulting in higher costs to manage the facilities. It is estimated that approximately 250 billion will be spent annually in the United States alone on facilities that require planning or replanning[1]. Since the cost involved is very high, more emphasis is being paid to make the design more adaptive in order to accommodate changes and additions in the layout when required. Though, the scope of facilities planning is indicated by the annual dollar volume, it does not appear that adequate planning is being performed. 


\subsection{Objectives of Facilities Planning}

The objective of facilities planning is to plan a facility that achieves the desired facilities location and incorporates the necessary facilities design. Dividing facilities planning into location and design, it is more appropriate to define objectives of these functions individually. The objective of facilities location can be defined as "to determine the location which, in consideration of all factors affecting deliver-to-customers cost of the product(s) to be manufactured, will afford the enterprise the greatest advantage to be obtained by virtue of location"[1]. This objective is applied not only to the products that are manufactured, but also to the services that are offered.

Similarly, some of the objectives of facilities design can be listed as follows.

1. Support the organization's vision by improving material handling, control and ensuring better housekeeping

2. Utilize the resources such as people, equipment, space and energy effectively to reduce defects and improve final quality of the product or service being offered.

3. Reduce the amount of capital investment required.

4. Be adaptable to changes if required in the future thereby promoting ease of maintenance.

5. Provide an environment which is safe for the employees working there thereby creating job satisfaction.

Facilities design is easily the most important aspect of facilities planning. Since there are many objectives involved in facilities design, careful evaluation of each of them is required based on the requirement.

\subsection{Facilities Planning Process}

The concept of facilities planning is always termed as a facility life cycle as it is frequently replanned or modified in order to meet the objectives of the organization, though it is planned only once. Modern manufacturing and service are characterized by the necessity to rapidly adapt to changes in the product quantity, design or mix resulting in modification of production facilities and processes. Such changes may develop from different resources. This process continues until the facility is completely redesigned to meet its objectives. Figure 1.4 shows the facilities planning cycle which shows the link between facilities planning and facilities replanning process. 


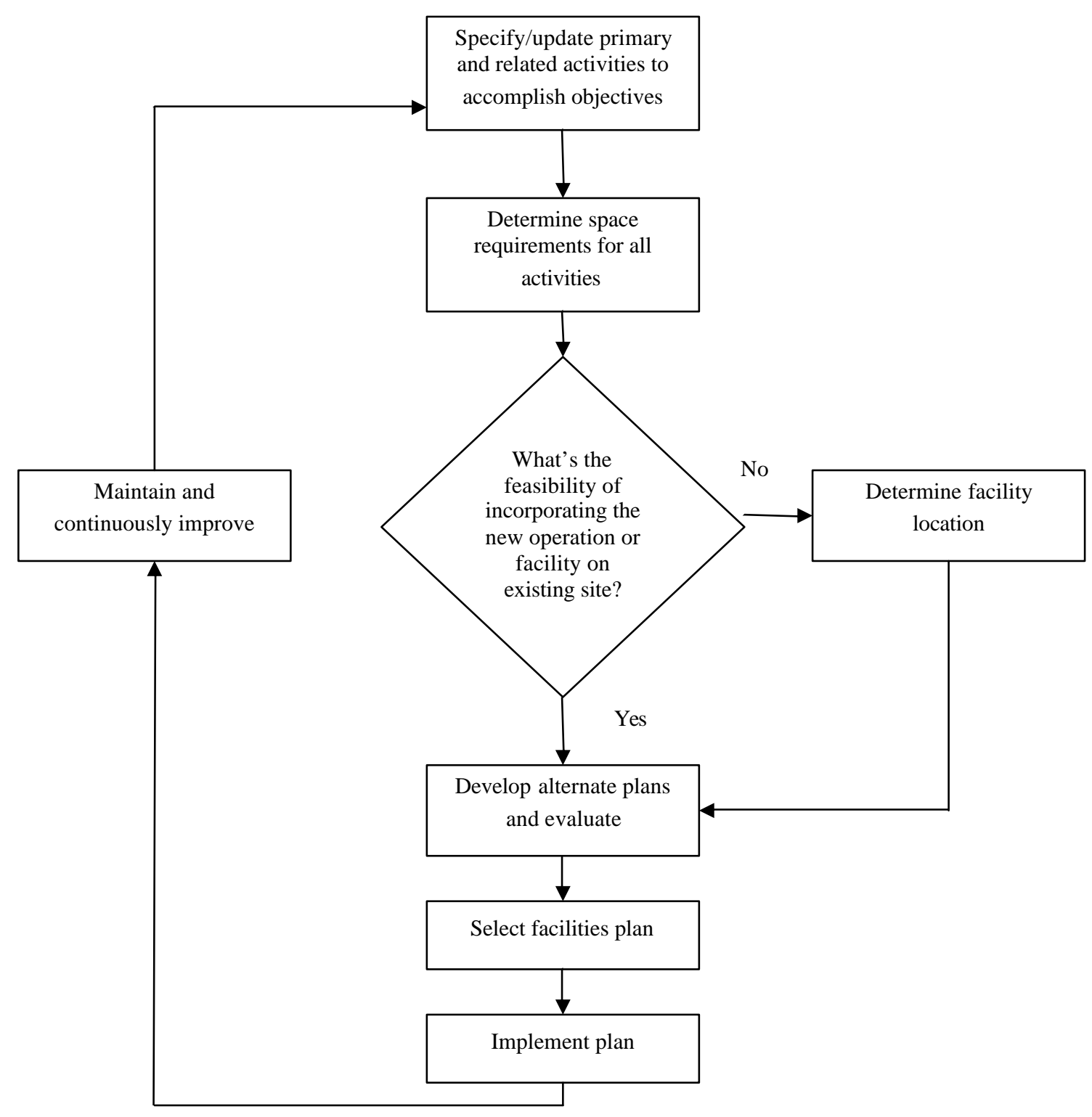

Figure 1.4 Continuous improvement facilities planning cycle [1]

The facilities planning process is given below in the form of steps. There might be some additions based on the requirement of the facility. In order to improve on this, researchers have been adding additional processes to refine and improve the planning process.

1. The first step is to define the primary activities to accomplish the objectives of the facility. It is essential to decide on the product or service that is being produced or offered and decide on the quantities involved. This is irrespective of whether it is a new facility or whether an existing facility is being redesigned. The 
identification of the volume and the type of activity involved makes the planning process simple and makes it easier to work towards achieving the objectives.

2. The second step is to identify and specify the primary and secondary activities that need to be performed in order to meet the desired objectives of the facility. They can be the defined in terms of the operations that need to be performed and the equipment, personnel and material flow involved.

3. The next step is to determine the relationships between the different activities that are present. It is important to define both qualitative and quantitative relationships and know how these activities interact or support one another within the facility.

4. The next step is to determine the space required for all the activities which need to be carried out within the facility. The requirements of all the equipment, material and personnel needs to be considered before calculating the space requirements.

5. The next step is to generate alternate facilities plans which would include alternative facilities location and facilities designs which in turn would contain alternate layout, structural and material handling designs. Depending on the type of situation and requirement, the decision on facility location and design is made.

6. Once the alternative facilities plans are made, they are evaluated and are ranked. They are evaluated by checking the subjective factors in each plan and how they affect the facility or its operation.

7. After the evaluation of the plans, the goal in this step is to determine the plan which is the most suited to achieve the goals and objectives of the company. Cost is one of the major factors for evaluation, though it might be not be the only basis for selection.

8. Once the plan is selected, the next step is to implement the plan. A lot of planning and effort goes into the actual construction. This phase involves coordinating the actual construction, installation of the layout, actually starting up, running and debugging.

9. In this step, the facilities plan is maintained and adapted for future changes. The rate at which modern markets demand new products puts an ever increasing demand on the manufacturing facilities. Hence, any new requirements demanding change in facilities plan need to be accommodated thereby reflecting any energy 
saving measures or improved material handling equipment that are available. These changes may also result in changes in the actual facilities plan.

10. As the changes are incorporated in the facility plan, the objectives of the facility change which need to be considered and redefined. We need to determine products that need to be produced or the services that need to be provided in specific quantifiable terms. If there are any potential costs or energy savings available, they need to be considered and integrated in the layout plan.

As mentioned earlier, in order to achieve the desired objectives of a facility, the above mentioned facilities planning approach has been modified and some more activities added in order to present a clearer understanding of the planning process. One of these contemporary approaches, called the winning facilities process is shown in Figure 1.5.

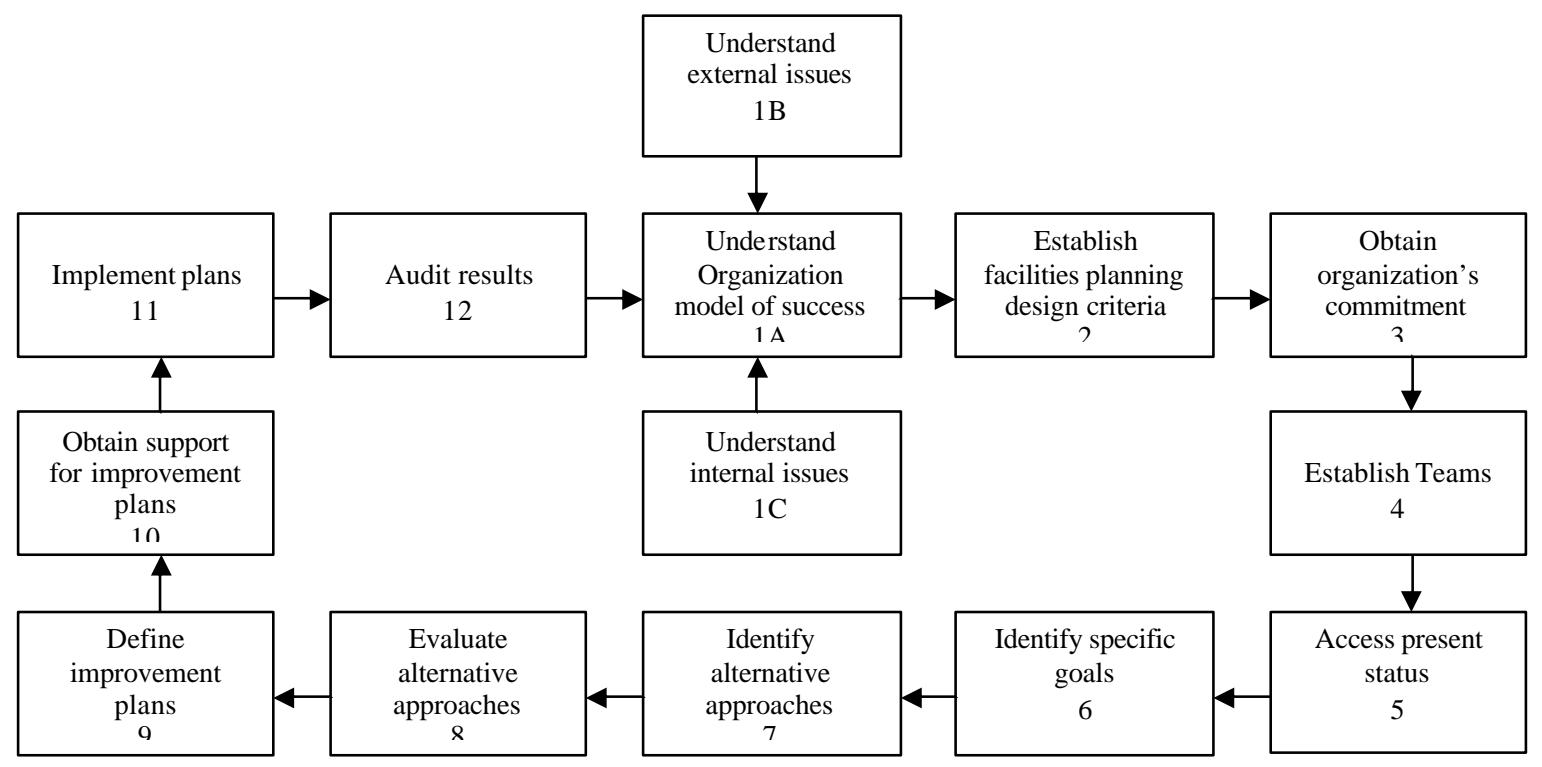

Figure 1.5 Winning facilities planning process. Source Tompkins [1]

Figure 1.5 depicts a systematic procedure of arriving at a winning facilities layout. The first step starts with identifying the organizational model and objectives for success. Then, the next steps involve establishing the different facilities planning design criteria and obtaining the organization's commitment to support these plans. Teams are established and the specific goals for each of these teams are developed and alternative approaches are identified to accomplish these specific goals. The different approaches are evaluated for their feasibility and improvement plans are suggested to these approaches. 
Necessary support is obtained to improve these different improvement plans and the best facilities design plan is implemented. The results are audited and recorded for future analysis.

\subsection{Layout of Facilities}

Once the production process has been identified and defined, it is necessary to lay out the facility in such a way that the production activities are performed with minimum cost and time. This physical definition of the layout is important as this would decide on the final shape and size of the facility. Layouts are classified into four basic types: process layout, product layout, fixed position layout and group layout. Based on the requirements of the manufacturing process and the product being manufactured, the most appropriate layout type is selected. Process layouts are designed by keeping the process being performed in mind. This type of layout is generally used in facilities where a number of different types of products are manufactured in batches. Since the quantities involved for the different types are generally small, the layouts are divided into segments based on the type of operation being carried out. Product layout is used where the same type of product or product groups are manufactured in large quantities. Here, the product and not the process is important and hence the focus in more on the product being manufactured. The layout is based on the production sequence of the product being manufactured in the production line. Fixed Position layout is used when the product being manufactured is large and cannot be moved. Hence the workstations are brought to the product rather than the product going to the different workstations. The production of ships, airplanes and railroad stock are examples of fixed position layouts. A group layout is used when production volumes for individual products are not enough to justify product layouts, but on grouping these similar products, a product family is formed for which a layout can be justified. Products can be grouped into product families based on similar processing, design, material composition, tooling requirement and so on. This grouping of processes is called cells and hence group layout is sometimes called as cellular layout. The group layout has high intradepartmental flow and less interdepartmental flow. Group layout is sometimes also called as product family layout. 


\subsection{Approaches to Layout Problems}

The type of layout depends on the type of product being manufactured. The more complicated the product being made is, the more complicated the layout of the facility. Sometimes, even a simple production process may create problems because of some design feature of the product. Hence deciding on a layout which is simple and efficient is not an easy task. A number of procedures have been developed to facilitate the design of plant layouts. These procedures can be basically classified into two main types: Construction type layout methods which basically deal with developing the layout from scratch and improvement type layout methods which deal with generating alternative layouts to the existing layout. We start our discussion by considering the approaches to new layouts.

\subsubsection{Nadler's Ideal Systems Approach}

"This approach was initially developed for work systems but is also applicable for designing facility layouts. This system is based on the following hierarchical approach toward design.

1. Aim for the theoretical ideal system

2. Conceptualize the ultimate ideal system

3. Design the technologically workable ideal system

4. Install the recommended system" [4].

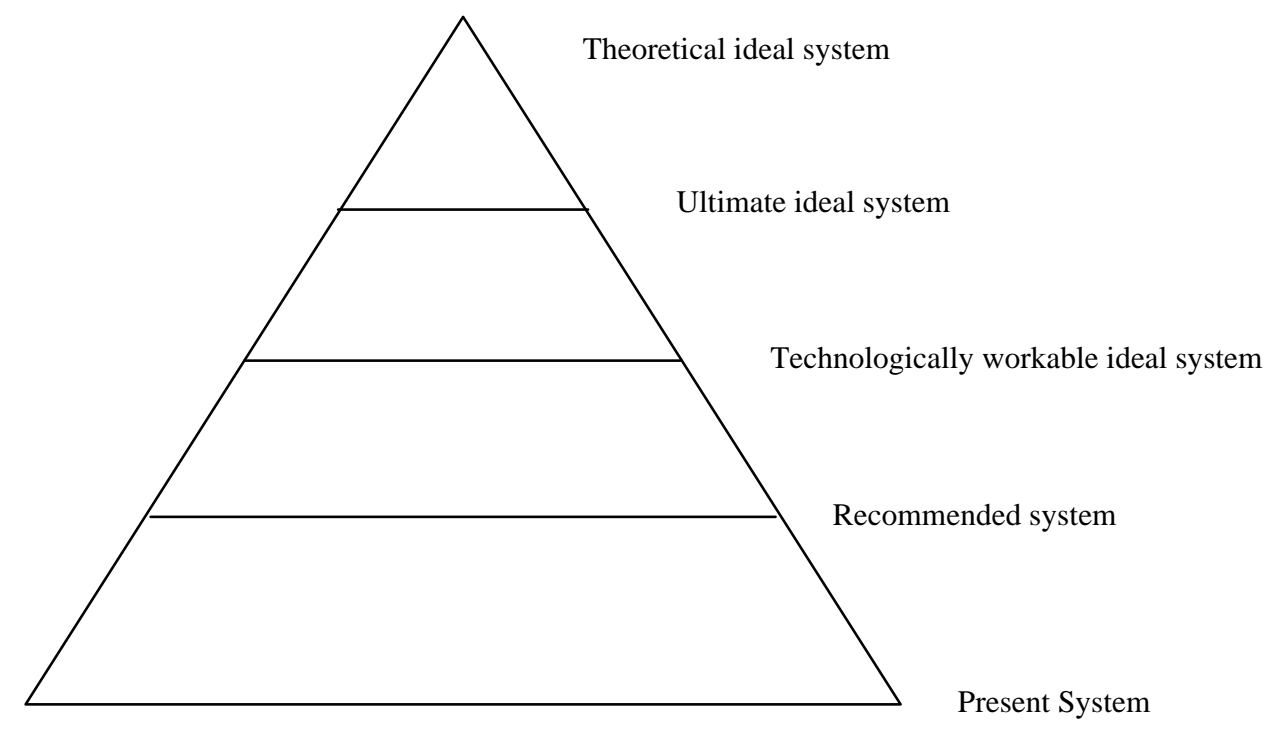

Figure 1.6 Ideal systems hierarchy [4] 


\subsubsection{Immer's Basic Steps}

According to Immer, the analysis of a layout problem should have three basic steps which can be applied to any type of layout problem. These steps are

1. Put the problem on paper

2. Show lines of flow

3. Convert flow lines to machine lines

\subsubsection{Apple's Plant Layout Procedure}

"Apple proposed the following detailed sequence of steps in producing a plant layout.

1. Procure the basic data.

2. Analyze the basic data.

3. Design the productive process.

4. Plan the material flow pattern.

5. Consider the general material handling plan.

6. Calculate the equipment requirements.

7. Plan individual workstations.

8. Select specific material handling equipment.

9. Coordinate groups of related operations.

10. Design activity relationships.

11. Determine storage requirements.

12. Plan service and auxiliary activities.

13. Determine space requirements.

14. Allocate activities to total space.

15. Consider building types.

16. Construct master layout.

17. Evaluate, adjust and check the layout with the appropriate persons.

18. Obtain approvals.

19. Install the layout.

20. Follow up on implementation of the layout"[4]. 


\subsubsection{Reed's Plant Layout Procedure}

"In the planning and preparation of the layout, Reed recommended the following steps to be taken in his systematic plan of attack.

1. Analyze the product or products to be produced.

2. Determine the process required to manufacture the product.

3. Prepare layout planning charts.

4. Determine workstations.

5. Analyze storage area requirements.

6. Establish minimum aisle widths.

7. Establish office requirements.

8. Consider personnel facilities and services.

9. Survey plant services.

10. Provide for future expansion"[4].

\subsubsection{Muther's Systematic Layout Planning (SLP) Procedure}

The systematic layout planning approach developed by Muther is one of the most popular approaches for designing plant layouts and has been applied to production, transportation, storage, supporting services and office activities among others. Once the necessary information is available, a flow analysis can be merged with the activity analysis to develop the relationship between the two. This relationship is shown using the relationship chart which measures flows qualitatively between departments using the closeness relationship values developed by Muther.

The SLP Procedure is shown in Figure 1.7 below. 


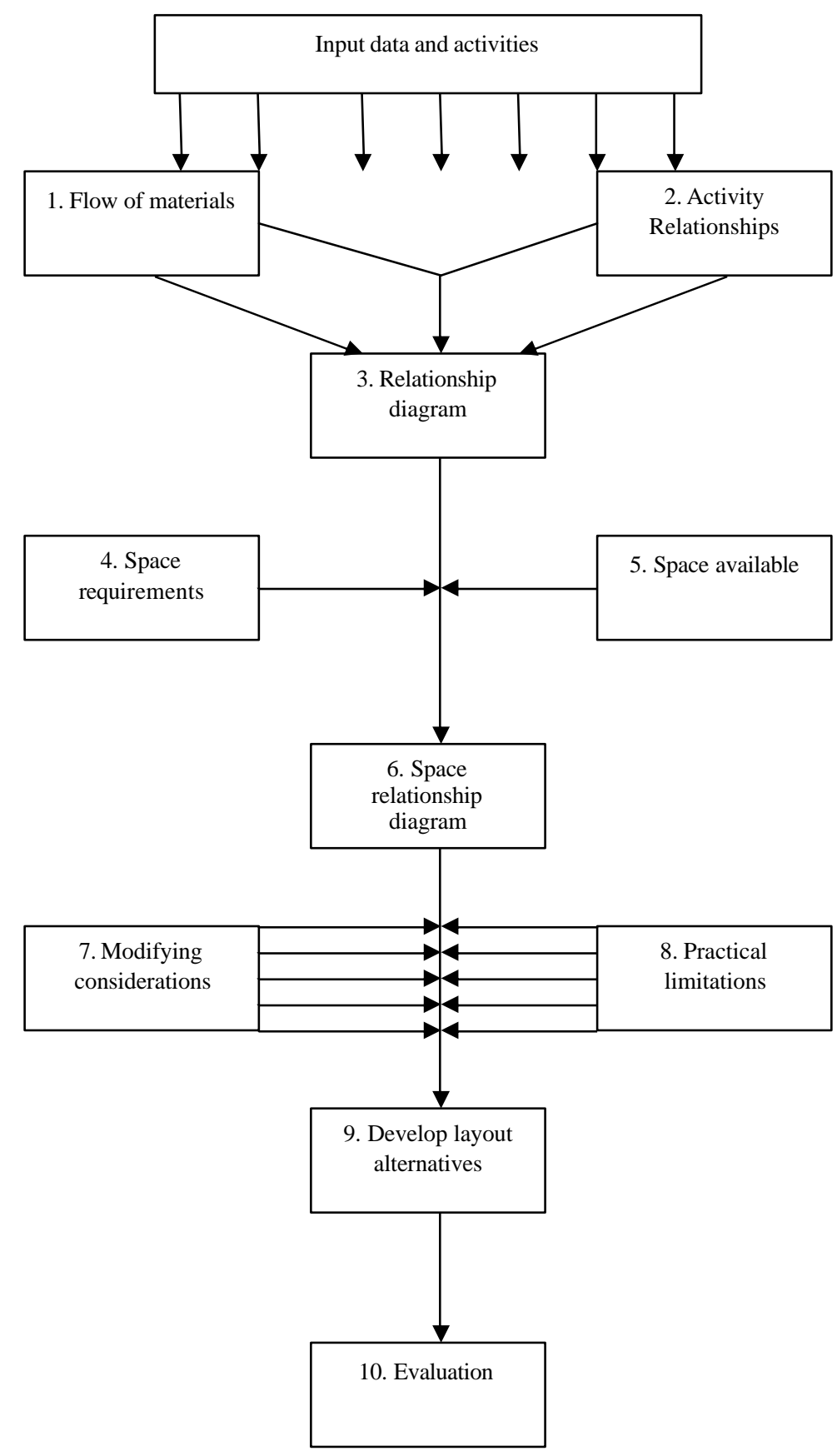

Figure 1.7 Systematic layout planning (SLP) procedure [1]

\subsubsection{Algorithmic Approaches}

These are some of the most extensively used layout procedures which find considerable application in the modern day facilities. Significant research has been done in this area and new and improved algorithms are available now for different types of layout problems. The relative placement of the departments based on their closeness ratings or 
their material flow intensities is one that can be reduced to an algorithmic process. There are three main types of algorithmic layout approaches

1. Relationship Diagramming which is a variation of SLP

2. Pairwise Exchange Method based on the Travel Chart Method

3. The Graph Based Construction Method based on Graph Theory

\subsection{Computer Aided Layout Planning}

The facilities planning process has been simplified to a large extent with the advent of computers and the availability of user friendly and effective computer assisted design and manufacturing programs. The layout can now be easily constructed, evaluated and discarded till the most effective layout is obtained. Though computers cannot replace human judgment and experience, they significantly enhance the productivity of the layout planner and quality of the solution by evaluating large number of alternatives in a short duration. Some of the important and commonly used computerized layout algorithms are CRAFT, M-CRAFT, BLOCPLAN, LOGIC, MULTIPLE, CORELAP and ALDEP. They are discussed in detail in the literature review chapter. M-CRAFT is being used in the research for validation of the model as this is the new version of CRAFT, which is one of the earliest layout algorithms and also one of the best algorithms to arrive at the best possible layout with the lowest material handling costs. It performs all possible two or three way exchanges and arrives at a layout with the lowest cost.

\subsection{Economic Consequences of Facilities Planning}

"Facilities decisions can have a direct and lasting impact on financial resources and operating efficiency. An expensive plan or design will consume extra cash or incur extra debt during construction"[2]. The facility manager needs to have the ability and skill to justify projects economically as companies set requirements for funds more than what is required every year. An inefficient plan can consume cash and resources over its entire lifespan if not considered in detail. Thus, there are two basic approaches which are considered to quantify the economic benefits for projects. One approach sets a benchmark (ex. Benefit-cost ratio $=3.5$ ), where anything above this is accepted and anything below rejected. The other approach is to rank these projects (ex. ranking based on internal rate of return) up to the funds available are accepted and the others rejected. 
The facilities managers should have knowledge of the working of these tools and also be aware of their benefits and limitations.

Cost justification is very important for any project being considered. This helps in identifying the project which has the highest potential for reward, projects that limits or reduces financial risk and also in prioritizing the projects competing for limited resources. It turns out the economic consequences of facilities planning can be related directly to the resources invested which ise rapidly during the detailed planning and construction. Also, we have influence on profit and operating efficiency which is the greatest during preplanning and becomes smaller as the detailed designs are formulated. Capacity decisions have the greatest influence on profit. Location decisions are the next greatest influence as the decisions on site plan and building design are taken in this phase. For any facilities project, whether it is a new project or an improvement project, efficient means of financing must be found. In facilities planning, the amount involved is generally high, careful consideration must be given to how the financing happens. Various factors like whether to lease or buy or build a facility, decision to purchase or modify a facility for cash or finance and also the various ways financing can take place needs to be studied and evaluated before any decision is made.

\subsection{Need for Research}

Increasing global competition, rapid changes in technology and the necessity to cater quickly to a cost and quality conscious customer have changed the dynamics of facilities planning [6]. Modern day manufacturing facilities need to be responsive to the frequent changes in the product mix and demand and thereby minimize the material handling and machine relocation costs. A principal goal of concurrent engineering has been the reduction of development cycle time of new products. This success brings about a parallel need for the evaluation and reconfiguration of the facilities where these products need to be manufactured. This is because of the rate at which modern markets demand new products which puts ever increasing burden on the existing manufacturing facilities.

The current manufacturing scenario retards any change in the existing settings. Significant research has been carried out in order to determine whether the changes in work settings help in the goals that have been set to be achieved. The redesign of workspace has become relevant to business success in ways that many business people 
and even higher proportion of facility managers still do not understand. Since, considerable attention needs to be paid to facilities of the modern era because of the costs associated with it and also the resources expended, the senior management is scrutinizing the contribution of facility management departments to an organization's success. Because of the development happening in this area, in the near future, work will no longer be a place, but a range of activities that can be conducted virtually anywhere and at any time.

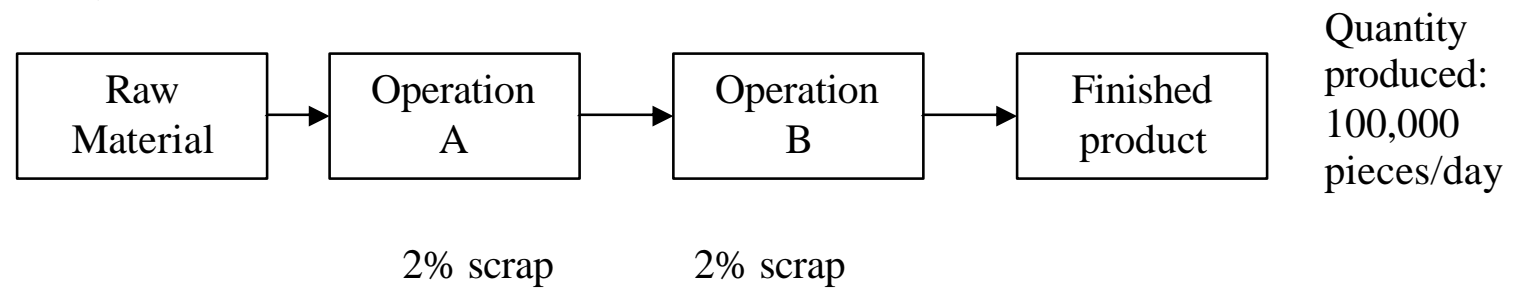

Figure 1.8Example of a manufacturing process

Consider Figure 1.8, which shows a simple manufacturing process. A given raw material is converted into a finished product after operation A and operation B. Both of these operations have a scrap rate of $2 \%$ each and the quantity of finished product produced is 100,000 pieces/day. Now let us assume that the scrap rate increases to $5 \%$ for both the operations. Naturally, the quantity of raw material increases in order to produce the same number of finished product, along with increase in the operation times for $\mathrm{A}$ and B. This would also result in additional requirements of equipment and personnel for which additional space needs to be allocated. Thus, there is an immediate modification and upgrading required in the existing facility. This is the effect of only one of the many parameters involved in the manufacture of the product. There are many parameters which are involved in manufacturing process and hence any variation in these parameters would have a direct impact on the facility design.

Thus, the primary objective is to emphasize the fact that change in process or parameter values result in changes in the facility size. Cost of the product is of importance because any change in the size of the facility has direct impact on the final cost of the product being manufactured. The objective of facility design and planning as mentioned earlier is to have a facility with the right equipment, product and size. Also, changes in the facility bring about changes in the number of personnel involved which 
adds to the cost of the product. Hence, a model is necessary which gives a facility manager of designer the tool to study the effects of product parameters on facility size.

\subsubsection{Verification and validation of the system}

A product is identified and the parts that go into its manufacture are considered with the different manufacturing parameters associated with it. Other details which are considered are the equipment used to manufacture these different parts. Analysis is done using specific values of these parameters and the cost and space required for the manufacture is initially calculated. In order to determine how these parameters have an effect on the cost of the product and the size of the facility, these parameters are varied one at a time keeping the other parameters constant and the results tabulated.

The development of computer models has eased the task of evaluating different solutions. There are many computer programs available, which have been discussed earlier that can be used to validate the any type of facilities layout. These computer models can design the layout, determine the cost of material handling and layout changes and also shows a working model of the actual layout to help the user in determining the best possible solution. This research also involves developing a model initially in MS-EXCEL to study the effects and the results are validated in M-CRAFT facility design software.

\subsubsection{Sensitivity Analysis}

Since there is a possibility of a large number of factors affecting the facility size and the final cost of product, it is important to identify the most decisive factors which could be considered for future analysis. Also, some factors may affect the result in a different way when used isolated than when used in conjunction with other factors as there might be many factors which might be correlated. Various parameters can be changed and their impact on the facility and cost of the product be analyzed. The effects of altering these factors on the facility can be studied. Sensitivity analysis can be performed on these factors which would help the facility decision makers in making better decisions by concentrating on the important factors.

\subsubsection{Conclusions}

Large variation in production volume has become the norm due to the frequent changes in technologies and market. Many case studies have been discussed in [1] which further 
substantiate the above-mentioned conclusion. Modern day facilities need to be flexible to meet the ever-changing demands of the market and the end customers. The market demand is dynamic and hence facilities need to be able to cater to this dynamic change in product demand. Since resources need to be added or modified, significant cost and labor is involved in order to incorporate these additions or modifications. Facilities need to be designed such that introduction of newer products with shorter life cycles enforcing modifications and renewal of production facilities much earlier than their life time do not result in major capital expenditure. Hence a model needs to be built and investigation needs to be done to access the effect of manufacturing parameters on the effectiveness of the layout and the material handling system.

\subsubsection{Research Objectives}

The primary objectives of the research are given below.

- Investigate the impact of manufacturing parameters on facility layout.

- Develop a model in MS-EXCEL that will showcase the relationships between product and process design parameters and facility layout.

- Execute the model and develop relationship between manufacturing parameters and layout effectiveness by varying the different manufacturing parameters.

- Verify and validate the model after performing sensitivity analysis. 


\section{LITERATURE REVIEW}

"Modern manufacturing and service are characterized by the necessity to rapidly adapt production facilities and processes to changes in the required product quantity, mix and design. Such changes are arise from different sources like new regulations and environmental rules the manufacturer needs to comply, sudden changes in product demand, a new product line that the company's marketing people are eager to introduce or an integral part of the company's continuous productivity improvement program" [7]. Production managers are faced with matching the emerging product portfolio with the resources they have available [10]. Hence, many companies examine how complex their new products are before putting the $\mathrm{m}$ into full production. The role of the facilities manager has become crucial in the modern day manufacturing industries. Since any changes in the product mix or quantity bring about changes in the facility layout and design, a facilities manager needs to be prepared for these unforeseen requirements.

Earlier, when a new facility was planned, based on the selection and knowledge of the interaction between the different machining centers or departments, the facility manager attempts to maximize the adjacency measure, minimize the total cost of material handling or optimize some combination of the two. A heuristic or an optimal algorithm depending on the formulation and size of the problem is used to obtain a block layout [6]. The solution obtained is modified to include both, adjacency and total cost qualitative criteria under the assumption that:

- The product range and the composition remain constant over the lifetime of the facility

- If there are any changes in the product mix, they are made known at the design stage itself

These assumptions held in the past, but not in today's manufacturing industry. Today's manufacturing practices indicate that:

- The range and composition of products manufactured is changing frequently at an alarming rate [1].

- It is not possible to predict the changes which might be required in the future. 
Under these conditions, the effectiveness of the facility design is measured by the ability of the layout to adapt to the changes of the product mix and volume [6].

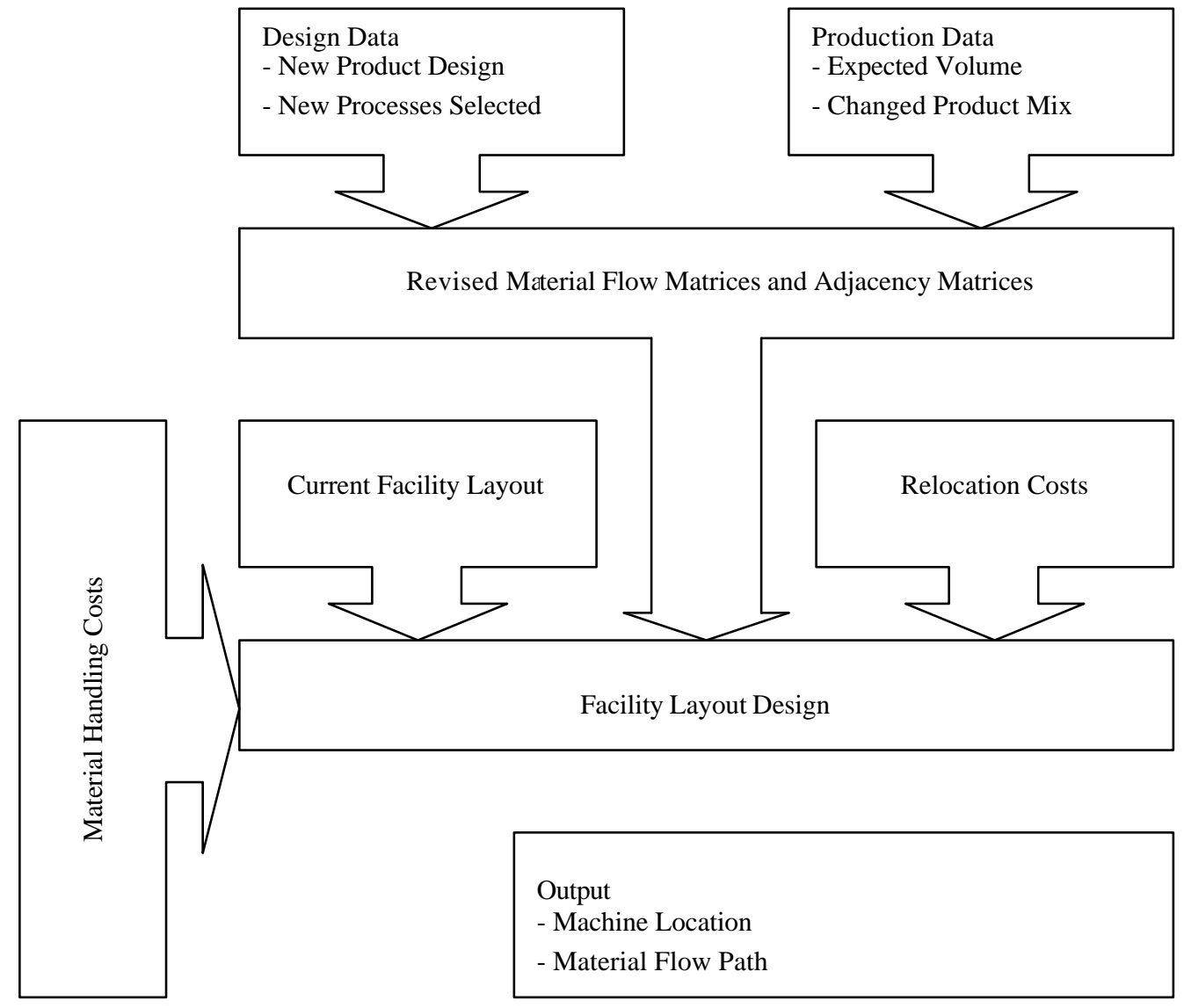

Figure 2.1Dynamic facility layout methodology [6]

The dynamic facility layout methodology addresses the layout issue considering the relocation of machines, workstations, personnel and support services in a dynamic environment. Since it is not possible to predict material flow patterns between workstations over long planning horizons and changes in flow patterns are known just before they occur, a manufacturer must alter the layout whenever the situation warrants. The above methodology considers the revised manufacturing conditions and accordingly designs the layout thereby minimizing the rearrangement costs while maximizing the potential savings in the material flow costs. The newer facilities should be designed in such a way that they respond to the underlying dynamics of operation and planning. A cycle of modeling, analysis and design will lead to better understanding of the problem dynamics and help define solutions that are fairly robust [6]. 
Regardless of the source and the extent of change, two important issues that need to be addressed are project development time and design quality. To reduce the development time and increase the quality, a collaborative approach to facility design is mandatory [7]. Facility design has evolved significantly over time and hence pioneering tools were based on manual algorithms and integrated methodologies.

Genetic algorithms are a class of adaptive search techniques which have gained popularity in facility design optimization problems. A lot of genetic algorithms have been designed to solve the quadratic assignment formulation of equal and unequal sized facilities layout problems. Genetic algorithms have received a great deal of attention due to the fact that they do not rely on the analytical properties of the function to be optimized which make them suited for a wide class of optimization problems [9]. An approach to solve a facility layout problem with equal sized and unequal-sized areas using genetic algorithms is given in [9].

Due to the availability of computer technology, automation of manual and error prone part of the design work was possible. More recently, computer systems for graphical simulation along with the advanced computer networking technology have provided the infrastructure for collaborative facility design.

\subsection{Computer Aided Layout Planning}

As mentioned earlier, facilities planning process has been simplified to a large extent with the advent of computers and the availability of user friendly and effective computer assisted design and manufacturing programs. The layouts can now be easily constructed, evaluated and discarded until the most effective layout is obtained. Actual models can be simulated and real life scenarios can be created and validated. Some of the important and commonly used computerized layout algorithms are discussed in the literature.

\subsubsection{CRAFT (Computerized Relative Allocation of Facilities Technique)[1]}

CRAFT is one of the earliest layout algorithms and was developed by Armour, Buffa and Vollman in 1963[1]. CRAFT is an improvement type of algorithm starting with an initial layout and develops alternate layouts. It begins by determining the centroids of the departments in the initial layout. It then calculates the rectilinear distances between pairs 
of department centroids and stores it in the distance matrix. The initial layout cost is calculated using entries on the from-to chart, unit cost matrix and distance matrix. CRAFT then considers all possible two-way and three-way department exchanges and identifies the best exchange, the one that results in the lowest layout cost. Once the exchanges are done, CRAFT calculates the new centroids for the departments and also calculates the new layout cost. The next iteration is done again with CRAFT trying to find out the best exchange possible. This process is continued till no further two or threeway exchanges and reduction in layout cost is possible.

CRAFT is generally flexible with respect to department shapes, exchanges departments only that are adjacent or equal in area, captures the initial layout with reasonable accuracy and is a highly path dependent heuristic. However, CRAFT is restricted to rectangular buildings and rarely generates department shapes that result in straight, uninterrupted aisles, which are generally desired in the final layout.

\subsubsection{MCRAFT (MicroCRAFT) [1]}

MCRAFT is the new version of CRAFT developed by Hosni, Whitehouse and Atkins. MCRAFT is similar to CRAFT except that it can exchange any two departments even if they are not equal in area and are not adjacent. MCRAFT divides the area into a number of bands and assigns the one or more departments in these bands. The number of bands is specified by the user. Though there are advantages using MCRAFT, it also has some shortcomings like its inability to capture the initial layout accurately unless the departments are already arranged in bands and assumes that the bandwidth is the same for all bands.

\subsubsection{BLOCPLAN [1]}

BLOCPLAN was developed by Donaghey and Pire. The departments are arranged in bands as in the case of MCRAFT but the number of bands are determined by the program and are generally limited to two or three bands. Also, the departments are present in only one band and hence they are rectangular in shape. The band widths are allowed to vary which was not possible in MCRAFT. This can be used both as a construction type and an improvement type algorithm as it calculates the initial layout fairly accurately. It uses the 
relationship chart and from-to chart to evaluate the layout though they can be used only one at a time.

\subsubsection{LOGIC (Layout Optimization with Guillotine Induced Cuts)[1]}

In LOGIC, assumption is made that it takes the from-to chart as the input data. Like BLOCPLAN, LOGIC can be used both as a constructive type and improvement type algorithm. LOGIC divides the building into smaller portions by executing successive "guillotine" cuts which are straight lines running from one end of the building to the other. LOGIC executes a series of horizontal and vertical cuts. After each cut, the departments are assigned to the east side or the west side of the cut. LOGIC constructs a tree in order to successfully execute these cuts. The departments generated by LOGIC are rectangular, provided that the building under consideration is also rectangular.

\subsubsection{MULTIPLE (MULTI-floor Plant Layout Evaluation)[1]}

MULTIPLE was developed by Bozer, Meller and Erlebacher for multiple floor facilities. It is similar to CRAFT except for the exchange procedure and layout formation. MULTIPLE uses from-to chart as input data and the departments need not be rectangular. It is an improvement type algorithm which starts with an initial layout specified by the layout planner. MULTIPLE can exchange any two departments whether they are adjacent or not. It achieves this by using "spacefilling curves" (SFCs). In MULTIPLE, SFCs are used to reconstruct a new layout when there is an exchange of any two departments.

\subsubsection{CORELAP (Computerized Relationship Layout Planning)[1]}

CORELAP is one of the oldest construction routine developed by James Moore in 1967. It determines the most effective overall layout on the basis of relationships between equipments and the steps involved in the production process. It constructs a layout by calculating the total closeness rating (TCR) for each department. TCR is the sum of the numerical values assigned to the closeness relationships by converting vowel letter ratings to their numerical equivalents $(A=6, E=5, I=4, O=3, U=2, X=1)$. The ratings for each activity area are summed up and evaluated to find the activity with the highest TCR. That activity is then placed at the center of the layout and the remaining areas are then examined again. 


\subsubsection{ALDEP (Automated Layout Design Program)[1]}

The ALDEP routine was developed Jerrold Seehof and Wayne Evans and has the same data input requirement and objectives as CORELAP. ALDEP takes a different approach to construct the layout by selecting the first department and breaking ties randomly. ALDEP produces may layouts, rates the layouts and the evaluation of the layouts is done by the facilities manager. Each layout is rated and scored based on the number of related activities that are adjacent and weighted based by the relative closeness required between them.

The shapes of the activity areas created by ALDEP are much more regular than the ones obtained by either CRAFT or CORELAP. This is a result of the sweep technique it employs. The assignment of activities in multistory building is a formidable planning problem and a variety of algorithms and approaches are available. Some of them resemble the ones already discussed. Some of the most commonly used techniques are SPACECRAFT which is an extension of CRAFT that incorporates vertical travel costs and is an improvement algorithm, Planning ADES which was a set of card input programs for use in IBM mainframe computers and SABA routine which is a combination of improvement and construction algorithms. Over the last few years, there have been progressive uses of interactive graphics. However, the underlying algorithms will be definitely similar if not the same for future layout solutions as well. It is always difficult to suggest one algorithm which would suit a particular layout problem. Hence it is always suggested that the facility planner looks at the solutions obtained by at least two or three algorithms before making the final decision.

\subsection{Advanced Computer based Technologies for Facility Design}

Techniques for facility design have progressed in parallel with the evolution of manufacturing [7]. In an effort to use space effectively and improve the production efficiency, various planning methods and algorithms were developed and introduced. Focus has always been on planning the arrangement of departments and machines to reduce the cost of moving materials and products through the facility. Computer technologies have been extensively to develop advanced tools for facility design. Table 2.1 shows the development of computer aided facility design methods. A description of some of the tools currently being used is given below. 


\subsubsection{Integration of Simulation and Graphics for Flow visualization}

Simulation is one of the fast growing computer packages used to solve facility layout problems. Simulation study is done to determine the inherent constraints and

\begin{tabular}{|c|c|c|}
\hline Stage of development & Tools for facility design & Examples \\
\hline $\begin{array}{l}\text { Manual design } \\
\text { Integrated manual methodology } \\
\text { Automation of methodology } \\
\text { elements }\end{array}$ & $\begin{array}{l}\text { Algorithms, templates } \\
\text { Systematic layout planning } \\
\text { Computerized Versions of } \\
\text { algorithms, mathematical } \\
\text { programming, heuristics etc } \\
\text { Discrete event simulation } \\
\text { (including simulation animation } \\
\text { packages) } \\
\text { Computer aided drafting }\end{array}$ & $\begin{array}{l}\text { (Tompkins and White 1984) } \\
\text { SLP (Muther 1973) } \\
\text { CRAFT (Armour and Buffa 1963) } \\
\text { CORELAP (Lee and Moore 1967) } \\
\text { SLAM II, GPSS (Pritsker 1986) } \\
\text { AutoCAD application (Masud and } \\
\text { Sathyana 1992) }\end{array}$ \\
\hline Integrated applications & $\begin{array}{l}\text { Database and simulation } \\
\text { Graphical simulator emulator systems } \\
\text { for robotics, Integration of CAD, } \\
\text { kinematics and discrete event } \\
\text { simulation and data libraries }\end{array}$ & $\begin{array}{l}\text { CAFP (Nof 1980) } \\
\text { ROBCAD } \quad \text { (Technomatix } \\
\text { Technologies 1989) } \\
\text { IGRIP/QUEST (Deneb Robotics } \\
\text { 1993) }\end{array}$ \\
\hline intelligence & $\begin{array}{l}\text { Knowledge based systems and } \\
\text { optimization }\end{array}$ & $\begin{array}{l}\text { FADES (Fisher and Nof 1984) and } \\
\text { QLAARP (Banerjee et al 1992) } \\
\text { respectively }\end{array}$ \\
\hline Facility description language & $\begin{array}{l}\text { Collaborative design semantics, multi } \\
\text { level design, integration of simulator } \\
\text { emulator and discrete event } \\
\text { simulation }\end{array}$ & $\begin{array}{l}\text { FDL (Witzerman and Nof 1995a, } \\
\text { 1995b) }\end{array}$ \\
\hline $\begin{array}{l}\text { Collaboration over internet for } \\
\text { facility engineering infrastructure }\end{array}$ & $\begin{array}{l}\text { Integrated architectural design, } \\
\text { structural engineering and energy } \\
\text { analysis }\end{array}$ & $\begin{array}{l}\text { SEED (Flemming et al 1994) for } \\
\text { architectural design, CONGEN } \\
\text { (Gorti and Sriran 1994) for } \\
\text { structural engineering and } \\
\text { ACE/BLAST (Case and Lu 1995, } \\
\text { Blast 1991) for energy analysis }\end{array}$ \\
\hline
\end{tabular}

Table 2.1 Development of computer aided facility design methods

bottleneck operations in the manufacturing process. The relevant performance measures from the simulation output along with factors like space requirements for each equipment and the expected production goal of the new facility can be analyzed to present new design alternatives for the proposed new facility. Commercial simulation packages have been developed with graphical modules to show flow relationships. Tumay (1992) presents an approach that integrates $\mathrm{CAD}$ and system simulation which result in accurate scale models for animation [7]. ROBCAD and IGRIP are graphical simulator emulators for detailed design of robotic workcells that support deterministic motion simulation of kinematic devices and plant layout alternatives. Linkage of cell simulation with material 
handling animation and discrete event simulation are allowed by incorporating Quest on IGRIP. AutoMOD II, an industrial simulation system developed by Thompson (1989) focuses on the physical geometry of manufacturing, material handling, storage and distribution.

\subsubsection{Databases and Computer Aided Drafting}

The use of computers has been extended to detailed facility plans with the advent of low cost software for computer aided drafting. It is important to store and maintain a database on information about the geometry, device parameters, processes and flow characteristics. Computer aided drafting is the primary design representation and the source of specialty drawings. Design layers with geometric data such as identification, location, volume and related information are calculated from the graphical model and placed into a database for further application [7].

\subsubsection{Artificial Intelligence in Facility Design}

FADES (Fisher and Nof 1984) was the first rule based system to support the facility design process supporting equipment selection, capacity analysis and workstation site selection. FADES selects an economic model, develops inputs and invokes the model based on the input provided by the user. Another iterative methodology which optimizes the layout with respect to material flow is QLAARP (Banerjee et. al. 1992). The algorithm is based on a linear programming solution to a design graph network minimizing the cumulative product of flow and distance. Another important feature of QLAARP is its ability to identify and eliminate qualitative layout anomalies. Wang and Bell (1992) apply a knowledge based design system with a focus on the simulation of part and tool flow in flexible manufacturing systems [7].

Though there have been significant advancements in computer based facility design methodologies, these tools have some limitations which are given below.

- Generally, tools focus on a specific task and often use a model that does not support the data requirements and outputs obtained from other tools.

- The design outputs from one model are used as input parameters at the next level of design abstraction though lower level models may invalidate the assumptions or results obtained at higher level models. 
- Most research focuses on facility layout problems ignoring the detailed aspects of facility design which might affect the ultimate solution.

Therefore, corrections that may be required may result in costly modifications to the physical facility along with changes in planned staffing levels, equipment configurations and material handling requirements. It is not known whether computers will ever be able to fully capture and use human experience and judgment in arriving at solutions for any given facility layout problem. Computers will continue to be used as design aids to the layout planner who will continue to play a key role in developing and evaluating the facility layout.

The most dramatic changes in the workplace are still to come. While many companies have yet to absorb the past decade's advances in areas such as technology, building codes and worker sophistication, it is time to think of the bigger changes ahead [19]. Companies will need help to design and facilitate innovations that fit the new work environment rather than those based on our industrial past.

Facility management is a fairly new business and management discipline which is defined as the practice of coordinating the physical workplace with the people and work of the organization, integrating the principles of business administration, architecture and the behavioral and engineering sciences. It embraces the concepts of cost effectiveness, productivity improvement, efficiency and employee quality of life [5]. The public and the private sector have been slow to realize the business nature of facility management. The following information helps in emphasizing the importance of facility management.

- The Department of Defense is estimated to own over $\$ 500$ billion in facilities.

- Facilities are usually the greatest component of a company's administrative expense after payroll.

- Some facilities have avoided or saved costs in the range of 30 to 35 percent without any diminution of services by simply applying the sound principles of facilities planning, lease management and energy management.

Figure 2.2 in the following page depicts the facility management life cycle. Its explains the different stages of a facility management lifecycle. The planning stage involves identifying the resources for the facility and planning the budget required. The next stage involves building the actual structure of the facility. This process involves evaluating 

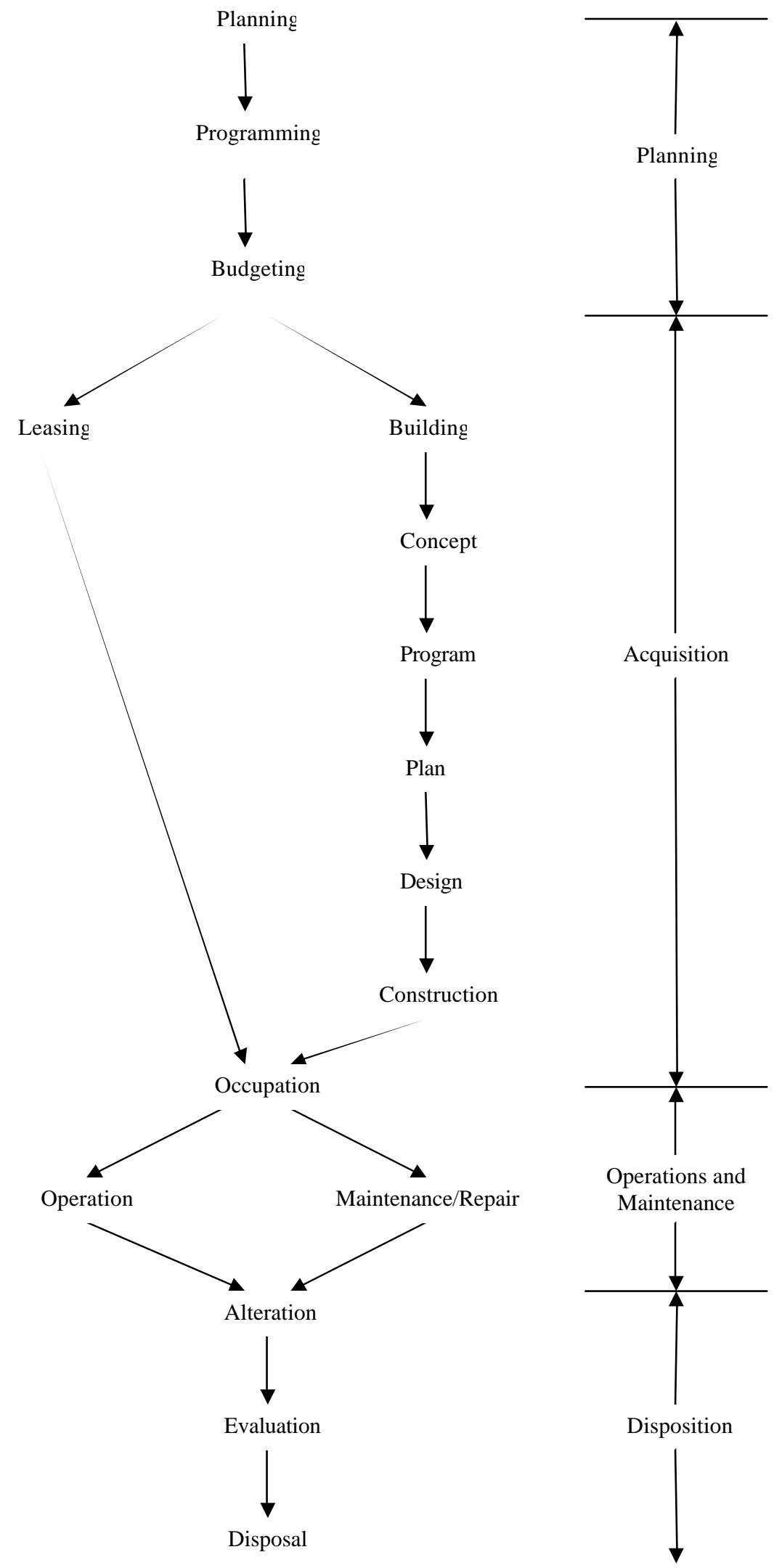

Figure 2.2 Facility management life cycle [5] 
whether to construct a new building or use an already existing structure. The facility concept, the design and construction plan are executed in this stage. The next stage involves placing each of the different operations and the necessary resources required to perform these operations like materials, equipment and labor. Provisions need to be made for regular maintenance of these areas whenever the need arises. The last stage involves provisions to make changes in the facility layout when required due to changes in market demand and dispose any resources, which may not be required for the new layout.

Another new development in layout planning is the development of flexible layouts. Flexible layouts use methods and equipment that can perform a variety of tasks under different operating conditions. Harmon and Peterson [1] have suggested the use of the following objectives to develop flexible layouts which are given below.

1. Reorganize factory subplants to achieve superior manufacturing status.

2. Provide maximum perimeter access for receiving and shipping materials, components and products as close to each subplant as possible.

3. Cluster all subplants dedicated to a product or product family around the final process subplant to minimize inventories, shortages and improve communication.

4. Locate supplier subplants of common component subplants in a central location to minimize component travel distances.

5. Minimize the factory size to avoid wasted time and motion of workers.

6. Eliminate centralized storage of purchased materials, components and assemblies and move storage to focused subplants.

7. Minimize the amount of factory reorganization that will be made necessary by future growth and change.

8. Avoid locating offices and support services on factory perimeters.

9. Minimize the ratio of isle space to production process space.

The issue of flexibility is becoming increasingly important to the design, planning and operation of manufacturing facilities [23]. This importance is due to the nature of the environment characterized by high degree of variability and volatility in which most manufacturing organizations have to compete. Manufacturing flexibility is now seen as a mechanism that allows organizations to compete despite the volatility of their operating environments by responding in a cost efficient and timely fashion to changing market demands [23]. 
Different approaches have been adopted and evaluated to address the facilities layout and design problems. Since the impact of work settings on organizational performance is visible, it is clearly explained in [12]. As cost is one of the most important consideration in any facilities problem, the strategies needed to reduce the cost of the product is explained in [8]. The impact of new products on the facility is explained in [10]. Newer methodologies have been introduced to address the facility layout problem like the use of genetic algorithms for facility layout design in [9] and simulation in [11]. The changes in design and facilities management over a period of time are explained in [14]. Since, it is important to study the current facility before making any changes or additions based on requirements; the procedure used to conduct a facility management audit is explained in [15].

\subsection{Conclusion}

The literature review reveals the work that has been done in the area of facilities layout and design and underlines its importance across the globe. Considerable efforts have been put into this area of research and the availability of improved technology has provided many tools that he improved the quality of research. Though many topics have been covered and dealt with in isolation, the focus on the overall facility design system is improving. The literature clearly shows that the effect of process parameters on the effectiveness of the facility layout has not been analyzed. Since changes in facility have direct impact on the expenses of the company and thereby on the cost of the product being manufactured, the methodology adopted in arriving at the solution needs to be carefully evaluated. The availability of computer based layout algorithms have helped in enhancing the productivity of the layout designer who can now evaluate different options available to him and select the most suitable one. But there is still no tool available to the facilities manager to determine how process parameters impact layout effectiveness. Research shows that demand of new products by the market, which bring about changes in the product mix, volume and process parameter changes have direct impact on the facility size and also the machine and operator activity cost. Hence, a tool is required which would help in understanding the effect of process parameter changes on layout effectiveness. It can be clearly established that the approach that reduces the total costs to the minimum and requires the minimum modifications in the facility is the most suited. 


\section{RESEARCH APPROACH}

\subsection{Collection of Data}

Evaluation of the current conditions that exist in the facility requires data on the process and product parameters that are being handled. The facilities manager needs to have close interaction with the product and process designer as these are the people responsible for changes in the product or process design which ultimately might result in changes in the facility design. The product designer is responsible for specifying what the end product would be in terms of the dimensions, material composition and sometimes packaging as well. The process planner or designer is responsible for determining how the product will be manufactured. Also involved is the production planner who specifies the production quantities and schedules the production equipment. The facility planner is dependent on the product, process and schedule designers for timely and accurate input to carry out his task effectively. Since these factors have some or the other impact on the facility, combination of these factors can be put to test and the effects on the size of the facility and cost of the product being manufactured can be analyzed. Also, sensitivity analysis can be done in order to determine the most decisive factors.

Any manufacturing facility is designed based on the annual volume that needs to be manufactured based on the market requirement. The process requirements to meet this demand can be categorized in three phases. The first phase determines the quantity of components to be manufactured including the scrap allowance to meet the market demand. The second phase determines the equipment required for each operation. The third phase combines the operation requirements to obtain the overall equipment requirements.

Once the decisions on the product, process and schedule design are made, the facilities planner needs to organize the information and generate and evaluate the layout, material handling, storage and unit load design alternatives. Then, consideration is given to the flow of materials and the relationship of activities using the different tools available like affinity diagram, interrelationship digraph, matrix diagram, prioritization matrix and the appropriate relationship diagram is constructed. The next step then is to evaluate the space requirements for the layout. Ideally, it is better to develop a layout and then construct the building around the layout, but more than often there are a lot of 
constraints like the presence of a building, limitation in the size of the building size or availability of capital for new construction resulting in considering not only space requirements but also its availability.

\subsection{Procedure}

In order to study the relationship between the process parameters on the facility size and the cost of the product being manufactured, a product was selected being manufactured in a job shop production and a facility was designed to manufacture the product. A job shop was considered for the research, as this type of production is the best platform to showcase process parameters in a manufacturing facility and their impact on layout effectiveness. Some of the important parameters, which are used in the manufacture of the product, and entities, which are required in arriving at the final size of the facility, are discussed in the following sections.

\subsubsection{Scrap Rate}

One of the most important considerations which need to be taken into account in the manufacture of any product is the scrap rate. Scrap is the material waste generated in the manufacturing process due to geometric or quality considerations [1]. Every company strives to keep the scrap rate to the minimum in an effort for continuous improvement. Scrap rate can be reduced by automating the process, loosening the tolerance, increasing the number of certified suppliers, improving the quality at the source and use of higher grade of material.

We have,

$\mathrm{O}_{\mathrm{k}}=\mathrm{I}_{\mathrm{k}}-\mathrm{P}_{\mathrm{k}} \mathrm{I}_{\mathrm{k}}$ or $\mathrm{O}_{\mathrm{k}}=\mathrm{I}_{\mathrm{k}}\left(1-\mathrm{P}_{\mathrm{k}}\right)$

Hence,

$\mathrm{I}_{\mathrm{k}}=\mathrm{O}_{\mathrm{k}} /\left(1-\mathrm{P}_{\mathrm{k}}\right)$

Where,

$\mathrm{P}_{\mathrm{k}}$ is the percentage scrap produced at the $\mathrm{k}^{\text {th }}$ operation

$\mathrm{O}_{\mathrm{k}}$ is desired output of non defective product from operation $\mathrm{k}$

$\mathrm{I}_{\mathrm{k}}$ is the production input to operation $\mathrm{k}$ 
Therefore, the expected number of input units to start production for a part having $\mathrm{n}$ operations is

$$
\mathrm{I}_{1}=\frac{\mathrm{O}_{\mathrm{n}}}{\left(1-\mathrm{P}_{1}\right)\left(1-\mathrm{P}_{2}\right) \ldots \ldots\left(1-\mathrm{P}_{\mathrm{n}}\right)} \quad \text { Eqn. } 3.1
$$

where in this case $\mathrm{O}_{\mathrm{n}}$ is the market estimate

\subsubsection{Equipment Fractions}

Another calculation required in order to determine the space requirement for any facility is the Equipment fraction. This is the quantity of equipment required for an operation. The equipment fraction for any operation may be determined by dividing the total time required for the operation (product of the standard time for the operation and the number of times the operation needs to be performed) by the time available to complete the operation. The following deterministic model given in [1] can be used to estimate the equipment fraction.

$\mathrm{F}=\stackrel{\mathrm{SQ}}{\mathrm{EHR}} \quad$ Eqn. 3.2

Where,

$\mathrm{F}=$ number of machines required per shift

$\mathrm{S}=$ standard time (minutes) per unit produced

$\mathrm{Q}=$ number of units to be produced per shift

$\mathrm{E}=$ actual performance, expressed as a percentage of standard time

$\mathrm{R}=$ reliability of the machine

Also, equipment fractions are a function of the following factors:

- Number of shifts as the same machine might work in more than one shift.

- Set-up times because whenever machines are not dedicated, more machines are required when the set-up times are longer.

- Degree of flexibility as customers may require small quantities of different products to be delivered frequently which may require extra machine capacity to handle these kinds of requests. 
- Layout type as more number of machines may be required to dedicate manufacturing cells or focused factories to the production of product families.

- Total productive time that will increase the machine up time and improve quality thereby reducing the number of machines required for production.

These models are used to plan facility which provides sufficient flexibility to handle changes in machine fraction variables.

The next step is to combine the equipment fractions for identical equipment types though it might not be straightforward. Overtime and subcontracting can be thought of if only one operation is to be performed on a particular equipment type, whereas if more than one operation is to be performed on a particular equipment type, several alternatives can be considered.

Once the decisions on the product, process and schedule design are made, the facilities planner needs to organize the information he has and generate and evaluate the layout, material handling, storage and unit load design alternatives. Then, consideration is given to the flow of materials and the relationship of activities using the different tools available like affinity diagram, interrelationship digraph, matrix diagram, prioritization matrix etc, and the appropriate relationship diagram is constructed. The next step then is to evaluate the space requirements for the layout. Ideally, it is better to develop a layout and the construct the building around the layout, but more than often there are a lot of constraints like the presence of a building, limitation in the size of the building size or availability of capital for new construction resulting in considering not only space requirements but also its availability.

\subsubsection{Employee Requirements}

After looking at ways of determining the production rate and the number of machines required per production period, we also need to look at the determination of the number of employees required. In the case of manual assembly operations where the operator is handling only one machine, the number of employees can be determined as follows:

$$
A_{j}=?_{i=1}^{n} \quad P_{i j} T_{i j}
$$

where,
Eqn. 3.3

$A_{j}=$ number of operators required for assembly operation $j$ 
$\mathrm{P}_{\mathrm{ij}}=$ desired production rate for product $\mathrm{i}$ and assembly operation $\mathrm{j}$, pieces per day

$\mathrm{T}_{\mathrm{ij}}=$ standard time to perform operation $\mathrm{j}$ on product $\mathrm{i}$, minutes per piece

$\mathrm{H}_{\mathrm{ij}}=$ number of hours available per day for assembly operation $\mathrm{j}$ on product $\mathrm{i}$

$\mathrm{n}=$ number of products

The number of machine operators required is dependent on the number of machines tended by one or more operators [3]. Whenever highly automated equipments are used, there is a strong possibility that a single operator might be tending to a number of machines and the determination of the number of machines to be supervised by one operator can take two approaches. One approach is to assume all time values as deterministic and treat the activity times as random variables and perform a probabilistic analysis. One deterministic model uses the multiple chart which is a descriptive, analog chart showing the multiple activity relationships on a time scale to determine the assignment of operators to machines. This chart can be used in analyzing the multiple activity relationships when an operator supervises identical and non-identical machines.

A symbolic model that can be used to determine the number of machines assigned to an operator when identical machines are used is given in [3] which is given below. Let $\mathrm{a}=$ independent activity time (e.g. loading, unloading)

$\mathrm{b}=$ independent operator activity time (e.g. walking, inspecting, packaging)

$\mathrm{t}=$ independent machine activity time (e.g. automatic run time)

n' $=$ number of machines assigned to an operator for neither machine or operator idle time

$\mathrm{m}=$ number of machines assigned to an operator

$\mathrm{T}_{\mathrm{c}}=$ repeating cycle time

$\mathrm{I}_{\mathrm{O}}=$ idle operator time during a repeating cycle

$\mathrm{I}_{\mathrm{m}}=$ idle time per machine during a repeating cycle

$\mathrm{TC}(\mathrm{m})=$ cost per unit produced, based on assignment of $\mathrm{m}$ machines per operator

$\mathrm{C}_{1}=$ cost per operator-hour

$\mathrm{C}_{2}=$ cost per machine-hour

It is seen that it takes $\mathrm{a}+\mathrm{b}$ time units for an operator to perform work on a single machine during one production cycle and it takes a machine $\mathrm{a}+\mathrm{t}$ time units to complete a production cycle. Hence, the ideal assignment n' which would not have either operator or machine idle time would be, 


$$
n^{\prime}=\frac{a+b}{a+t}
$$

If $\mathrm{m}$ is the number of machines assigned to an operator, then if $\mathrm{m}<\mathrm{n}$, the operator is idle and if $m>n$ ', then the machine is idle. Hence in order to balance this, the following formulation is arrived in [3] to determine the cost of the unit produced.

$$
\begin{array}{ccc}
\mathrm{TC}(\mathrm{m})=\left(\mathrm{C}_{1}+\mathrm{mC}_{2}\right)(\mathrm{a}+\mathrm{t}) & \text { when } \mathrm{m}<\mathrm{n}, & \\
\mathrm{m} & & \\
\mathrm{TC}(\mathrm{m})=\left(\mathrm{C}_{1}+\mathrm{mC}_{2}\right)(\mathrm{a}+\mathrm{b}) & \text { when } \mathrm{m}>\mathrm{n}, 5 & \text { Eqn. } 3.6
\end{array}
$$

The above formulation has been used for the determination of the cost of the product being manufactured in a facility.

\subsubsection{Parts of the Powerarm}

A Powerarm [22] was selected to do the research and conduct the analysis for the different process parameters involved in a job shop production scenario. Apple [22] gives the complete details on the manufacturing process, the sequence of operations, the operation times and the types of machines required to manufacture the Powerarm. This data is used to build a model in MS EXCEL and the impact of varying these parameters on the layout effectiveness is established. There are different parts which when assembled form the Powerarm. The important parts are considered and area required to manufacture each of the different parts is determined. These areas are added to arrive at the total area required to manufacture the Powerarm. The important parts considered are the Base, Eccentric rod, Handle, Cover, Cap, Pin, Pressure pad and Ball swivel.

\subsubsection{Operations on Powerarm [22]}

The different operations, the equipments and their manufacturing time are given in detail in Apple [22]. They are shown in Table 3.1 below. 


\begin{tabular}{|c|c|c|c|}
\hline $\begin{array}{l}\text { Operation } \\
\text { No. }\end{array}$ & Operation Description & Machine Name & Pieces/hr \\
\hline \multicolumn{4}{|c|}{ PART I - BASE } \\
\hline 1 & Face bottom & Leblond Eng. lathe & 60 \\
\hline 2 & Face top, turn OD, neck, drill and ream & $\begin{array}{l}\text { Warner and Swasey \#1A turret } \\
\text { lathe }\end{array}$ & 23.8 \\
\hline 3 & Drill three bolt holes & Cleereman drill press & 84 \\
\hline 4 & Drill pin hole & Delta drill press & 238 \\
\hline 5 & Drill and ream eccentric hole & 2 Spindle Fosdick drill press & 65.4 \\
\hline 6 & Inspect & Bench & 55.4 \\
\hline 7 & Degrease & Detrex washer & 143 \\
\hline \multicolumn{4}{|c|}{ PART II - ECCENTRIC ROD } \\
\hline 1 & Cut off and chamfer & Oster \#601 & 588 \\
\hline 2 & Drill 5/16 hole & Delta drill press & 250 \\
\hline 3 & Tap 3/8-16 hole & Delta drill press & 120 \\
\hline 4 & Turn eccentric & Leblond Eng. Lathe & 149 \\
\hline 5 & Inspect & Bench & 143 \\
\hline 6 & Heat treat & Furnace (subcontract) & 910 \\
\hline 7 & Grind O.D. & $\begin{array}{l}\text { Cinn. Centerless grinder } \\
\text { (subcontract) }\end{array}$ & 455 \\
\hline 8 & Degrease & Detrex washer & 455 \\
\hline \multicolumn{4}{|c|}{ PART III - HANDLE } \\
\hline 1 & Thread, cut off and chamfer & Warner and Swasey \#1A & 256 \\
\hline 2 & Thread, \& chamfer $2^{\text {nd }}$ end & Warner and Swasey \#1A & 232 \\
\hline 3 & Inspect & Bench & 500 \\
\hline 4 & Degrease & Detrex washer & 600 \\
\hline \multicolumn{4}{|c|}{ PART VII - COVER } \\
\hline 1 & Face, bore, turn and cut off & Warner and Swasey \#1A & 60 \\
\hline 2 & Drill 4-9/32 holes & Cleereman drill press & 178 \\
\hline 3 & Saw in two & Brown and Sharpe mill & 125 \\
\hline 4 & Inspect & Bench & 250 \\
\hline 5 & Degrease & Detrex washer & 300 \\
\hline \multicolumn{4}{|c|}{ PART VIII - CAP } \\
\hline 1 & Face, bore, and cut seat & Warner and Swasey \#1A & 30.3 \\
\hline 2 & Drill and tap & 2 Spindle Fosdick drill press & 62.5 \\
\hline 3 & Mill slot & Milwaukee vertical mill & 83.5 \\
\hline 4 & Inspect & Bench & 100 \\
\hline 5 & Degrease & Detrex washer & 143 \\
\hline \multicolumn{4}{|c|}{ PART IX - PIN } \\
\hline 1 & Cut off and chamfer & Oster\# 601 & 1000 \\
\hline \multicolumn{4}{|c|}{ PART X - PRESSURE PAD } \\
\hline 1 & Bore, face and chamfer & Warner and Swasey \#1A & 40 \\
\hline 2 & Mill slot & Brown and Sharpe mill & 120 \\
\hline 3 & Inspect & Bench & 100 \\
\hline 4 & Degrease & $\begin{array}{l}\text { Detrex washer } \\
\text { (continued) }\end{array}$ & 600 \\
\hline
\end{tabular}




\begin{tabular}{|l|l|l|l|}
\hline $\begin{array}{l}\text { Operation } \\
\text { No. }\end{array}$ & Operation Description & Machine Name & Pieces/hr \\
\hline PART XI - BALL SWIVEL & \multicolumn{2}{l|}{} \\
\hline 1 & Turn shank, form ball and cut off & Warner and Swasey \#1 A & 30.3 \\
\hline 2 & Grind ball & Landis grinder type C & 25 \\
\hline 3 & Mill shank & Milwaukee Simplex mill & 90 \\
\hline 4 & Drill and tap two holes & 2 Spindle Fosdick drill press & 62.5 \\
\hline 5 & Bnspect & 83.3 \\
\hline 6 & Dench & 600 \\
\hline ASSEMBLEase & Detrex washer & \multicolumn{2}{l|}{} \\
\hline SSA-1 & Knob to handle & 333 \\
\hline SA-1 & Handle assembly to Eccentric rod & 286 \\
\hline A-1 & Rod assembly to Base & 200 \\
\hline A-2 & Plunger, Pin and Pressure pad to Base & 357 \\
\hline SSA-3 & Lock washers to hexagonal head screws & 500 \\
\hline SA-3 & Hexagonal head screw assemblies to ball swivel & 350 \\
\hline A-3 & Ball swivel assembly to base & 90 \\
\hline A-4 & Cover and Cap to base & 100 \\
\hline A-5 & Inspect & 178 \\
\hline A-6 & Degrease & 143 \\
\hline A-7 & Mask and paint & 30 \\
\hline A-8 & \multicolumn{2}{|l|}{ Pack } & 30 \\
\hline
\end{tabular}

Table 3.1 Manufacturing Times for individual machines

\subsubsection{Parameters considered}

The parameters considered in this model are type of operation, scrap rate, availability of machine, reliability of machine, loading and unloading time, operator cost/hour and machine cost/hour. The first step of the analysis was to define the values for the different parameters. The values for these parameters were obtained from the IMSE 449 course where a similar project was done. Some of this data on the process parameters was used in the research. The values for the process parameters have been used for all the different machines and operations used in the manufacture of the Powerarm [22], the details for which are given below in Table 3.2, Table 3.3 and Table 3.4. 


\begin{tabular}{|c|c|}
\hline OPERATIONS & SCRAP RATE \\
\hline Face & $4 \%$ \\
\hline Turn & $2 \%$ \\
\hline Neck & $0.5 \%$ \\
\hline Drill & $3 \%$ \\
\hline Ream & $2 \%$ \\
\hline Inspect & $4 \%$ \\
\hline Degrease & $0 \%$ \\
\hline Cut off & $3 \%$ \\
\hline Chamfer & $6 \%$ \\
\hline Tap & $2 \%$ \\
\hline Heat treatment & $7 \%$ \\
\hline Grind & $5 \%$ \\
\hline Thread & $6 \%$ \\
\hline Saw & $3 \%$ \\
\hline Bore & $4 \%$ \\
\hline Cut & $3 \%$ \\
\hline Mill & $5 \%$ \\
\hline Form & $3 \%$ \\
\hline Assembly & $0 \%$ \\
\hline Table 3.2 Scrap & \\
\hline
\end{tabular}

Table 3.2 Scrap rates of different operations

Table 3.2 gives details on the scrap rate for each of the different types of operations performed during the manufacture of the Powerarm [22].

\begin{tabular}{|c|c|c|}
\hline MACHINE & OPERATION & SETUP \& UNLOAD $(\min )$ \\
\hline \multirow{2}{*}{ Leblond Lathe } & Face & 0.2 \\
\hline & Turn & 0.26 \\
\hline \multirow[t]{10}{*}{ Warner \& Swasey } & Turn & 0.6 \\
\hline & Face & 0.6 \\
\hline & Neck & 0.4 \\
\hline & Drill & 0.46 \\
\hline & Ream & 0.66 \\
\hline & Thread & 0.4 \\
\hline & Cut & 0.4 \\
\hline & Chamfer & 0.4 \\
\hline & Bore & 0.48 \\
\hline & Form & 0.4 \\
\hline Cleerman Drill Press & Drill & 0.32 \\
\hline Delta Drill Press & Drill Pin Holes & 0.60 \\
\hline Fosdick Drill Press & Drill & 0.70 \\
\hline Bench & Inspect & 0.44 \\
\hline Dextrex Washer & Degrease & 0.26 \\
\hline \multirow[t]{2}{*}{ Oster } & Cut off & 0.43 \\
\hline & Chamfer & 0.3 \\
\hline Brown \& Sharpe Mill & Saw & 0.28 \\
\hline Milwaukee Mill & Mill & 0.72 \\
\hline Landis Grinder & Grind & 0.54 \\
\hline Simplex Mill & Mill & 0.50 \\
\hline
\end{tabular}

Table 3.3 Loading and Unloading times for different machine operations 
Table 3.3 gives the times for loading and unloading the part on the different machines for each of the operations performed.

\begin{tabular}{|l|c|c|c|c|}
\hline \multicolumn{1}{|c|}{ MACHINE } & $\begin{array}{c}\text { AVAILABILITY } \\
\text { (hrs/day) }\end{array}$ & RELIABILITY (\%) & $\begin{array}{c}\text { COST } \\
(\mathbf{\$} / \mathbf{h r})\end{array}$ & SPACE (sft) \\
\hline Leblond lathe & 24 & 93 & 12 & 101 \\
\hline Warner \& Swasey & 24 & 83 & 15 & 123 \\
\hline Cleerman Drill Press & 24 & 88 & 10 & 78 \\
\hline Delta Drill Press & 24 & 88 & 9 & 99 \\
\hline Fosdick Drill Press & 24 & 77 & 13 & 120 \\
\hline Bench & 24 & 100 & 7 & 66 \\
\hline Dextrex Washer & 24 & 100 & 8 & 77 \\
\hline Oster & 24 & 80 & 21 & 134 \\
\hline Brown \& Sharpe Mill & 24 & 85 & 18 & 99 \\
\hline Milwaukee Mill & 24 & 78 & 15 & 113 \\
\hline Landis Grinder & 24 & 89 & 19 & 124 \\
\hline Simplex Mill & 24 & 92 & 17 & 101 \\
\hline
\end{tabular}

Table 3.4 Other parameters for machines

Finally, Table 3.4 provides details on the availability of each of the machines, their reliability in percentages, the operating cost of machine in dollar per hour and the space required for each of the machines to be installed in the facility being designed.

Independent operator activity time is taken as 1 minute, operator cost is taken as $\$ 25 / \mathrm{hr}$, operator efficiency as $80 \%$ and number of Powerarms [22] manufactured is 1000 .

\subsection{Operations Process Chart for the Powerarm [22]}

Figure 3.1 in the following page shows the operations process chart for the Powerarm [22]. The process chart clearly shows the product flow resulting in the final assembly of the Powerarm [22]. The assembly sequence for the different parts of the Powerarm [22], the different manufacturing operations on each of the parts for their manufacture and the sequence of these operations are depicted in the operations process chart. 


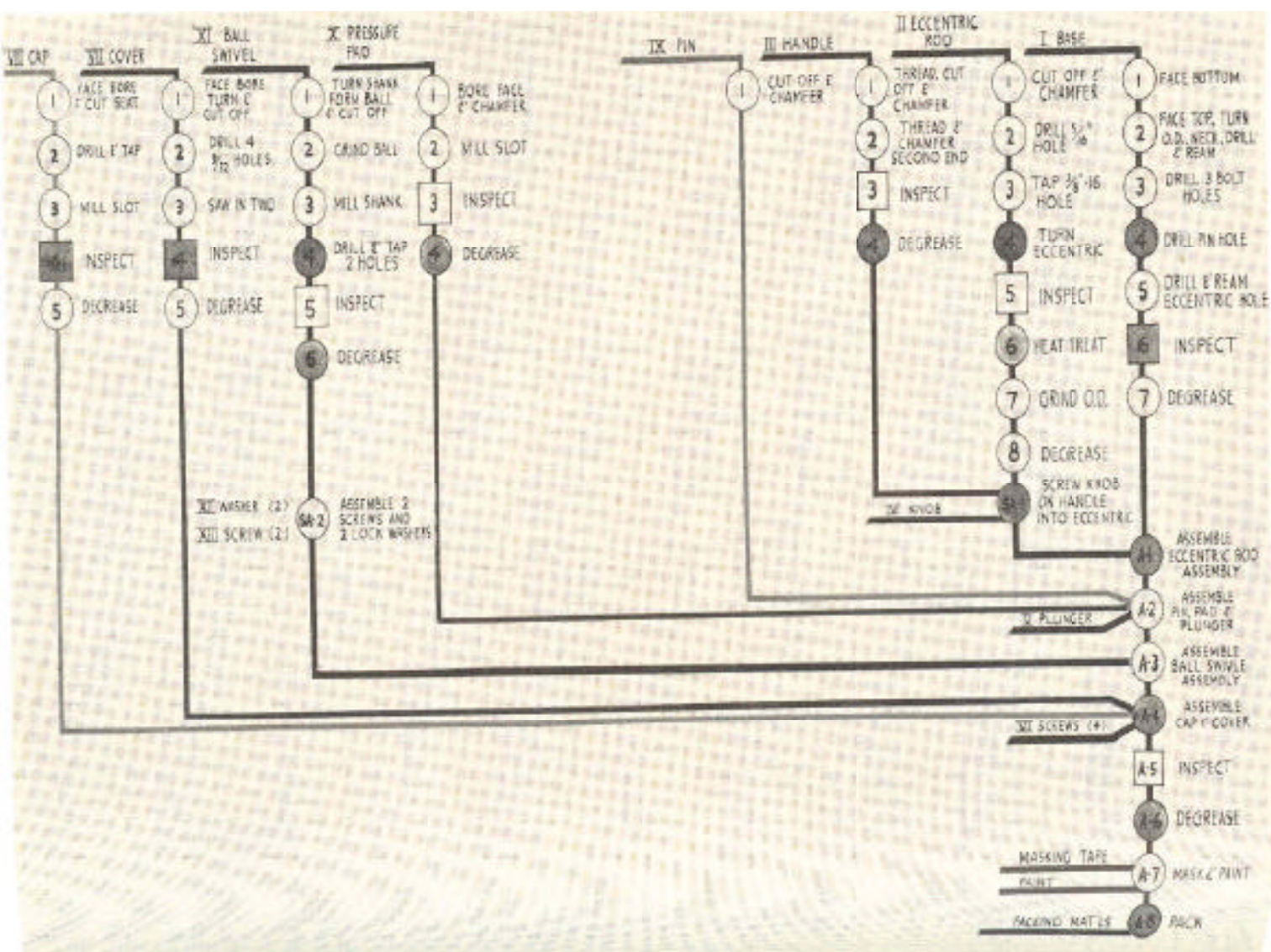

Figure 3.1 Operations Process Chart for the Powerarm

\subsection{Analysis}

\subsubsection{Assumptions}

1. The facility considered is designed for job shop production.

2. Demand is fixed and is known.

3. The cost of the product determined is only the operator and the machine activity cost. Other costs are not considered.

4. The results shown are only for the manufacture of Powerarm [22] for all the machines involved in its manufacture.

The first step was to determine the size of facility required in order to manufacture 1000 Powerarms [22] with the input parameters, machines and processes given above. Also determined was the cost of each Powerarm [22] that was manufactured in this facility. The first step is to determine the number of machines of each type for the different parts that go into the Powerarm [22]. The ideal assignment n' which would not have either operator or machine idle time for each operation and part is then determined. 
Then the number of machines per operator and the number of operators required for each operation are determined. Then the cost of the part being manufactured on that machine is then determined. In order to reduce the idle time of the machine and operator, similar machines are combined and availability of a particular machine after the required operation is utilized for another part which has similar machine requirements. Thus, the total activity cost of manufacturing the Powerarm [22] is obtained by combining the individual activity costs for the different parts.

The determination of the space requirements for the equipment, personnel and auxiliary areas is the next step. The values of space required for all the different machines are defined in square feet. The total number of different types of machines required in the manufacture of the Powerarm [22] is determined and the space required for them is calculated. Also, calculated is the space required for the operators who operate these along with auxiliary space requirements like the aisle space and space for plant services. The total space required is the summation of the equipment space, the operator space and the auxiliary space.

To explain the process of arriving at the final area of the facility, calculations for Leblond lathe used to face the bottom of the base part of the Powerarm [22] is shown. Using the data from Tables 3.2, Tables 3.3 and Table 3.4 and the formula for output, equipment fractions, n' and activity cost of the product, the number of machines, operators and activity cost of the product are determined to manufacture 1000 Powerarms [22].

The first step is to determine the number of base parts that go into the Leblond Lathe for facing operation taking into account the scrap rate for the Leblond Lathe and the machines which are used in the manufacture of the base part. For 1000 Powerarms [22], the quantity of parts that go into the manufacture of base in the Leblond Lathe is

$$
\begin{aligned}
& 1000 \\
& \mathrm{I}=\quad \text { - } \\
& (1-0.04)(1-0.04)(1-0.03)(1-0.03)(1-0.03)(1-0.03)(1-0.02)(1-0.04)
\end{aligned}
$$

The number of Leblond lathes required to do the facing operation per day are calculated next as follows.

$$
\text { F }=\frac{1 \mathrm{~min} / \text { part x } 1264 \text { parts }}{-{ }^{100 \%} \text { x } 1440 \mathrm{~min} / \text { day x } 0.93}=0.93 \text { lathes per day }
$$


The next step is to determine the n', which is the assignment of operators to the machines. The values for loading and unloading time for the Leblond lathe are obtained from Table 3.3, the value for independent machine activity time (t) for the Leblond lathe is calculated using the details from Table 3.1 and the operator activity time (b) is taken as 1 minute. Using this data of loading and unloading time, machine activity time and independent operator time, the n' for this operation is.

$$
\mathrm{n}^{\prime}=\frac{\mathrm{a}+\mathrm{b}}{\mathrm{a}+\mathrm{t} \quad \mathrm{-} \quad(0.1+0.1)+1}
$$

This indicates that there will be no machine or operator idle time if one operator is assigned to one machine. However, this is not a normal scenario as often, the n' is a decimal value and the decision to round up or round down the n' value is based on the lowest cost, for which the procedure to calculate is given below.

As stated earlier, if $\mathrm{m}$ is the number of machines assigned to an operator, then if $\mathrm{m}<\mathrm{n}$ ', the operator is idle and if $\mathrm{m}>\mathrm{n}$, then the machine is idle. Hence in order to balance this, the following formulation is arrived in [3] to determine the cost of the unit produced:

$$
\mathrm{TC}(\mathrm{m})=
$$

$\mathrm{m}$

$\mathrm{TC}(\mathrm{m})=\left(\mathrm{C}_{1}+\mathrm{mC}_{2}\right)(\mathrm{a}+\mathrm{b}) \quad$ when $\mathrm{m}>\mathrm{n}$ '

In the research, values for number of machines of similar machines are grouped together and their n' are added. For the Leblond lathe, the combined value for the number of machines is 1.31 and the combined value of n' for Leblond lathes is 1.51 . The number of Leblond lathes is rounded up to 2 . The number of machines per operator is decided based on the assignment that results in the lowest cost. For the Leblond lathe, the number of machines per operator can be either one machine per operator or two machines per operator. The assignment is decided using the formula given above.

If one machine is assigned per operator, the activity cost of the product is

$$
\mathrm{TC}(1)=\frac{(\$ 25 / \mathrm{hr}+1 \times \$ 12 / \mathrm{hr})((0.1+0.1)+1)}{1 \times 60 \mathrm{~min} / \mathrm{hr}}=\$ 0.74
$$


If two machines are assigned to each operator, the activity cost of the product is

$$
\mathrm{TC}(2)=(\$ 25 / \mathrm{hr}+2 \times \$ 12 / \mathrm{hr})((0.1+0.1)+1)
$$

$60 \mathrm{~min} / \mathrm{hr}$

Since the cost of assigning one machine per operator is less than assigning two machines per operator, one machine is assigned per operator. Similar calculations are done for all the different parts, operations and machines and the total number of different types of machines and operators for them are calculated. The total activity cost of the product is arrived by adding the activity cost for each of the different types of machines. Finally, the area required to accommodate these calculated machines and operators using the values defined earlier. The facility is divided into six different departments by grouping the same type of machines. The details calculated values of machines, operators, are show below in Tables 3.5 and the Appendix gives the complete details on the process parameters, machines and operation sequence.

\begin{tabular}{|c|c|}
\hline \multicolumn{2}{|c|}{ FINAL CALCULATIONS } \\
\hline Total Number of Machines & 30 \\
\hline Total Number of Operators & 22 \\
\hline Total Machine and Operator Space (Sq.ft) & 3364 \\
\hline Plant Services (Sq.ft) & 60 \\
\hline Total Space (Sq.ft) & 3424 \\
\hline Machine and Operator Activity Cost (\$) & 10.27 \\
\hline
\end{tabular}

Table 3.5 Calculation of Total Space

As shown in the table above, considering the given parameters, the total space required for the facility in order to manufacture the Powerarm [22] is 3424 sq. feet. Since there are many process parameters involved in the manufacture of the Powerarm [22], it is important to determine the manufacturing parameters that are of importance and have an impact on the facility layout. In order to determine the relationship between these manufacturing parameters and facility layout, each of these parameters were considered one at a time and varied keeping the other parameters constant. The results obtained and their impact on the facility layout and the activity cost of the product are explained below. 


\subsubsection{Effect of Scrap Rate}

Scrap rate is one of the most important manufacturing parameters and needs to be carefully evaluated and studied. Small changes in scrap rate can have adverse effects on the other parameters involved in the manufacturing process. In our analysis, scrap rate was varied in steps of $5 \%$ and the effect of this variation on the other parameters was noted. It was observed that as the scrap rate was increased, the facility size also increased proportionately. The number of machines and operators also increased as the scrap rate increased. The cost of the product though remained constant because the cost considered in the research is only the operator and machine activity cost. This activity cost does not take into account the material cost and other related manufacturing cost. Also, the scrap rate is independent of operator and machine cost. Hence, even though the number of machines and operators change, the machine and operator activity cost remains the same. The changes incurred in the area, number of machines and number of operators are shown in the table and the details of this variation are given in the table below.

\begin{tabular}{|c|c|c|c|c|c|c|c|c|c|}
\hline \multicolumn{10}{|c|}{ EFFET OF SCRAP RATE } \\
\hline Scrap Rate & Area (sft) & $\begin{array}{l}\text { Number of } \\
\text { Machines }\end{array}$ & & $\begin{array}{l}\text { e and } \\
\text { rator } \\
\text { y Cost }\end{array}$ & Operator & $\begin{array}{c}\% \\
\text { change } \\
\text { in Area }\end{array}$ & $\begin{array}{c}\% \text { change } \\
\text { in } \\
\text { machines }\end{array}$ & $\begin{array}{c}\% \text { change } \\
\text { in cost }\end{array}$ & $\begin{array}{c}\text { \% change } \\
\text { in } \\
\text { operators }\end{array}$ \\
\hline$-50 \%$ & 3139 & 28 & $\$$ & 10.27 & 20 & $-8.32 \%$ & $-6.67 \%$ & $0.00 \%$ & $-9.09 \%$ \\
\hline$-45 \%$ & 3270 & 29 & $\$$ & 10.27 & 20 & $-4.50 \%$ & $-3.33 \%$ & $0.00 \%$ & $-9.09 \%$ \\
\hline$-40 \%$ & 3270 & 29 & $\$$ & 10.27 & 20 & $-4.50 \%$ & $-3.33 \%$ & $0.00 \%$ & $-9.09 \%$ \\
\hline$-35 \%$ & 3272 & 29 & $\$$ & 10.27 & 21 & $-4.44 \%$ & $-3.33 \%$ & $0.00 \%$ & $-4.55 \%$ \\
\hline$-30 \%$ & 3272 & 29 & $\$$ & 10.27 & 21 & $-4.44 \%$ & $-3.33 \%$ & $0.00 \%$ & $-4.55 \%$ \\
\hline$-25 \%$ & 3272 & 29 & $\$$ & 10.27 & 21 & $-4.44 \%$ & $-3.33 \%$ & $0.00 \%$ & $-4.55 \%$ \\
\hline$-20 \%$ & 3272 & 29 & $\$$ & 10.27 & 21 & $-4.44 \%$ & $-3.33 \%$ & $0.00 \%$ & $-4.55 \%$ \\
\hline$-15 \%$ & 3272 & 29 & $\$$ & 10.27 & 21 & $-4.44 \%$ & $-3.33 \%$ & $0.00 \%$ & $-4.55 \%$ \\
\hline$-10 \%$ & 3272 & 29 & $\$$ & 10.27 & 21 & $-4.44 \%$ & $-3.33 \%$ & $0.00 \%$ & $-4.55 \%$ \\
\hline$-5 \%$ & 3424 & 30 & $\$$ & 10.27 & 22 & $0.00 \%$ & $0.00 \%$ & $0.00 \%$ & $0.00 \%$ \\
\hline $5 \%$ & 3424 & 30 & $\$$ & 10.27 & 22 & $0.00 \%$ & $0.00 \%$ & $0.00 \%$ & $0.00 \%$ \\
\hline $10 \%$ & 3424 & 30 & $\$$ & 10.27 & 22 & $0.00 \%$ & $0 \%$ & $0 \%$ & $0 \%$ \\
\hline $15 \%$ & 3424 & 30 & $\$$ & 10.27 & 22 & $0.00 \%$ & $0 \%$ & $0 \%$ & $0 \%$ \\
\hline $20 \%$ & 3424 & 30 & $\$$ & 10.27 & 22 & $0.00 \%$ & $0 \%$ & $0 \%$ & $0 \%$ \\
\hline $25 \%$ & 3426 & 30 & $\$$ & 10.27 & 23 & $0.06 \%$ & $0 \%$ & $0 \%$ & $5 \%$ \\
\hline $30 \%$ & 3559 & 31 & $\$$ & 10.27 & 23 & $3.94 \%$ & $3 \%$ & $0 \%$ & $5 \%$ \\
\hline $35 \%$ & 3559 & 31 & $\$$ & 10.27 & 23 & $3.94 \%$ & $3 \%$ & $0 \%$ & $5 \%$ \\
\hline $40 \%$ & 3559 & 31 & $\$$ & 10.27 & 23 & $3.94 \%$ & $3 \%$ & $0 \%$ & $5 \%$ \\
\hline $45 \%$ & 3659 & 32 & $\$$ & 10.27 & 23 & $6.86 \%$ & $7 \%$ & $0 \%$ & $5 \%$ \\
\hline $50 \%$ & 3659 & 32 & $\$$ & 10.27 & 23 & $6.86 \%$ & $7 \%$ & $0 \%$ & $5 \%$ \\
\hline
\end{tabular}

Table 3.6 Effect of Scrap Rate 
Table 3.6 above indicates that scrap rate has a strong influence on the facility design changing the facility size, number of machines and the operators. The lower the scrap rate, the lesser area is required because of lesser number of machines and operators required to manufacture the Powerarm [22]. Table 3.6 shows when the scrap rate is reduced by $50 \%$, the number of machines and operators required to manufacture the Powerarms [22] is the lowest and the highest when the scrap rate is increased by $50 \%$.

\subsubsection{Effect of Reliability of Machines}

The next parameter considered for the analysis was the reliability of the machines used in the manufacture of the Powerarm [22]. The reliability values for the different types of machines used have been defined earlier. In order to study the effects of change in reliability values on the facility layout, its values were reduced by $50 \%$ in steps of $5 \%$. It was seen that as the reliability was reduced, the area required for the facility increased and so did the number of machines required and the operators required. There was no change in the activity cost for changes in the reliability values because as mentioned earlier, the cost calculated is only the machine and operator activity cost and change in reliability of the machine does not have any impact on the activity cost of the product. Also, reliability values are independent of machine and operator activity cost, hence change in reliability values does not result in changes in the activity cost. Table 3.7 shows this analysis for the different reliability values in detail.

\begin{tabular}{|c|c|c|c|c|c|c|c|c|c|}
\hline \multicolumn{10}{|c|}{ EFFECT OF REЦABITY OF MACHINES } \\
\hline Reliability & Area (Sft) & $\begin{array}{l}\text { Number of } \\
\text { Machines }\end{array}$ & & $\begin{array}{l}\text { e and } \\
\text { rator } \\
\text { y Cost }\end{array}$ & Operator & $\begin{array}{c}\% \\
\text { change } \\
\text { in Area }\end{array}$ & $\begin{array}{c}\% \text { change } \\
\text { in } \\
\text { machines }\end{array}$ & $\begin{array}{c}\% \text { change } \\
\text { in cost }\end{array}$ & $\begin{array}{c}\% \text { change } \\
\text { in } \\
\text { operators }\end{array}$ \\
\hline$-50.00 \%$ & 6373 & 53 & $\$$ & 10.27 & 38 & $86.13 \%$ & $77 \%$ & $0 \%$ & $73 \%$ \\
\hline$-45.00 \%$ & 5826 & 49 & $\$$ & 10.27 & 34 & $70.15 \%$ & $63 \%$ & $0 \%$ & $55 \%$ \\
\hline$-40.00 \%$ & 5269 & 45 & $\$$ & 10.27 & 31 & $53.88 \%$ & $50 \%$ & $0 \%$ & $41 \%$ \\
\hline$-35.00 \%$ & 5023 & 43 & $\$$ & 10.27 & 29 & $46.70 \%$ & $43 \%$ & $0 \%$ & $32 \%$ \\
\hline$-30.00 \%$ & 4645 & 40 & $\$$ & 10.27 & 28 & $35.66 \%$ & $33 \%$ & $0 \%$ & $27 \%$ \\
\hline$-25.00 \%$ & 4285 & 37 & $\$$ & 10.27 & 26 & $25.15 \%$ & $23 \%$ & $0 \%$ & $18 \%$ \\
\hline$-20.00 \%$ & 4021 & 35 & $\$$ & 10.27 & 25 & $17.44 \%$ & $17 \%$ & $0 \%$ & $14 \%$ \\
\hline$-15.00 \%$ & 3789 & 33 & $\$$ & 10.27 & 23 & $10.66 \%$ & $10 \%$ & $0 \%$ & $5 \%$ \\
\hline$-10.00 \%$ & 3659 & 32 & $\$$ & 10.27 & 23 & $6.86 \%$ & $7 \%$ & $0 \%$ & $5 \%$ \\
\hline$-5.00 \%$ & 3424 & 30 & $\$$ & 10.27 & 22 & $0.00 \%$ & $0 \%$ & $0 \%$ & $0 \%$ \\
\hline
\end{tabular}

Table 3.7 Effect of Reliability of Machines 
The results above establish the fact that reliability of machines is another important parameter, which needs to be evaluated and studied before designing any facility. The changes in the area, number of machines and operators further substantiate our claim.

\subsubsection{Effect of Availability of Machines}

The next manufacturing parameter considered for analysis is the availability of machines. The initial assumption was that the machines used in the manufacturing process are available round the clock for manufacture. In order to study the effect of change of availability on the facility, the availability values for the machines were reduced in 10 steps of 5\% each. It was observed that as the availability for the machines decreased, the area required for the facility increased and to compensate for the drop in the availability of machines, number of machines and operators also increased. However, the activity cost to manufacture the Powerarm [22] remained the same for the different values of availability due to the same reasons as explained in the analysis for scrap rate and reliability of machines. Table 3.8 shows the details on the behavior of the different parameters for different availability values.

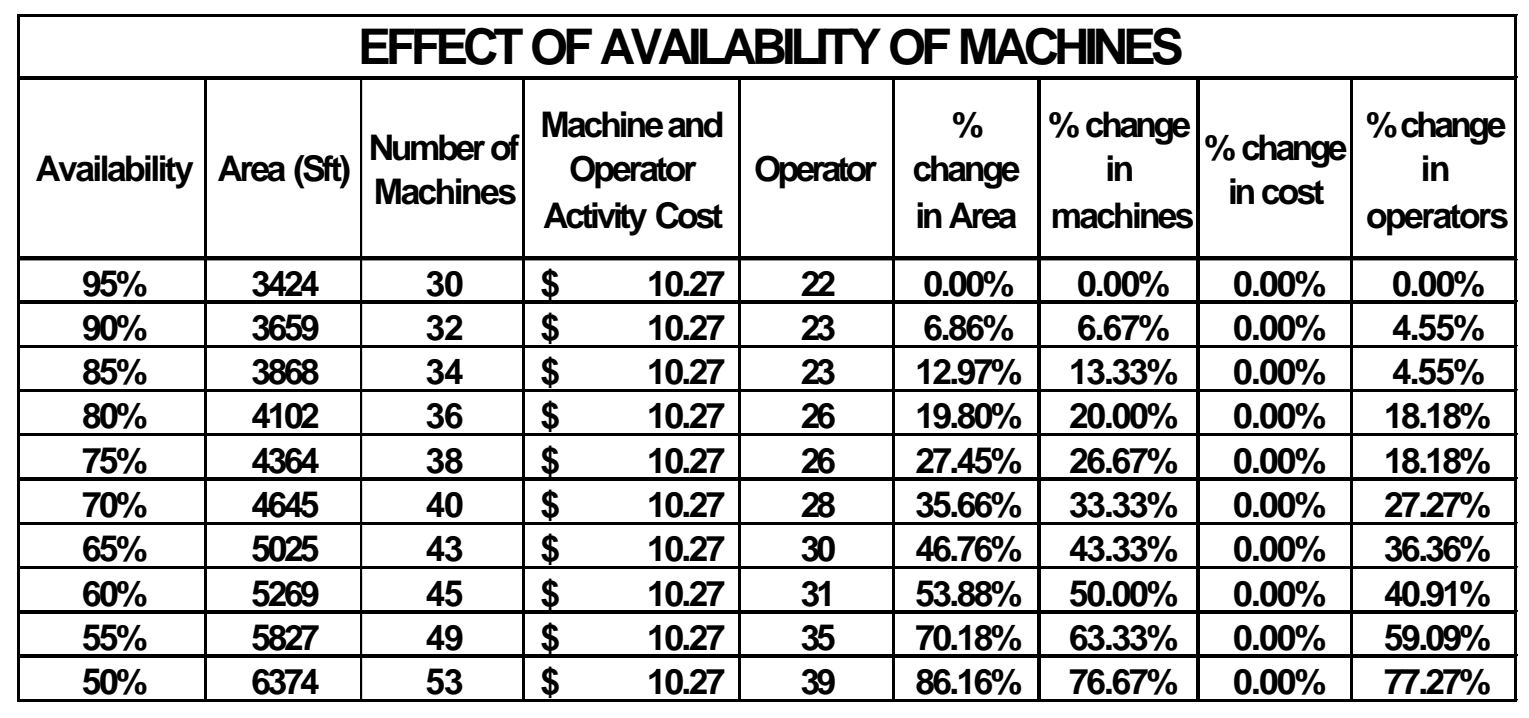

Table 3.8 Effect of Availability of Machines

The results in the above table indicate that availability of machines is one of the key parameters, which needs to be evaluated and studied during any facility layout design or modification. 


\subsubsection{Effect of Loading and Unloading Time}

The last parameter considered for our analysis was the loading and unloading time. The loading and unloading times for each of the machines involved in the manufacture of the Powerarm [22] were given earlier. It was observed that changes in this manufacturing parameter did not result in any changes in the area of the facility, the number of machines required or operators needed to operate these machines. However, as the loading and unloading time was decreased, the machine and operator activity cost of the product being manufactured also decreased and increased when the loading and unloading time increased. This is because, as the loading and unloading time changes, the amount of work done by the operator also changes, resulting in increase or decrease in the operator activity cost. Hence whe never the value for loading and unloading time changes, the activity cost of the product also changes as the cost considered in the research is only the machine and operator activity cost. Table 3.9 below gives the details on the changes in the cost of the product with respect to changes in the loading and unloading time.

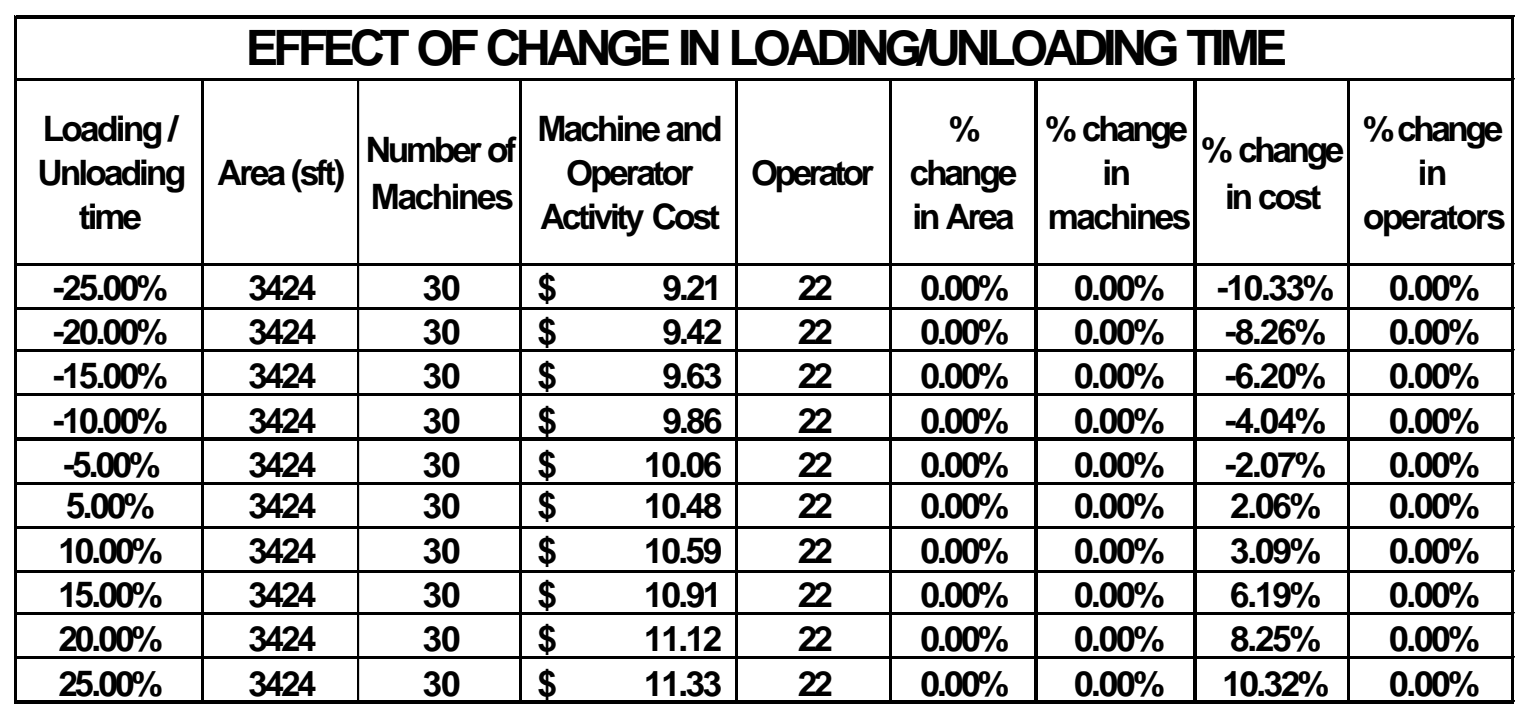

Table 3.9 Effect of Loading and Unloading time

The results in the table above indicate that loading and unloading time also affects the facility design and has direct implication on the activity cost of the product being manufactured. 


\subsection{Evaluation of Model in M-CRAFT}

The final part of the research was to use the results of the Excel model and use it as input in M-CRAFT facility design software. This evaluation was necessary to determine how the manufacturing parameters affect the facility layout and material handling costs of the facility. Some of the relationship was established in the Excel model itself where it was seen that change in manufacturing parameters had impact on the area of the facility, the number of machines used for the manufacture of the Powerarm [22], the number of operators required to handle these machines and the cost of the product. However, to substantiate our claim that manufacturing parameters do have an effect on the facility layout and material handling costs of the facility. The procedure adopted is explained below.

\subsubsection{Procedure}

The first step was to determine the area of the facility, the number of machines required to manufacture the Powerarms [22], the number of operators required to operate the machines used in the manufacture and the machine and operator activity cost. The number of different types of machines required to manufacture the Powerarm [22], number of operators, space requirements for machines, operators and auxiliary areas and activity cost were determined using the model built in Excel. The results obtained were used as input in M-CRAFT which was the only tool available to me. Input data for MCRAFT can be entered by either generating a From-To chart, or by entering data directly into M-CRAFT. The data obtained was directly entered into the M-CRAFT program. The different areas were defined with the machine departments and their calculated respective area sizes were entered. The operational sequence used in the manufacture of the different parts of the Powerarms [22] was defined as the initial sequence. The initial sequence was the same for all the different runs of the program. The cost of moving the parts from one department to another was also constant. One department ( Inspection Area) was fixed as all the parts in the program had to go to this area for inspection. MCRAFT calculated the best possible sequence and the cost of material handling. This result was taken as the base result. The results obtained and the layout are shown below. 


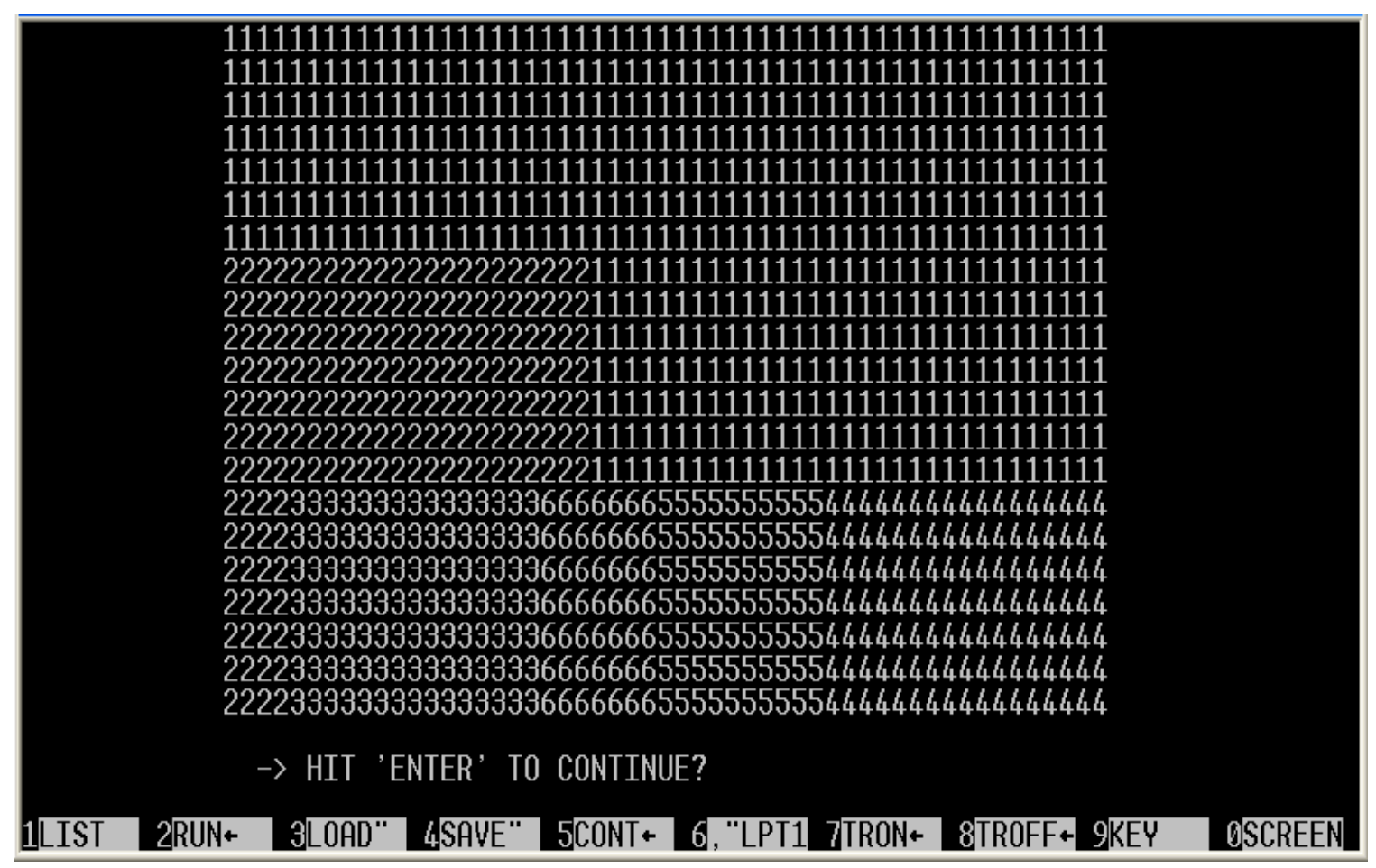

Figure 3.2 Initial input sequence in M-CRAFT

PLANT LENGTH: 64

PLANT WIDTH : 53.5

NUMBER OF BAYS: 3

NUMBER OF DEPARTMENTS: 6

DEPT SEQUENCE :

$1-2-3-6-5 * *-4$

** DESIGNATES DEPARTMENTS WITH FIXED SEQUENCE

DEPT AREA

$1802-553-318-384-208-159$

TOTAL COST : \$3783.324

BASED UPON RECTILINEAR DISTANCE

-> HIT 'ENTER' TO CONTINUE? _

1LIST 2RUN* 3 LOAD" 4 SAVE" 5CONT+ 6,"LPT1 7TRON+ 8TROFF+ 9REY OSCREEN

Figure 3.3 Final Layout obtained in M-CRAFT 
Figure 3.2 and Figure 3.3 show the results obtained in M-CRAFT for the input entered with the standard parameters. The input used here are the results obtained from the Excel model with the actual manufacturing parameters. The values entered for the areas for the different machines and the sequence of operations were obtained from the Excel model and published data.

To establish the fact that manufacturing parameters have a strong impact on the facility layout, the results obtained by varying the different manufacturing parameters in the Excel model were used as input for analysis in the MCRAFT design software. The changes in the area, the number of machines and operators was recorded due to change in the manufacturing parameters was recorded from the Excel model. The plant length, the number of bays, initial sequence and the number of trips of the part from one department to the other was the same. Since the area of the facility changed, the change was incorporated by increasing or decreasing the width of the facility and also changing the areas of the individual machines. It was observed that changes in manufacturing cost of the product (Powerarm [22] in our case) being manufactured.

In order to further substantiate the claim that process parameters impact layout effectiveness, the results obtained from the MS EXCEL model were run in M-CRAFT. The results obtained are further explained below.

\subsubsection{M-CRAFT Analysis with Scrap Rate}

The first process parameter considered for the M-CRAFT analysis was the scrap rate. The values obtained for areas by varying the scrap rate in the Excel model were used as input in the M-CRAFT program. The same manufacturing sequence was followed as mentioned in Apple [22]. The results obtained are shown in Table 3.10 in the following page. As seen in Table 3.10, as the percentages of scrap rate changes, the area of the facility changes thereby changing the material handling cost of the facility. Also observed is that the final sequence of material flow between department also changes with change in values for scrap rates because of the change in the flow between the departments due to the increase in the number of machines. The cost of material handling increases as the scrap rate increases because of more material being handled between different departments resulting in increased material handling costs. This analysis proves further that variation in scrap rate has a strong impact on the facility layout effectiveness. 


\begin{tabular}{|c|c|c|cc|c|}
\hline \multicolumn{5}{|c|}{ M-CRAFT RESULTS ON CHANGE OF SCRAP RATE } \\
\hline Scrap Rate & Initial Sequence & Final Sequence & $\begin{array}{c}\text { Material Handling } \\
\text { Cost }\end{array}$ & Area (sft) \\
\hline$-50 \%$ & $1-2-3-4-5-6$ & $1-2-4-3-5-6$ & $\$$ & $3,465.91$ & $64 \times 49$ \\
\hline$-40 \%$ & $1-2-3-4-5-6$ & $1-2-4-3-5-6$ & $\$$ & $3,686.09$ & $64 \times 51.1$ \\
\hline$-30 \%$ & $1-2-3-4-5-6$ & $1-2-4-3-5-6$ & $\$$ & $3,731.16$ & $64 \times 51.1$ \\
\hline$-20 \%$ & $1-2-3-4-5-6$ & $1-2-4-3-5-6$ & $\$$ & $3,756.07$ & $64 \times 51.1$ \\
\hline$-10 \%$ & $1-2-3-4-5-6$ & $1-2-4-3-5-6$ & $\$$ & $3,783.56$ & $64 \times 51.1$ \\
\hline $10 \%$ & $1-2-3-4-5-6$ & $1-2-3-6-5-4$ & $\$$ & $3,825.11$ & $64 \times 53.5$ \\
\hline $20 \%$ & $1-2-3-4-5-6$ & $1-2-3-6-5-4$ & $\$$ & $3,872.41$ & $64 \times 53.5$ \\
\hline $30 \%$ & $1-2-3-4-5-6$ & $1-2-3-6-5-4$ & $\$$ & $4,077.65$ & $64 \times 55.6$ \\
\hline $40 \%$ & $1-2-3-4-5-6$ & $1-2-3-6-5-4$ & $\$$ & $4,148.22$ & $64 \times 55.6$ \\
\hline $50 \%$ & $1-2-3-4-5-6$ & $1-2-3-6-5-4$ & $\$$ & $4,167.92$ & $64 \times 57.15$ \\
\hline
\end{tabular}

Table 3.10 M-CRAFT Results on Change of Scrap Rate

\subsubsection{M-CRAFT Analysis with Reliability of Machines}

The next process parameter considered for the M-CRAFT analysis was the reliability of machines. The values obtained for areas by varying the machine reliability values in the Excel model were used as input in the MCRAFT program. The same manufacturing sequence was followed as mentioned in Apple [22]. The results obtained are shown in Table 3.12 below.

\begin{tabular}{|c|c|c|cc|c|}
\hline \multicolumn{5}{|c|}{ M-CRAFT RESULTS ON CHANGE OF MACHINE RELIABILITY } \\
\hline Reliability & Initial Sequence & Final Sequence & $\begin{array}{c}\text { Material Handling } \\
\text { Cost }\end{array}$ & Area (sft) \\
\hline$-50 \%$ & $1-2-3-4-5-6$ & $1-2-3-6-5-4$ & $\$$ & $5,208.11$ & $64 \times 99.6$ \\
\hline$-45 \%$ & $1-2-3-4-5-6$ & $1-2-3-6-5-4$ & $\$$ & $4,819.68$ & $64 \times 91$ \\
\hline$-40 \%$ & $1-2-3-4-5-6$ & $1-2-3-6-5-4$ & $\$$ & $4,697.19$ & $64 \times 82.33$ \\
\hline$-35 \%$ & $1-2-3-4-5-6$ & $1-2-3-6-5-4$ & $\$$ & $4,532.78$ & $64 \times 78.5$ \\
\hline$-30 \%$ & $1-2-3-4-5-6$ & $1-2-3-6-5-4$ & $\$$ & $4,232.73$ & $64 \times 72.6$ \\
\hline$-25 \%$ & $1-2-3-4-5-6$ & $1-2-3-6-5-4$ & $\$$ & $4,116.57$ & $64 \times 66.95$ \\
\hline$-20 \%$ & $1-2-3-4-5-6$ & $1-2-3-6-5-4$ & $\$$ & $4,034.10$ & $64 \times 62.83$ \\
\hline$-15 \%$ & $1-2-3-4-5-6$ & $1-2-3-6-5-4$ & $\$$ & $3,949.71$ & $64 \times 59.2$ \\
\hline$-10 \%$ & $1-2-3-4-5-6$ & $1-2-3-6-5-4$ & $\$$ & $3,908.29$ & $64 \times 57.2$ \\
\hline$-5 \%$ & $1-2-3-4-5-6$ & $1-2-3-6-5-4$ & $\$$ & $3,780.23$ & $64 \times 53.5$ \\
\hline
\end{tabular}

Table 3.11 M-CRAFT Results on Reliability Values of Machines 
As seen in Table 3.11, as the reliability of machines increases, the area of the facility required to manufacture the same quantity of Powerarms [22] decreases due to the reduction in the number of machines and operators required. This results in lesser area requirements for the facility reducing the distance of travel of product between the various departments which further reduces the material handling costs. As seen in Table 3.11 , the initial sequence remained the same for all values of reliability and also the length of the facility was kept constant. Increasing the width of the facility incorporated the increase in area of the facility due to reduction in the reliability values of machines. This analysis also proves that machine reliability has a strong effect on the layout effectiveness and needs to be carefully evaluated whenever a facility is designed.

\subsubsection{M-CRAFT Analysis with Availability of Machines}

The last process parameter which was analyzed using M-CRAFT program was the availability of machines. The results obtained are shown in Table 3.12 and explained below.

\begin{tabular}{|c|c|c|c|c|c|}
\hline \multicolumn{6}{|c|}{ M-CRAFT RESULTS ON CHANGE OF MACHINE AVAILABILTY } \\
\hline Availability & Initial Sequence & Final Sequence & & $\begin{array}{l}\text { II Handling } \\
\text { Cost }\end{array}$ & Area (sft) \\
\hline $95 \%$ & $1-2-3-4-5-6$ & $1-2-3-6-5-4$ & $\$$ & $3,780.23$ & $64 \times 53.5$ \\
\hline $90 \%$ & $1-2-3-4-5-6$ & $1-2-3-6-5-4$ & $\$$ & $3,908.29$ & $64 \times 57.2$ \\
\hline $85 \%$ & $1-2-3-4-5-6$ & $1-2-3-6-5-4$ & $\$$ & $3,962.38$ & $64 \times 60.45$ \\
\hline $80 \%$ & $1-2-3-4-5-6$ & $1-2-3-6-5-4$ & $\$$ & $4,048.23$ & $64 \times 64.1$ \\
\hline $75 \%$ & $1-2-3-4-5-6$ & $1-2-3-6-5-4$ & $\$$ & $4,121.24$ & $64 \times 68.2$ \\
\hline $70 \%$ & $1-2-3-4-5-6$ & $1-2-3-6-5-4$ & $\$$ & $4,232.73$ & $64 \times 72.6$ \\
\hline $65 \%$ & $1-2-3-4-5-6$ & $1-2-3-6-5-4$ & $\$$ & $4,532.78$ & $64 \times 78.5$ \\
\hline $60 \%$ & $1-2-3-4-5-6$ & $1-2-3-6-5-4$ & $\$$ & $4,698.43$ & $64 \times 82.33$ \\
\hline $55 \%$ & $1-2-3-4-5-6$ & $1-2-3-6-5-4$ & $\$$ & $4,820.29$ & $64 \times 91$ \\
\hline $50 \%$ & $1-2-3-4-5-6$ & $1-2-3-6-5-4$ & $\$$ & $5,211.05$ & $64 \times 99.6$ \\
\hline
\end{tabular}

Table 3.12 M-CRAFT Analysis with Availability of Machines

As seen in Table 3.12, as the availability values for machines increases, the area of the facility required to manufacture the same quantity of Powerarms [22] decreases due to the reduction in the number of machines and operators required. This results in lesser area requirements for the facility reducing the distance of travel of product between the various departments which further reduces the material handling costs. As mentioned earlier, the initial sequence remained the same for all values of availability and also the 
length of the facility was kept constant. Increasing the width of the facility incorporated the increase in area of the facility due to reduction in the availability values of machines. This analysis proves that machine availability also has a strong effect on the layout effectiveness and needs to be carefully evaluated whenever a facility is designed.

\subsection{Sensitivity Analysis}

The next step was to do sensitivity analysis by comparing each of the parameters with respect to the cost of the product, the area of the facility under consideration, number of machines and the number of operators and see changes in their behavior with changes made in these parameters. In order to establish the relationships between the different parameters, graphs were plotted in Microsoft Excel to see the changes and results. Some of these graphs plotted have been given below and explained.

\subsubsection{Sensitivity Analysis with Scrap rate}

The first process parameter considered for the sensitivity analysis was the scrap rate for the different machines used in the manufacture of the Powerarm [22]. As explained in the earlier sections, variation in scrap rate has a large impact on the layout effectiveness which is further substantiated by performing this sensitivity analysis.

Number of Machines Vs Scrap Rate (\%)

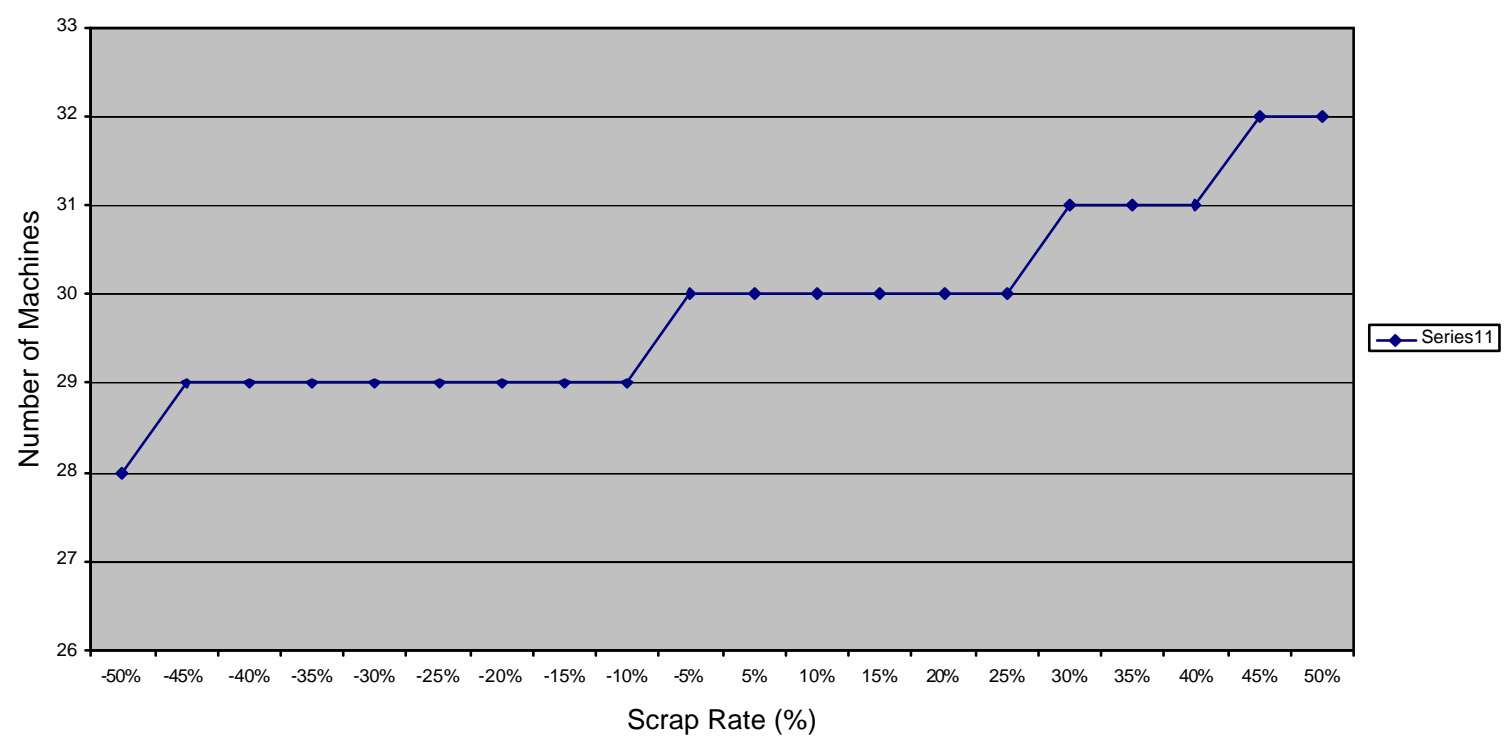

Figure 3.4 Number of Machines Vs \% Change in Scrap Rate 
As shown in Figure 3.4, as the scrap rate increases, the number of machines required to manufacture the Powerarms [22] also increases. It is seen in Figure 3.4 that the number of machines remains the same for certain percentages of scrap rate. Since the number of machines are rounded up to the next higher value, it appears that the number of machines remain the same for different values of scrap rate though in actual scenario, the number of machines did change in decimal values for every change in the value of scrap rate. Since the change in the number of machines is a decimal value and the machines are being rounded to the next integer values, certain values of scrap rate have the same number of machines. In an actual manufacturing scenario, where the product quantity is large, smaller changes of scrap rate would result in large changes in the number of machines.

The next analysis was done to see the effect change in scrap rate percentages on the number of operators used in the manufacture of the Powerarm [22]. The results obtained are shown in Figure 3.5 and explained below.

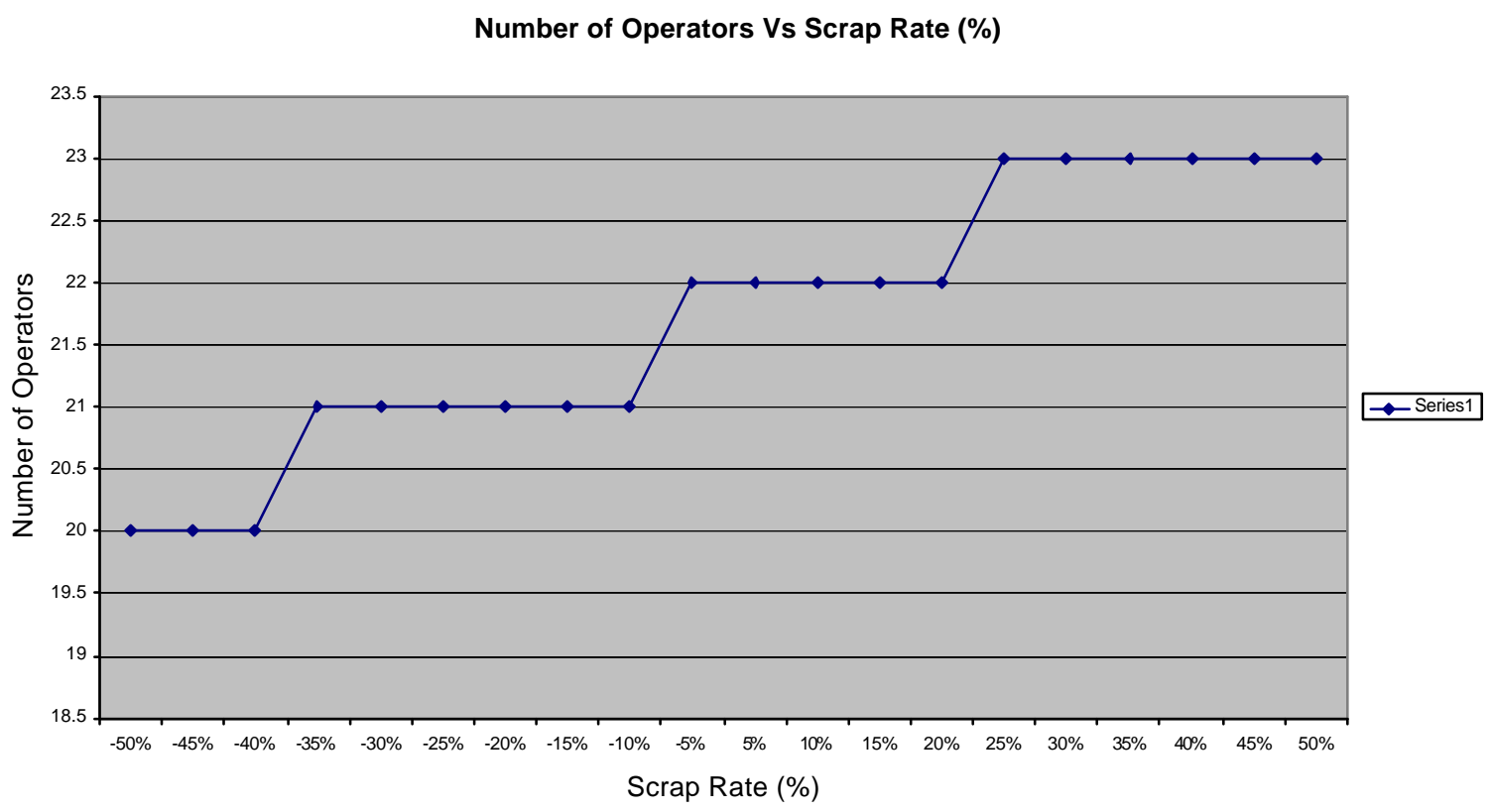

Figure 3.5 Number of Operators Vs \% Change in Scrap Rate

Figure 3.5 shows the relationship between the number of operators and scrap rate percentages. The number of operators required to manufacture the Powerarms [22] 
increased as the scrap rate was increased because of the increase in the number of machines required to manufacture the same number of Powerarms [22]. As in the case of the number of machines, the number of operators does not change for every change of scrap rate percentage. This is similar to the case of number of machines where the decimal values are rounded to the next higher integer value. This is the reason that for certain percentages of scrap rate, the number of operators remains the same. As mentioned before, in an actual manufacturing scenario, where the product quantity is large, smaller changes of scrap rate would result in large changes in the number of operators handling these machines.

The next analysis was done for the area of the facility to analyze how the area of the facility changes when the scrap rate of the machines used in the manufacture of Powerarm [22] changes.

Area Vs Scrap Rate (\%)

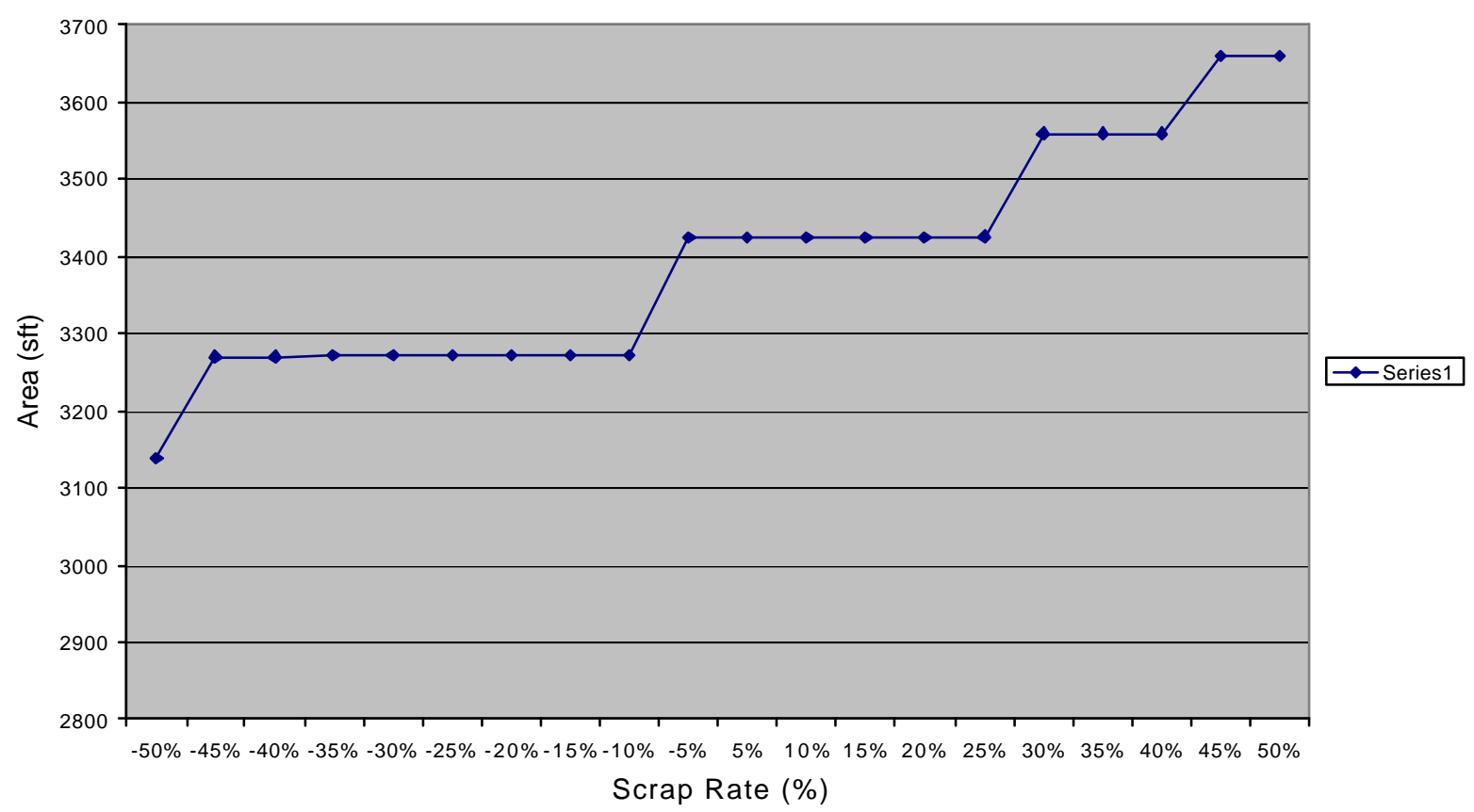

Figure 3.6 Area of the Facility Vs \% Change in Scrap Rate

Figure 3.6 shows the behavior of the area of the facility as the scrap rate percentages of the machines changes. It is seen that as the scrap rate percentage of the machines increases, the area required to manufacture the same number of Powerarms [22] also increases. This is because of the increase in the number of machines and operators 
required to manufacture the Powerarms [22] which correspondingly increases the area of the facility to accommodate the extra machines and operators. Also, as seen in the analysis with the number of machines and operators, the area of the facility remains constant for certain percentages of scrap rate because of the rounding of the values of machines and operators to the next integer value. If a larger setup is considered, even small changes in scrap rate would result in major changes in the size of the facility.

Machine and Operator Activity Cost (\$) Vs Scrap Rate (\%)

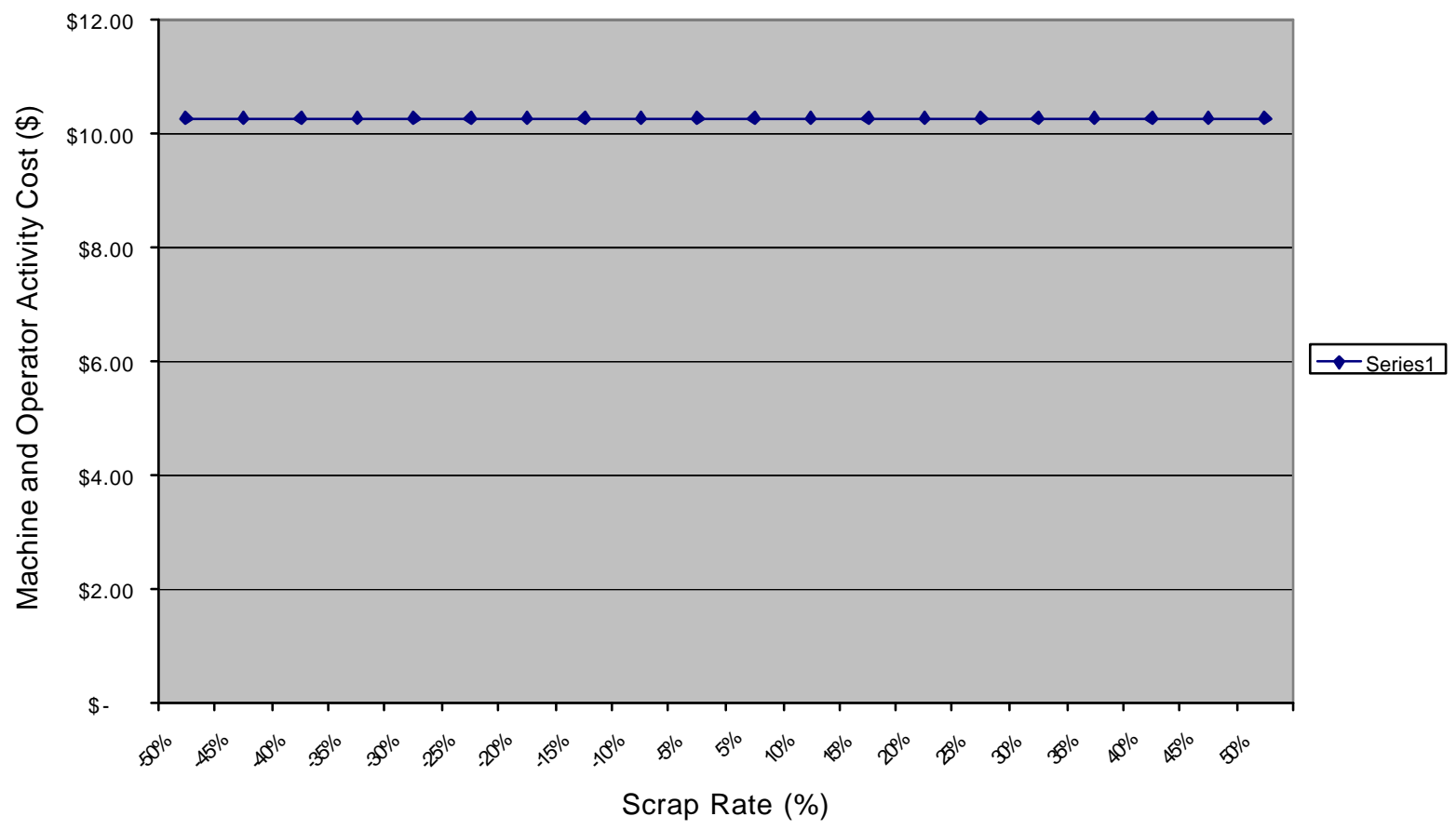

Figure 3.7 Machine and Operator Activity Cost Vs \% Change in Scrap Rate

Figure 3.7 shows the relationship between cost of the product and scrap rate. As seen in the figure, the cost of the product does not change even when the scrap rate percentages are increased or decreased by more than $50 \%$ of the original value. This is because, the cost of the product considered for our analysis is only the machine and operator activity cost. This does not include the material cost and other related manufacturing cost. Also, as mentioned earlier, scrap rate is independent of the operator and machine activity cost. Therefore, any variation in the percentages of the scrap rate must not impact the activity cost of the product being manufactured. Hence, the results obtained are as shown in Figure 3.7 where the activity cost of the product remains unchanged even though large 
variations occur in the manufacturing parameters. This fact is even more substantiated when the other manufacturing parameters are also varied as well in the sensitivity analysis to follow further.

\subsubsection{Sensitivity Analysis with Reliability of Machines}

The next manufacturing parameter considered for sensitivity analysis is the reliability of the machines used in the manufacture of the Powerarm [22]. The results and explanations are shown and explained below.

Number of Machines Vs Change in Reliability of Machines (\%)

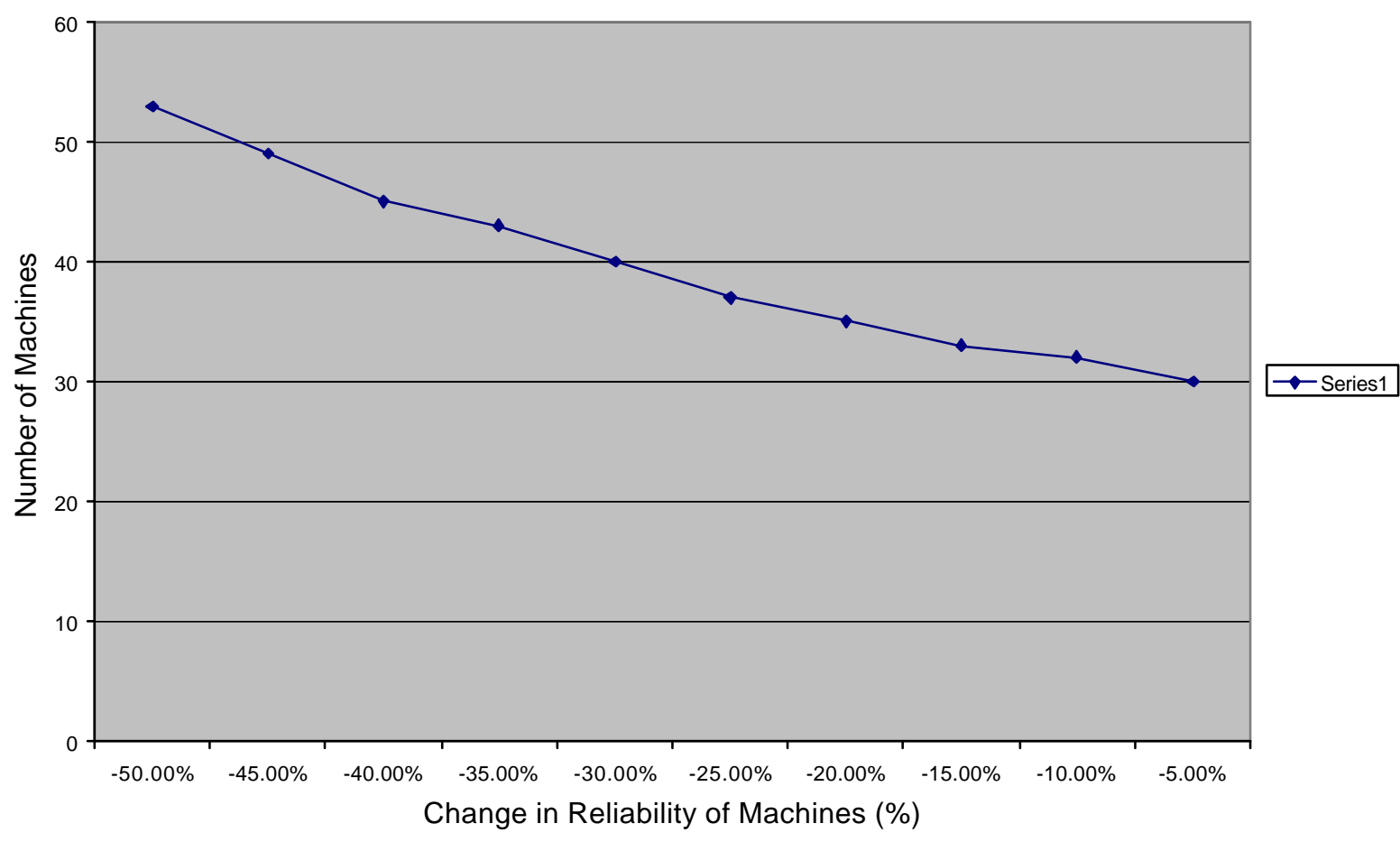

Figure 3.8 Number of Machines Vs \% Change in Reliability of Machines 
Figure 3.8 depicts that as the reliability of the machines decreases, the number of machines required to manufacture the Powerarm [22] increases due to increase in number of machines required to manufacture the same number of Powerarms [22].

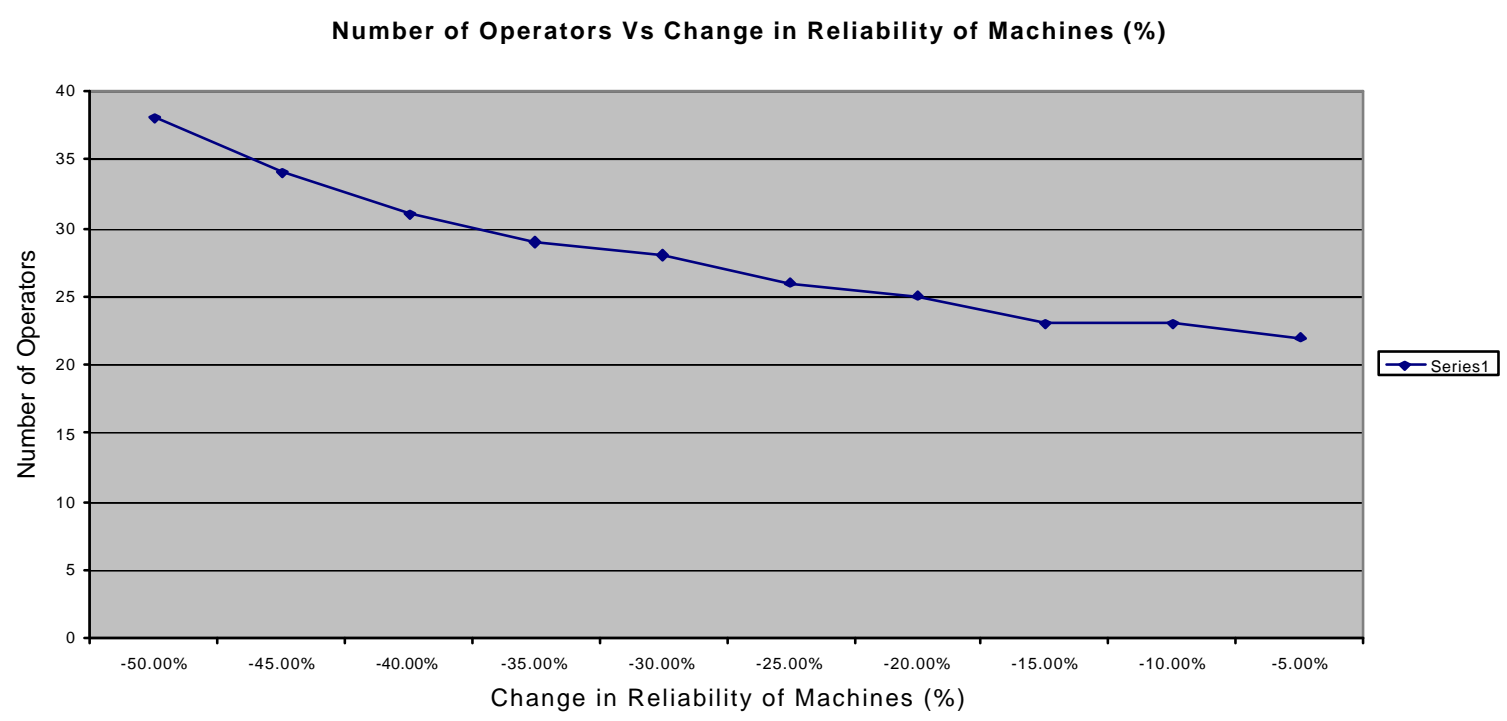

Figure 3.9 Number of Operators Vs \% Change in Reliability of Machines

Figure 3.9 shows the relationship between reliability of the machines used in the manufacture of the Powerarm [22] and the number of operators operating these machines. As explained earlier, the number of operators required to operate these machines increases as the reliability of machines decreases due to increase in the number of machines required to manufacture the same number of Powerarms [22].

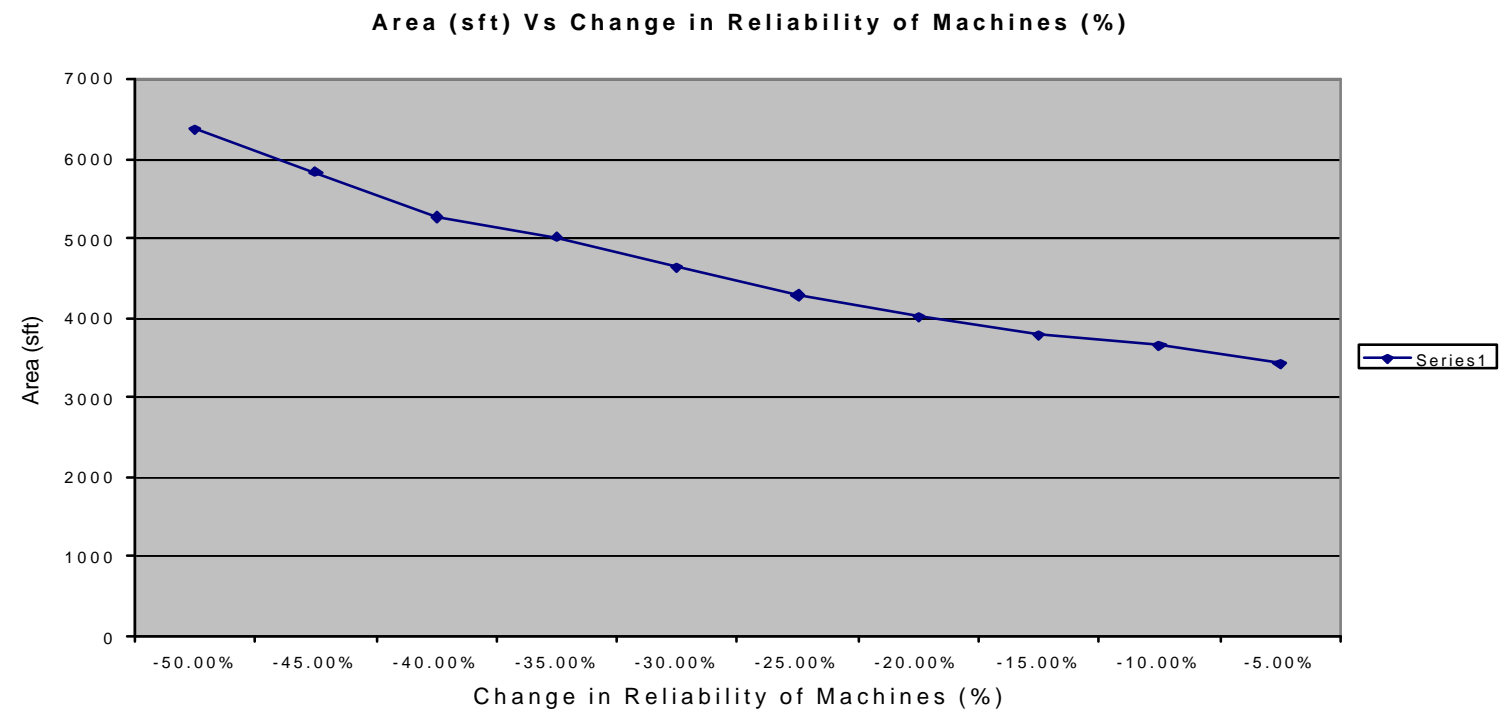

Figure 3.10 Area of the Facility Vs \% Change in Reliability of Machines 
Figure 3.10 shows the behavior of the area of the facility as the reliability percentages of the machines changes. It is seen that as the machine reliability percentage decreases, the area required to manufacture the same number of Powerarms [22] increases. This is because of the increase in the number of machines and operators required to manufacture the Powerarms [22], which correspondingly increases the area of the facility to accommodate the extra machines, and operators.

The last parameter analyzed with the reliability of machines was the machine and operator activity cost, the results for which are shown in Figure 3.11 and explained below.

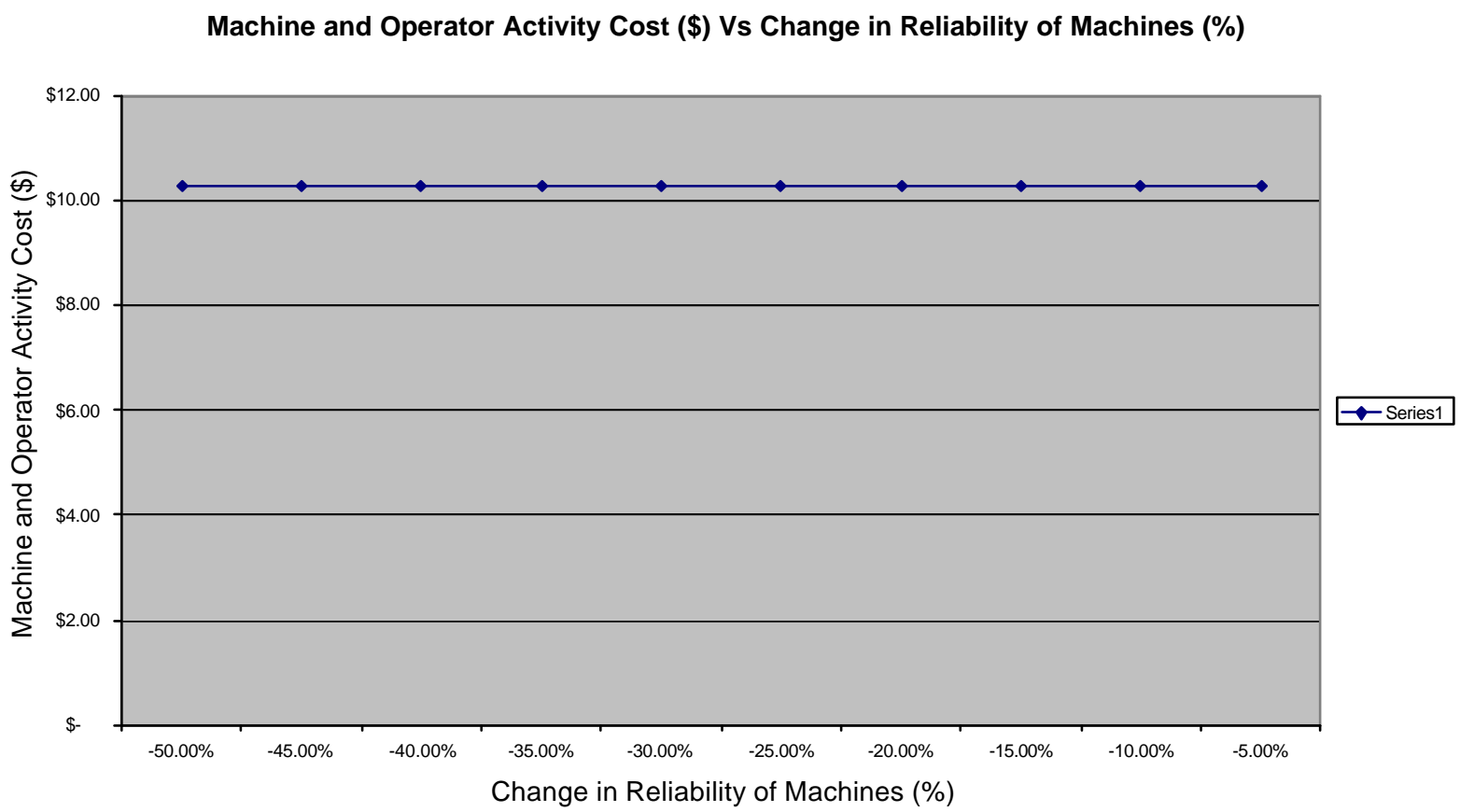

Figure 3.11Cost of the Product Vs \% Change in the Reliability of Machines

The activity cost of the product does not change for change in values of reliability of machines. This is because of the same reason explained earlier during the comparison of scrap rate and cost of the product where we had stated that the costs considered are only the operator and machine activity costs and hence reliability value change does not impact these activity costs for the product being manufactured. Also, as mentioned earlier in the analysis with scrap rate, reliability values of machines are also independent of the operator and machine activity cost. Therefore, any variation in the reliability values must 
not impact these activity costs of the product being manufactured. Hence, the results obtained are as shown in Figure 3.11 where the activity cost of the product remains unchanged even though large variations occur in the manufacturing parameters.

\subsubsection{Sensitivity Analysis with Availability of Machines}

Figure 3.12 below shows the relationship between the number of machines and the availability of these machines. It is seen that as the availability of machines decreases, the machines required to manufacture the same number of Powerarms [22] increases.

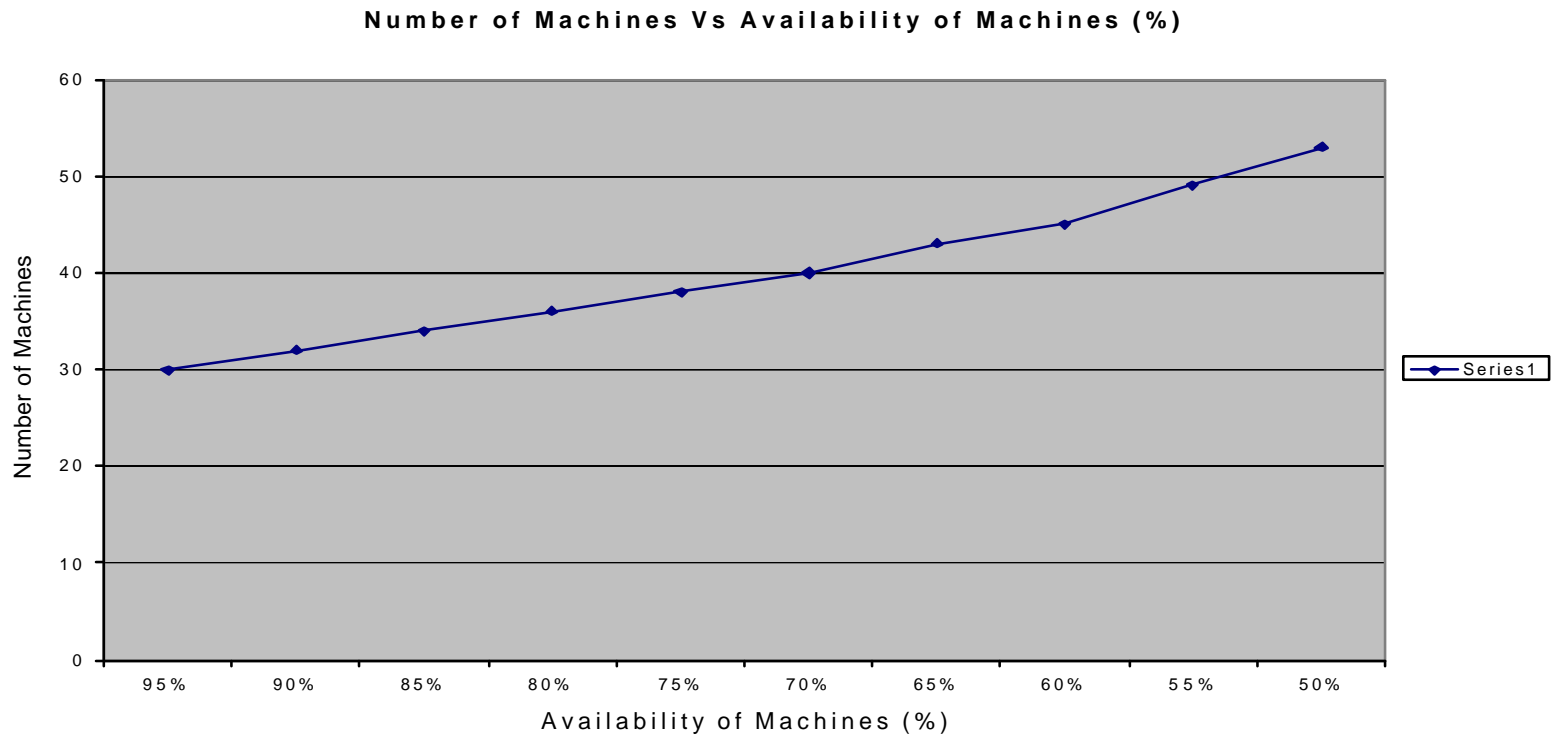

Figure 3.12 Number of Machines Vs \% Change in Availability of Machines

Number of Operators Vs Change in Availability of Machines (\%)

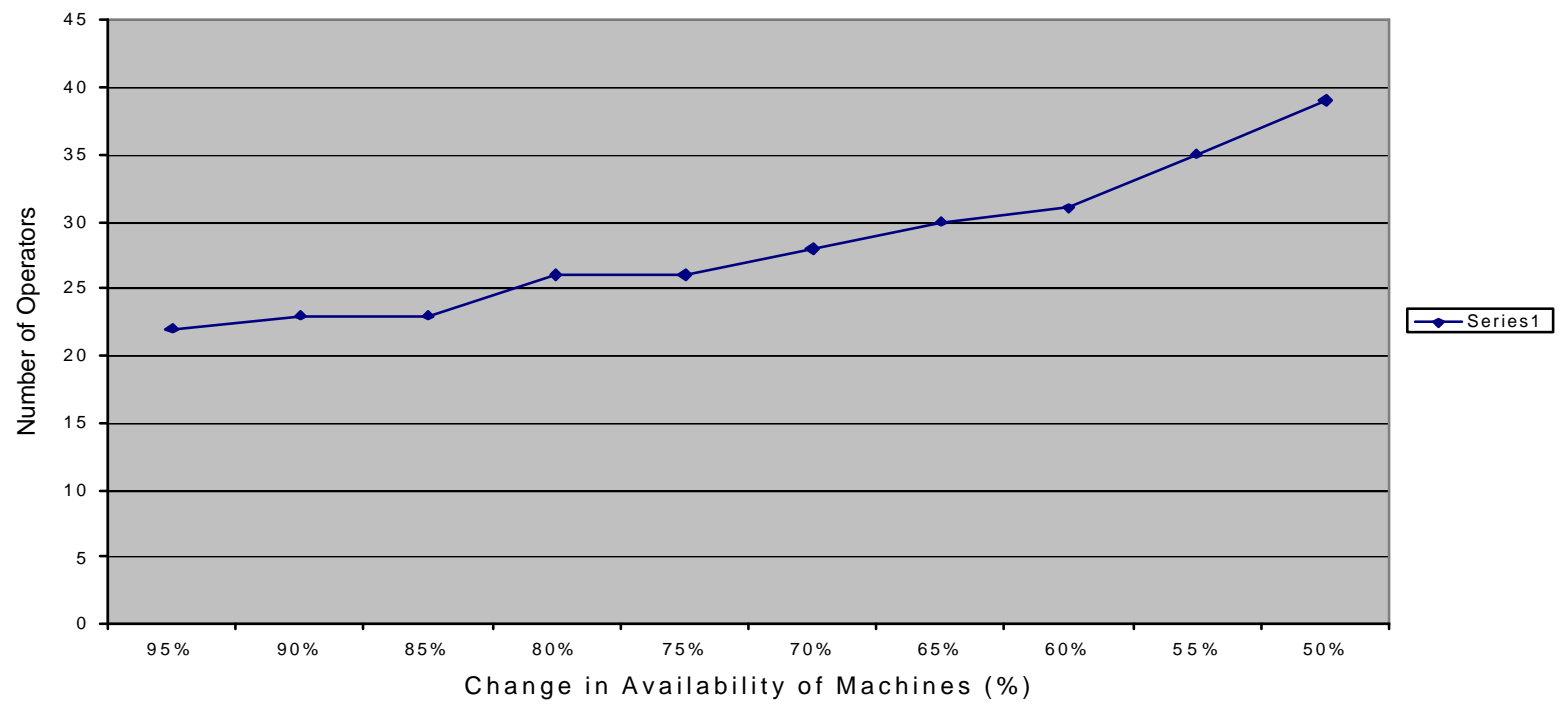

Figure 3.13Number of Operators Vs \% Change in Availability of Machines 
Figure 3.13 shows the relationship between the number of operators used in the manufacture of the Powerarm [22] and the availability of the machines. It is seen that as the availability of the machine decreases, the number of operators required to manufacture the Powerarm [22] increases due to the increase in the number of machines required to manufacture the same number of Powerarms [22].

Area (sft) Vs Change in Availability of Machines (\%)

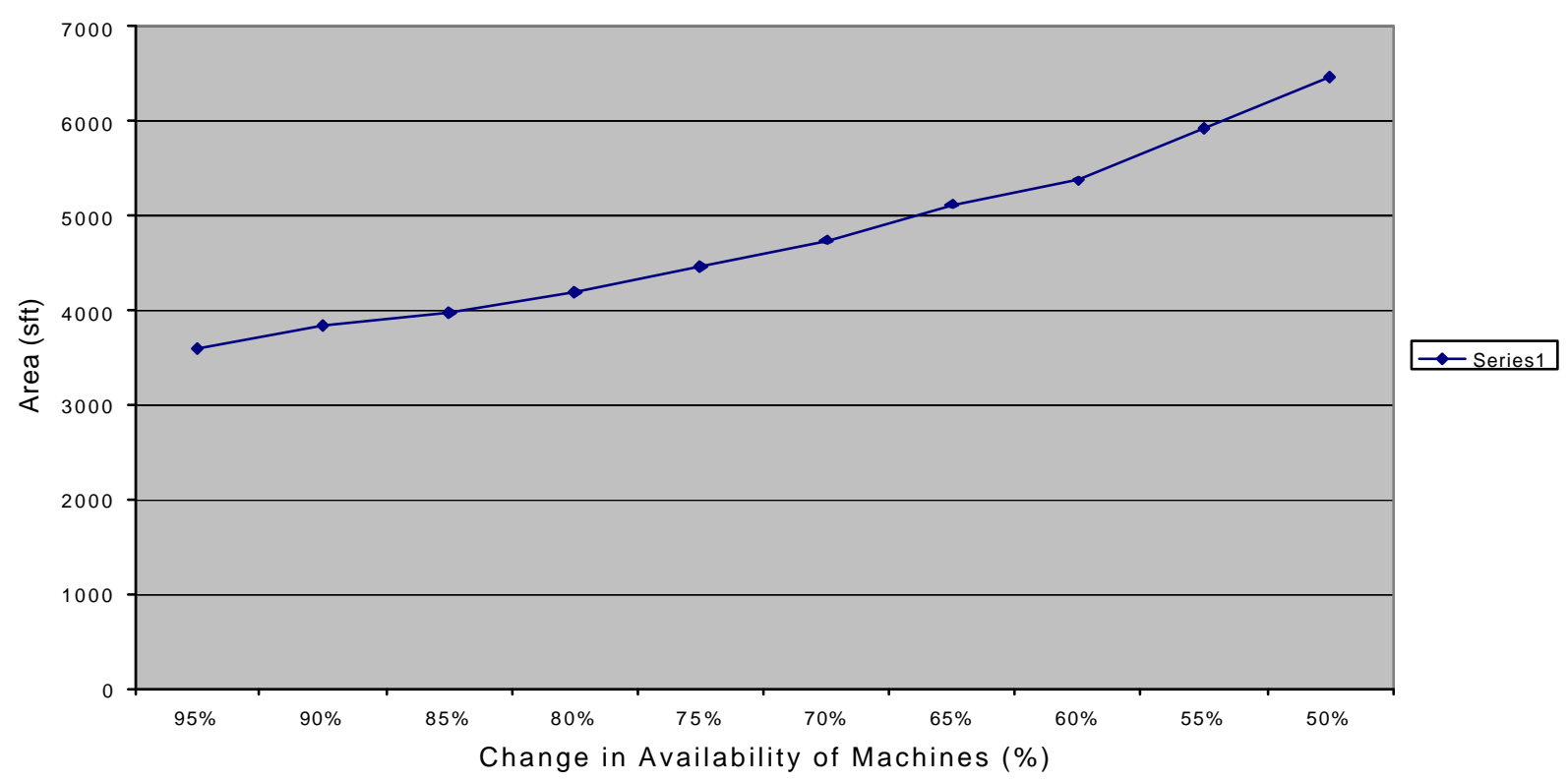

Figure 3.14 Area of the Facility Vs\% Change in Availability of Machine

As the availability of the machines is reduced, the area of the facility increases. This is due to the increase in the number of machines and operators correspondingly increasing the area of the facility in order to accommodate the additional number of machines and operators. This is indicated in Figure 3.14.

The last analysis for the availability of machines involved the cost of manufacture of the Powerarm [22]. This is shown in the following page in Figure 3.15. 
Machine and Operator Activity Cost (\$) Vs Change in Availability of Machines

(\%)

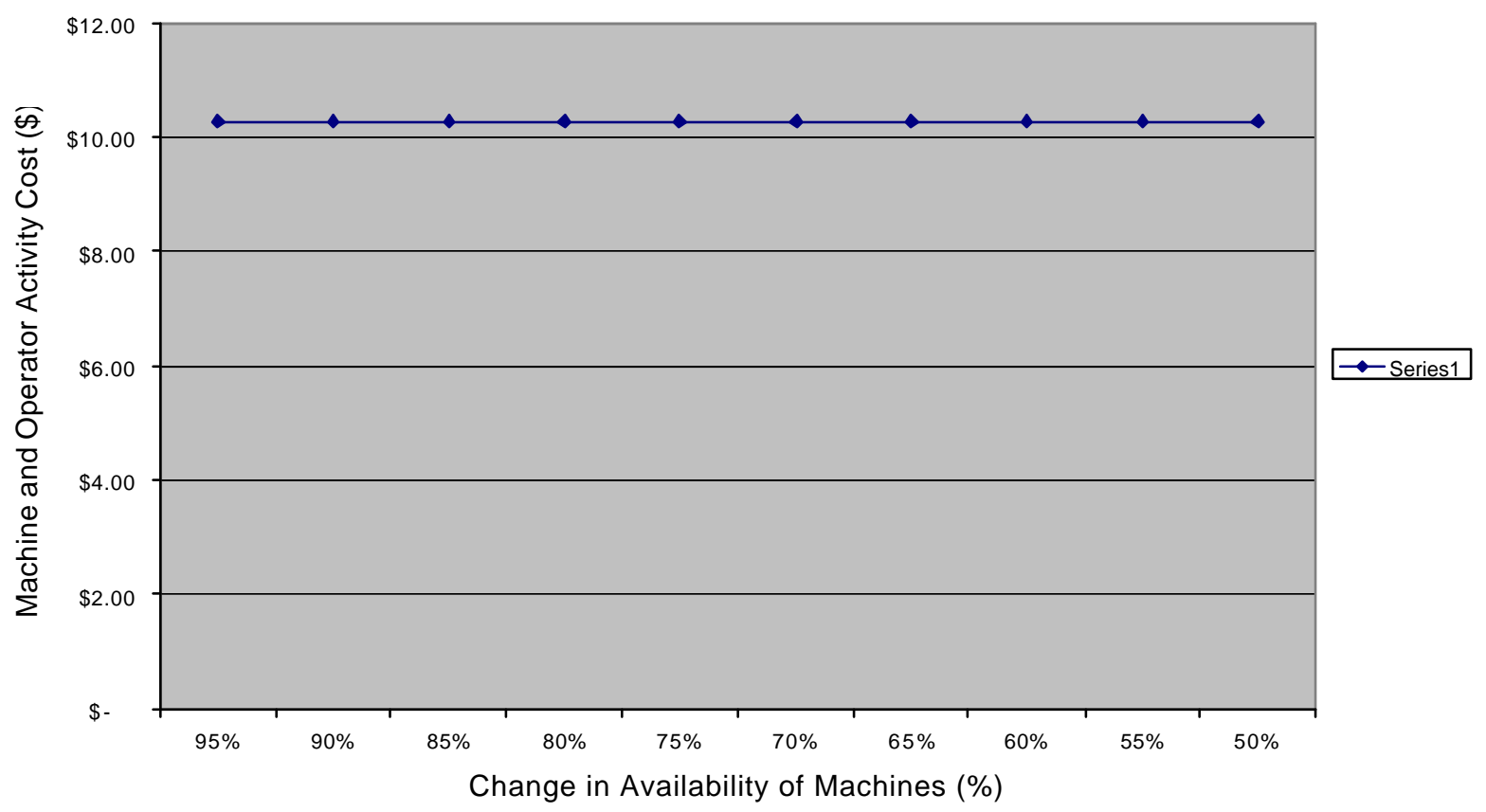

Figure 3.15 Cost of the Product Vs \% Change in Availability of Machines

The activity cost of the Powerarm [22] does not change for changes in the value of the availability of machines. As mentioned earlier during the analysis with scrap rate and reliability of machines, the cost considered in the analysis is only the machine activity cost and the operator activity cost. Hence the change in the availability of machines does not have any impact on this activity cost of the Powerarm [22]. This is indicated in Figure 3.15 above. Availability values of machines are independent of the operator and machine activity cost. Therefore, any variation in the availability values must not impact this activity cost of the product being manufactured. The same scenario was explained earlier with respect to the scrap rate and the reliability of machines where changes in those parameters also did not result in any changes in the activity cost of the Powerarm [22].

\subsubsection{Sensitivity Analysis with Loading/Unloading Time}

The last analysis is with loading/unloading time and is explained below. 


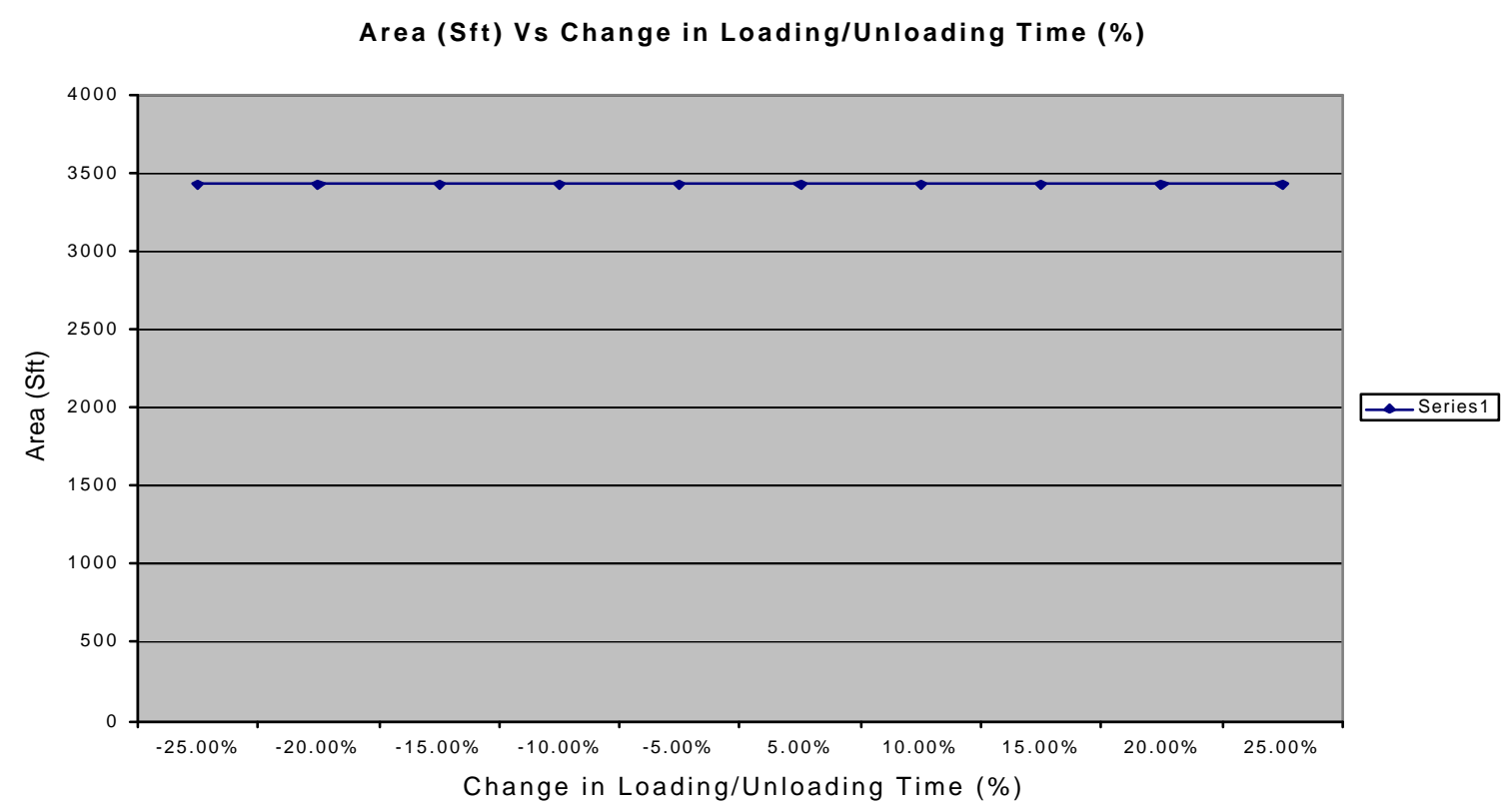

Figure 3.16 Area Vs \% Change in Loading/Unloading Time of Machines

The loading/unloading time does not have any impact on the area of the facility because it increases the operator labor time and activity cost and hence there is no change in the area for changes in loading/unloading time of machines, which is shown in Figure 3.16.

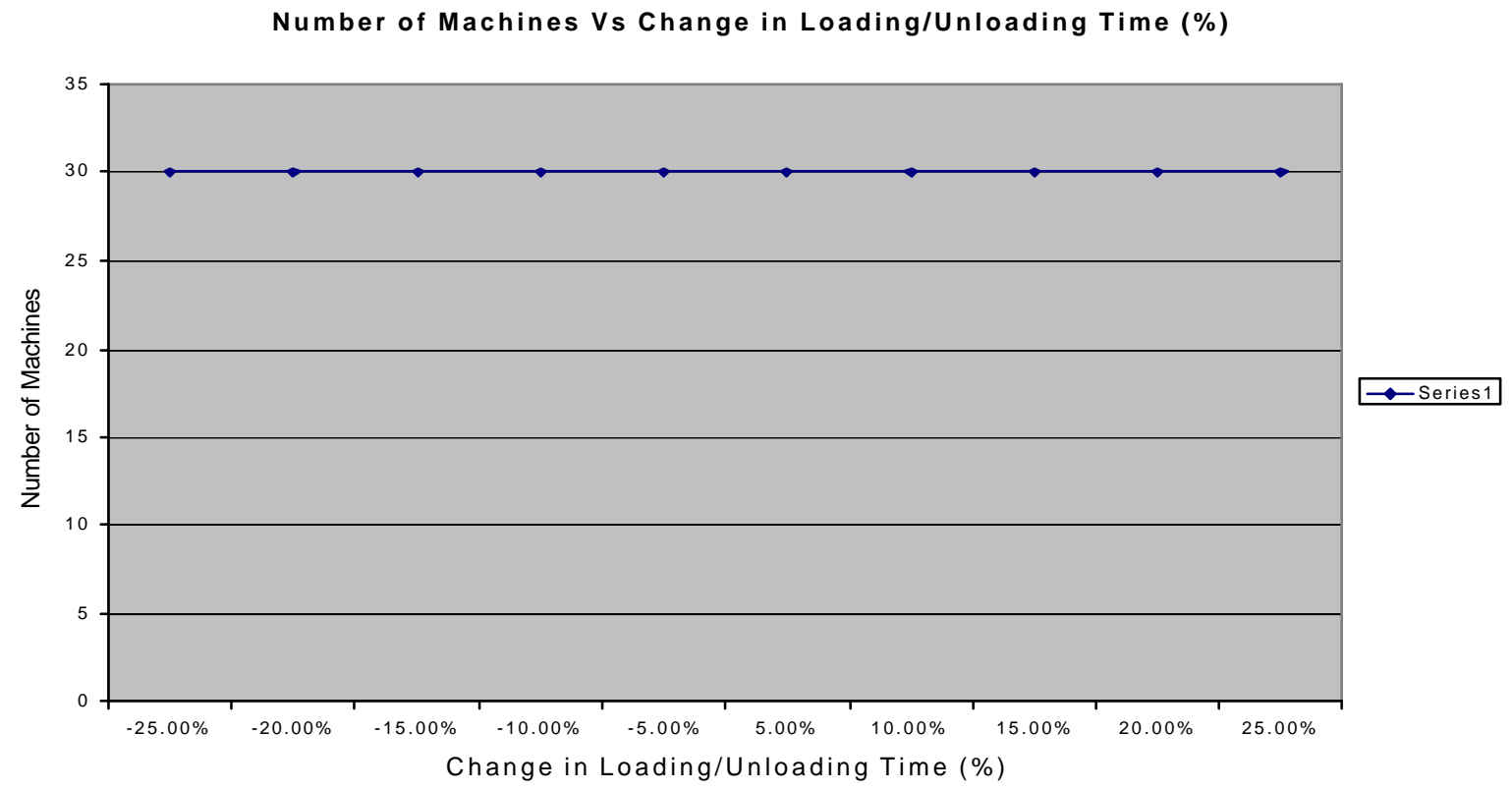

Figure 3.17 Number of Machines Vs\% Change in Loading/Unloading Time 
The loading/unloading time does not have any impact on the number of machines used to manufacture the Powerarms [22]. The number of machines remains constant for different values of loading/unloading time, which is shown in Figure 3.17.

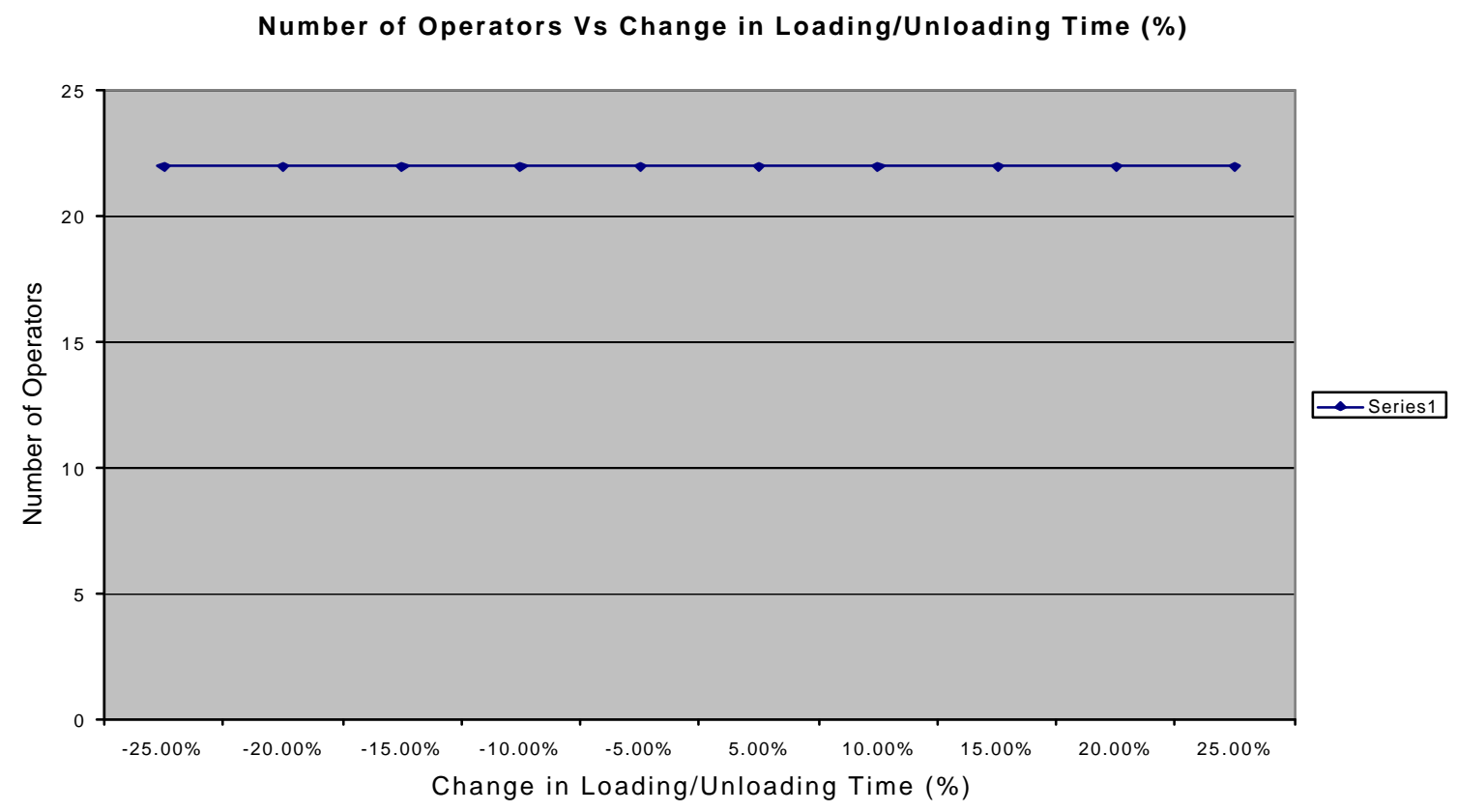

Figure 3.18 Loading/Unloading time Vs Number of Operators

The loading/unloading time does not have any impact on the number of operators. This is because, the number of operators are dependent on the calculated value of n'. If the value of loading and unloading time is changed, the value changes both in the numerator and the denominator in the n' calculation. The resulting change in the value of n' is not significant and further evaluation of the activity costs actually gives the same number of operator assignments to machines. The same scenario was tested in the model and the results are shown in Figure 3.18. Though many different types of machines have been used in the model, the change in their loading and unloading time did not result in any change in the number of operators.

The final analysis for loading/unloading time was done with the cost of the Powerarm [22]. The cost of the product changed when the loading/unloading time was changed. This is because, in our research, the cost of the product is only the machine and labor cost. If the loading/unloading time increases, the time spent by the operators increases thereby increasing the operator cost thereby increasing the cost of the Powerarm [22] 
being manufactured. This is further shown and explained in the graph on the following page.

Machine and Operator Activity Cost (\$) Vs Change in Loading/Unloading Time

(\%)

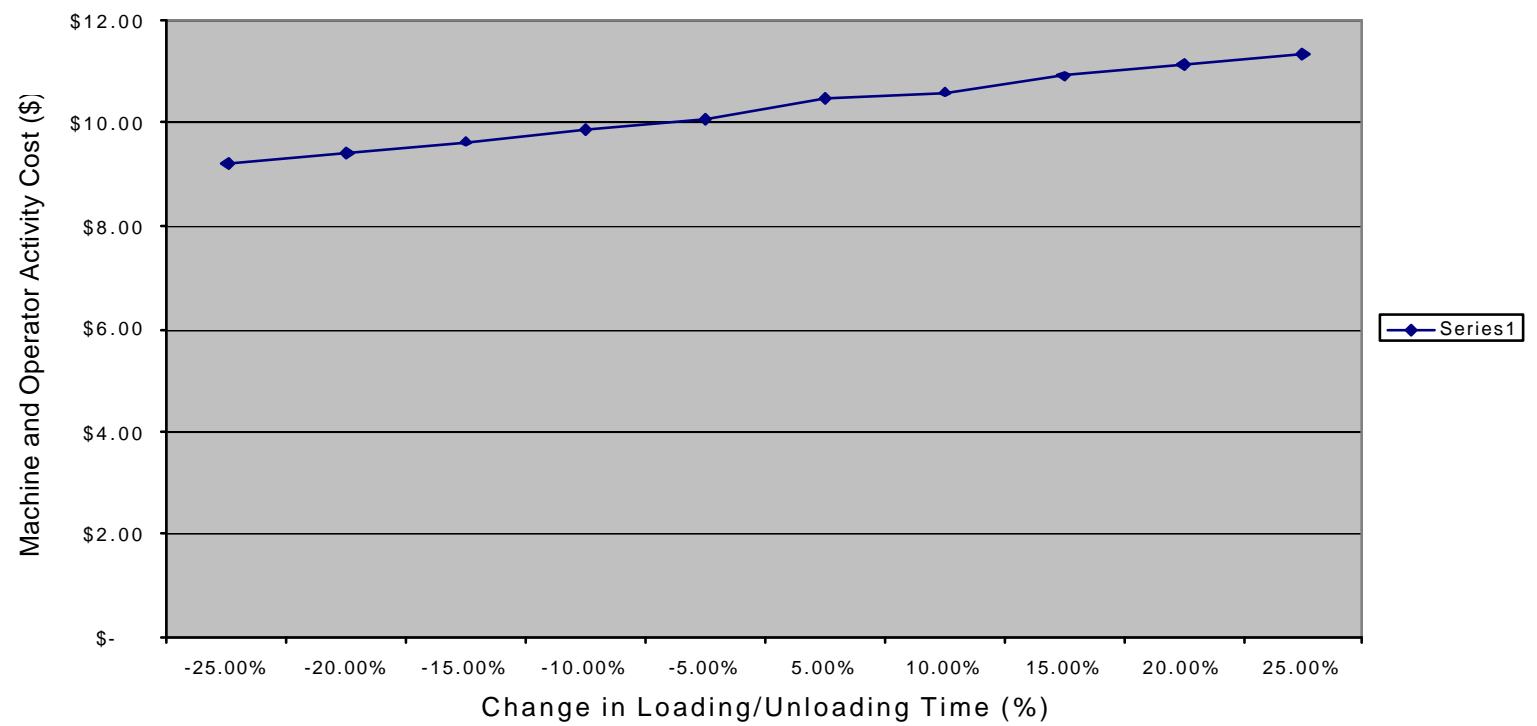

Figure 3.19 Cost of Product Vs \% Change in Loading/Unloading Time

The cost to manufacture the Powerarm [22] increases with increase in loading and unloading time due to the increased operator cost associated with it. Increase in loading and unloading time results in more time spent by the operator in setting up the machine for manufacture resulting in higher operator cost thereby resulting in higher cost of the product being manufactured. This is shown in Figure 3.19 above.

\subsubsection{Sensitivity Analysis with M-CRAFT Results}

The last part of the sensitivity analysis involved studying the results obtained using the M-CRAFT facility design software for each of the process parameters studied earlier. Scrap Rate, reliability of machines and availability of machines were each considered individually and the impact of variation of these parameters on the material handling costs is analyzed.

Figure 3.20 shows the analysis between scrap rate and material handling costs in the facility. It is established that as the scrap rate of the product being manufactured increases, the material handling costs also increase. This is because, as the scrap rate 
increases, the area of the facility increases due to the increase in the number of machines and operators. This results in larger distances of material handling between departments resulting in higher handling costs. This is shown in Figure 3.20 below.

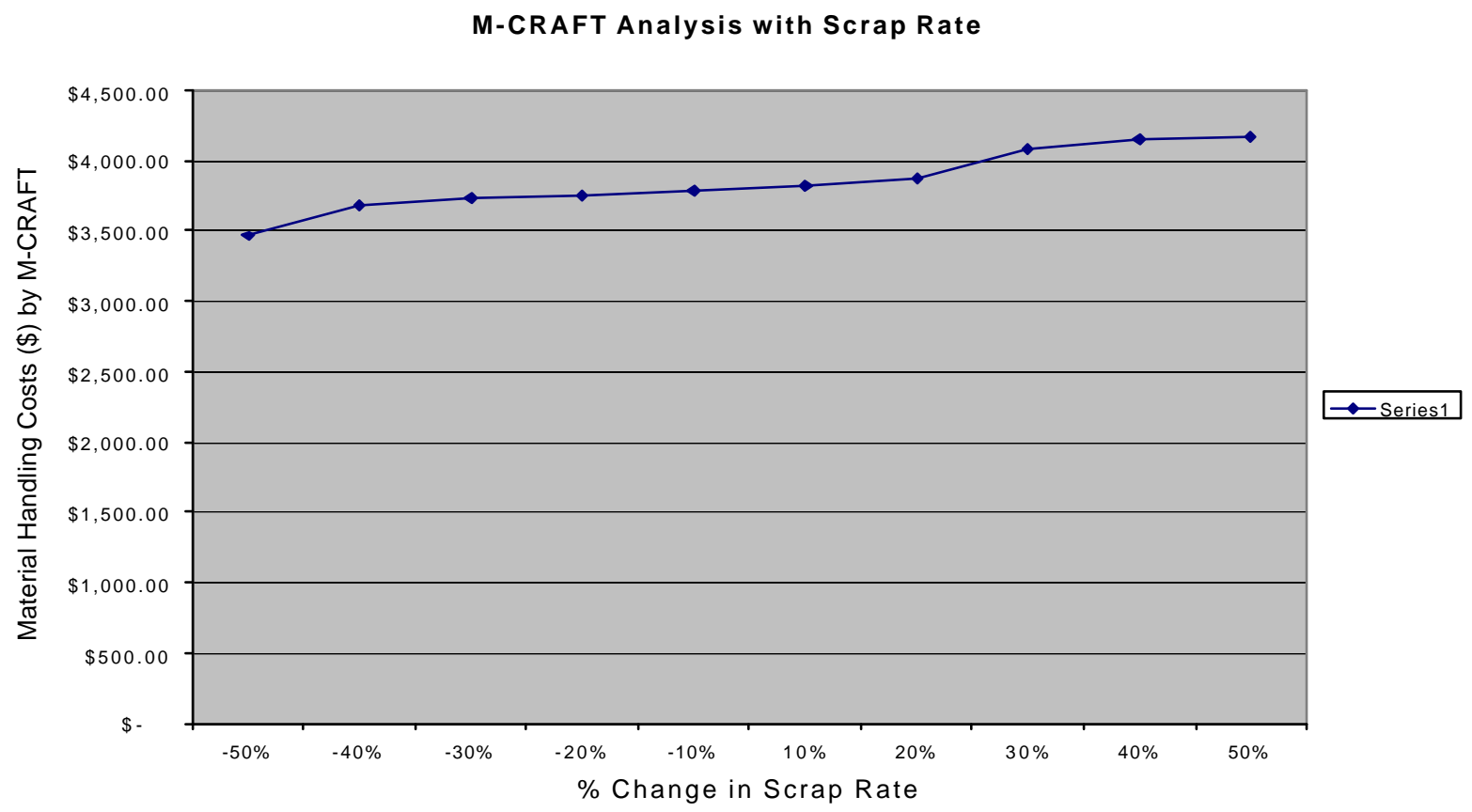

Figure 3.20 Material Handling Costs (\$) by M-CRAFT Vs \% Change in Scrap Rate

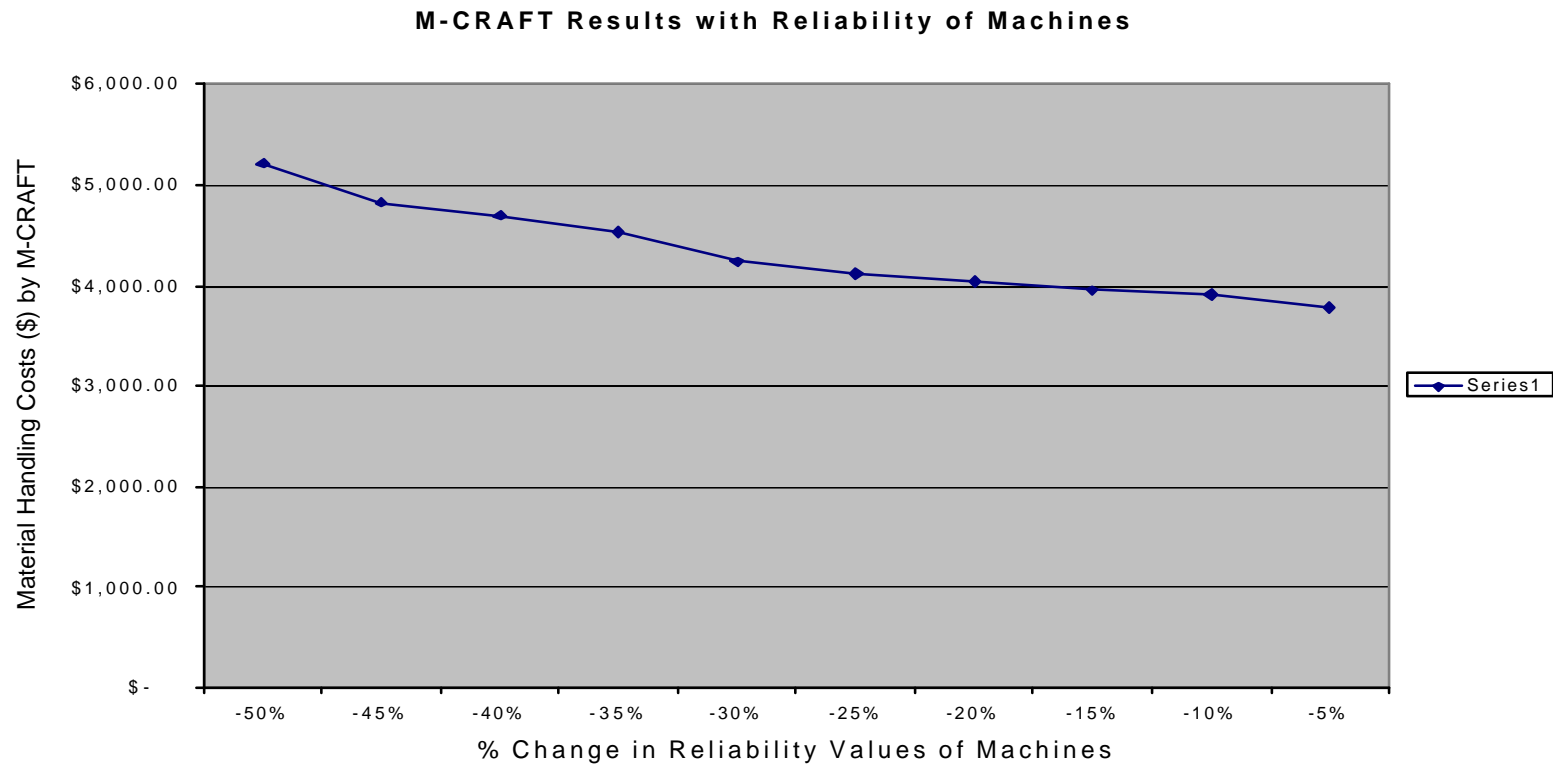

Figure 3.21 Material Handling Costs (\$) by M-CRAFT Vs \% Change in Reliability Values of Machines 
Figure 3.21 shows the analysis between reliability values of machines and material handling costs in the facility. It is established that as the reliability of machines decreases, the material handling costs increase. This is due to increase in the number of machines required to manufacture the same number of products, which increases the area requirements of the facility. This results in larger travel distances for materials between departments resulting in higher handling costs.

\section{M-CRAFT Results with Availability of Machines}

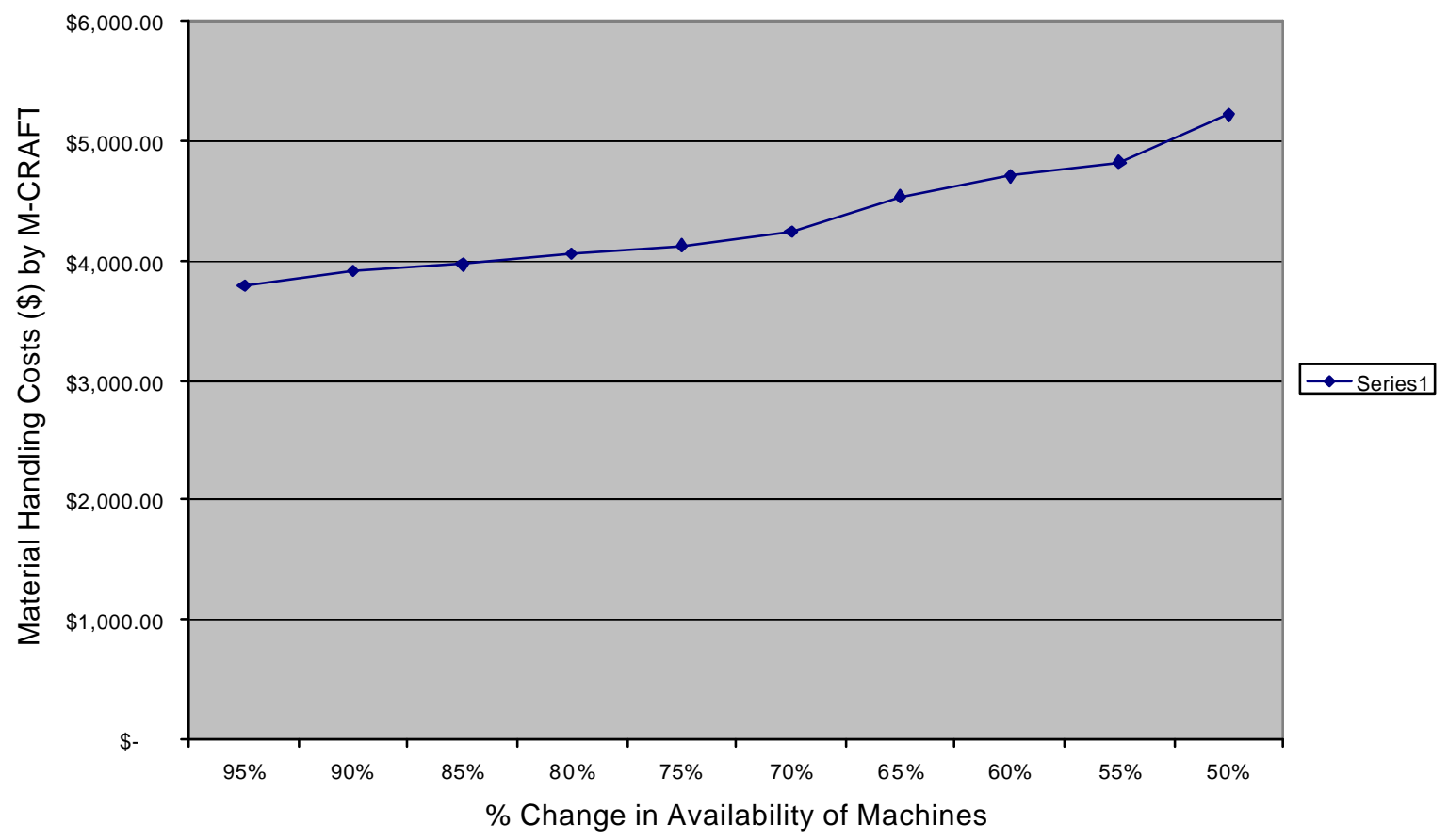

Figure 3.22 Material Handling Costs (\$) by M-CRAFT Vs \% Change in Availability of Machines

Figure 3.22 shows the analysis between availability values of machines and material handling costs in the facility. It is established that as the availability of machines decreases, the material handling costs increase. This is due to increase in the number of machines required to manufacture the same number of products which increases the area requirements of the facility. This results in larger travel distances for materials between departments resulting in higher handling costs. 


\subsection{Chapter Conclusion}

The research proved that we need to be sensitive to the manufacturing operations in the facility being designed. Variation in process parameters results in changes in facility size, machines, operators and cost of the product being manufactured. If these relationships are not considered, facility design changes in order to meet the changing market demand would result in high facility costs. If this relationship is studied, changes required would be fewer, thus resulting in lower facility costs. Also, the details on the equipment and operators need to be worked out before the facility is designed. If this aspect is not

considered, there might be frequent changes in the facility design in order to accommodate the equipment and resources. The results and conclusions of this research are explained in the next chapter. 


\section{Conclusion and Future Work}

\subsection{Conclusion}

From the results obtained of the Excel model and the analysis done in M-CRAFT, it is seen that manufacturing parameters have a strong impact on the facility layout and to a large extent are responsible for the layout costs. This research shows that that a model that can establish relationship between the facility design and process and product parameters can be developed. It will be extremely helpful to the industrial end users who cannot devote required time and cost that goes into this analysis and estimation. Such a model will also provide information on the important parameters which have maximum impact on the facility design and cost of the product being manufactured. This model would help in estimating the effects on the facility in terms of cost whenever changes or modifications are required in an existing facility. The model in our research was for job shop production involving a single product having different parts which go into the final product. The model helped us in understanding the fact that careful analysis is required before making any changes in the manufacturing parameters as small variations can have large effects on the layout of the facility and material handling costs, especially in a large setup.

The model developed helped us in establishing and understanding the following:

- Enabled to identify the important manufacturing parameters that govern facility design, in our case, it was scrap rate, reliability of machines, availability of machines and loading/unloading time.

- Provided a tool to determine the size of a facility given the necessary parameters and the cost of the product with respect to operator and equipment. Our analysis started after determining the size of the layout, the machines and operators required to manufacture the 1,000 Powerarms.

- The developed model showed the relationships between the product and process design parameters and how they impact the facility layout and design.

- Provides a simple tool to validate the designed layout and perform sensitivity analysis for the important parameters. 


\subsection{Scope for Future Work}

As mentioned earlier, the model in our research was for job shop production involving a single product having different parts, which go into the final product. The same model can be extended to a large setup if information is available on the products being manufactured and the manufacturing parameters associated with it. Since the facility in our research was a job shop type and the production quantity considered was only 1000 Powerarms [22], only larger changes in manufacturing parameters indicated changes in layout size and cost of handling the product. If a bigger facility is considered having the resources to manufacture different types of products in large quantities, even small changes in manufacturing parameters would reflect changes in the facility layout and cost of material handling. Also, in our analysis, due to the non-availability of resources, we used a DOS based facility design software M-CRAFT which could not be linked to the Excel model and had very limited output features. If resources are available, there are software available like FDL, CONGEN etc which are far more advanced and can be used for better validation and analysis and linked with other tools also. An excellent tool can be built if these resources are available with the complete product and process data, which can serve as a reference for any facility executive to monitor the effects of process and product parameter changes on facility design and product handling costs. The robust model would help in:

- Determine the effects of processes and products on facility design.

- Statistically analyze the relationships between the different parameters.

- Determine the product handling costs and their variation when the process and product parameters vary. 


\section{Bibliography}

[1] Tompkins, James A.... [et al.], "Facilities Planning”/J. Wiley, c2003.

[2] Hales, Lee H., “Computer Aided Facilities Planning”, Marcel Dekker Inc., 1984.

[3] James, Robert W., Alcorn, Paul A., "A Guide to Facilities Planning”, Prentice Hall 1991.

[4] Francis, Richard L., Mcginnis Jr, Leon F., White, John A., "Facility Layout and Location: An Analytical Approach", Second Edition, Prentice Hall, 1992.

[5] Cotts, David G., Lee, Michael., "The Facility Management Handbook”, American Management Association, 1992.

[6] Kochhar, J.H., Heragu, S.S., "Facility Layout design in a changing environment", International Journal of Production Research, August 1998, pp. 2429-2446.

[7] Lara, Marco A., Witzerman, James P., Nof, Shimon Y., "Facility description language for integrating distributed designs", International Journal of Production Research, February 1999.

[8] Smith, Terrence A., Randhawa, Sabah U., "Manufacturing Facility design: World Quality at Global prices", Institute of Industrial Engineers, IE Solutions '97 Conference Proceedings, pp. 60-64.

[9] Moghaddain, Tavakkoli R., Shayan E., "Facilities layout design by Genetic algorithms", Computers Ind. Engg Vol. 35, Nos. 3-4, pp. 527-530, 1998.

[10] Frizelle, G.D.M., "Assessing the impact of new products on the factory", $5^{\text {th }}$ International Conference on Factory 2000, 2-4 ${ }^{\text {th }}$ April 1997, Conference Publication No. 435, IEE 1997.

[11] Eneyo, Emmanuel S., Pannirselvam, Gertrude P., "The use of simulation in facility layout design: a practical consulting experience", Proceedings of the 1998 winter Simulation Conference.

[12] Ilozor, Ben Dozie., Lovem Peter E.D., Treloar, Graham., "The impact of work settings on organizational performance measures in built facilities", Facilities, vol. 20 , issue $1 / 22002$, pp.61-67.

[13] Grimshaw, R.W., "FM: the professional interface", facilities, vol. 21, issue 5/6 2003, pp. 50-57.

[14] Duffy, Francis, "Design and facilities management in a time of change", facilities, vol. 18, issue 10/11/12 2000, pp. 371-375 
[15] Whitaker, Martha J., "Conducting a facility management audit", facilities, vol. 13 , issue 61995 , pp. 6-12

[16] Cairns, George., "Seeking a facilities management philosophy for the changing workplace", facilities, vol. 21, issue 5/6 2003, pp. 95-105

[17] Mcgregor, Wes., "The future of workspace management”, facilities, vol. 18, issue $3 / 4$ 2000, pp. 138-143

[18] Blair, Lynne., Thatcher, Meredith., "calculating occupiable floor area: a North American initiative", facilities, vol. 13, issue 7 1995, pp. 17-72

[19] Vaughan, Beth Harmon., “Tomorrow's workplace: anywhere, anytime”, facilities, vol. 13, issue 4 1995, pp. 6-13

[20] So, Albert T.P., Wong, Alvin C.W., Wong, K-c., “ A new definition of intelligent buildings for Asia”, facilities, vol. 17, issue 12/13 1999, pp. 485-491

[21] Brauer, Roger L., "Facilities Planning”, American Management association 1992

[22] Apple, James M., "Plant Layout and Material Handling", second edition, The Ronald Press Company 1963

[23] Benajaafar, Saifallah., "Design of flexible layouts for manufacturing systems", IEEE International Engineering Management conference, Institute of Electical and Electronics Engineers 1995, pp. 421-427 


\section{Appendix}

\section{FAOITYDESGNMODE_FORMANUFACIUFEOFPONGAFM}

\begin{tabular}{|c|c|}
\hline Number of Powerams Noeded & 1000 \\
\hline hdependent operator activity fmer(min) & 1 \\
\hline Avalabily of machinesperday(min) & 1440 \\
\hline Eficiency of themadines & 1 \\
\hline Batch Size & 100 \\
\hline
\end{tabular}

\begin{tabular}{|c|c|c|c|c|c|c|c|c|c|c|}
\hline MedineName & Operation & Pieces/H & $\begin{array}{l}\text { Scrap } \\
\text { Rate }\end{array}$ & Avalability & Reliability & $\begin{array}{c}\text { Loeding } \\
\text { Trme(min) }\end{array}$ & $\begin{array}{l}\text { Unbading } \\
\text { Tme(min) }\end{array}$ & $\begin{array}{l}\text { Operalor } \\
\text { Costhr(\$) }\end{array}$ & $\begin{array}{l}\text { Machine } \\
\text { Costhr(\$) }\end{array}$ & $\begin{array}{l}\text { Numberof } \\
\text { Machines } \\
\text { required }\end{array}$ \\
\hline ШRONDLATIE & FaceBollom & 60 & 0.04 & 24 & 0.93 & 0.1 & 0.1 & 25 & 12 & 0.94 \\
\hline WARNR\&SWASEY & FactopOD & 23.8 & 0.04 & 24 & 0.83 & 0.3 & 0.3 & 25 & 15 & 256 \\
\hline QR⿴囗十MANDRLPFESS & DilthreHoles & 84 & 0.03 & 24 & 0.88 & 0.16 & 0.16 & 25 & 10 & 0.58 \\
\hline DEATADR—PRESS & Dill pin holes & 238 & 0.03 & 24 & 0.88 & 0.3 & 0.3 & 25 & 9 & 022 \\
\hline \multirow{2}{*}{ FOSDCKDF—PFESS } & Drill & 65.4 & 0.03 & 24 & 0.77 & 0.35 & 0.35 & 25 & 13 & 0.91 \\
\hline & Peam & & 0.02 & 0 & 0 & 0 & 0 & 0 & 0 & \\
\hline ENOH & Inspect & 55.4 & 0.04 & 24 & 1 & 0.22 & 022 & 25 & 7 & 0.78 \\
\hline DEIREXWASTR & Degrease & 143 & 0 & 24 & 1 & 0.13 & 0.13 & 25 & 8 & 0.29 \\
\hline \multicolumn{11}{|l|}{ EOOENIFCROD } \\
\hline \multirow{2}{*}{ OSTRR61 } & Qutoff & 588 & 0.03 & 24 & 0.8 & 0.43 & 0.43 & 25 & 21 & 0.12 \\
\hline & Chamfar & & 0.06 & 0 & 0 & 0 & 0 & 0 & 0 & \\
\hline DEATADR—PRESS & Dill 5/16 hole & 250 & 0.03 & 24 & 0.88 & 0.3 & 0.3 & 25 & 9 & 024 \\
\hline DEATADR—PRESS & Tap38-16hole & 120 & 0.02 & 24 & 0.88 & 0.2 & 02 & 25 & 9 & 0.48 \\
\hline LRONDLATIE & TumEcoentic & 149 & 0.02 & 24 & 0.93 & 0.13 & 0.13 & $\mathbf{2 5}$ & 12 & 0.36 \\
\hline ENOH & hspect & 143 & 0.04 & 24 & 1 & 0.22 & 022 & 25 & 7 & 0.34 \\
\hline HEATTREATMENT & Fumace & 910 & 0.07 & 0 & 0 & 0 & 0 & 0 & 0 & \\
\hline GRDDD & Cin Ginder & 455 & 0.05 & 0 & 0 & 0 & 0 & 0 & 0 & \\
\hline DEIREXWASGR & Degrease & 455 & 0 & 24 & 1 & 0.13 & 0.13 & 25 & 8 & 0.09 \\
\hline \multicolumn{11}{|l|}{ HANDE } \\
\hline \multirow{3}{*}{ WAFNRRSWASEY } & Thread & 256 & 0.06 & 24 & 0.83 & 0.2 & 02 & 25 & 15 & 027 \\
\hline & attoff & & 0.03 & 0 & 0 & 0 & 0 & 0 & 0 & \\
\hline & Chamter & & 0.06 & 0 & 0 & 0 & 0 & 0 & 0 & \\
\hline \multirow{2}{*}{ WAFNR\&SWASYY } & Thread & 232 & 0.06 & 24 & 0.83 & 0.2 & 02 & 25 & 15 & 026 \\
\hline & Chamfer & & 0.06 & 0 & 0 & 0 & 0 & 0 & 0 & \\
\hline ENOH & inspect & 500 & 0.04 & 24 & 1 & 0.22 & 022 & 25 & 7 & 0.09 \\
\hline DEIREXWASER & Degrease & 600 & 0 & 24 & 1 & 0.13 & 0.13 & 25 & 8 & 0.07 \\
\hline \multicolumn{11}{|l|}{ CNR } \\
\hline \multirow{4}{*}{ WAFNR\&SWASEY } & Face & $\mathbf{6 0}$ & 0.04 & 24 & 0.83 & 0.3 & 0.3 & $\mathbf{2 5}$ & 15 & 122 \\
\hline & Bore & & 0.04 & 0 & 0 & 0 & 0 & 0 & 0 & \\
\hline & Tum & & 0.02 & 0 & 0 & 0 & 0 & 0 & 0 & \\
\hline & attoff & & 0.03 & 0 & 0 & 0 & 0 & 0 & 0 & \\
\hline arRBMANDRUPRESS & Dill 4931 holed & 178 & 0.03 & 24 & 0.99 & 0.16 & 0.16 & 25 & 10 & 0.30 \\
\hline BROMN\&SHAFM丩 & Sawintwo & 125 & 0.03 & 24 & 0.85 & 0.14 & 0.14 & 25 & 18 & 0.48 \\
\hline ENAH & hspect & 250 & 0.04 & 24 & 1 & 0.22 & 022 & 25 & 7 & 020 \\
\hline DEIREXWASGR & Decrease & 300 & 0.13 & 24 & 1 & 0.13 & 0.13 & 25 & 8 & 0.16 \\
\hline \multicolumn{11}{|l|}{ CP } \\
\hline \multirow{3}{*}{ WAFNR\&SWASEY } & Face & 30.3 & 0.04 & 24 & 0.83 & 0.3 & 0.3 & 25 & 15 & 207 \\
\hline & Bore & & 0.04 & 0 & 0 & 0 & 0 & 0 & 0 & \\
\hline & atsent & & 0.02 & 0 & $\mathbf{0}$ & 0 & 0 & 0 & 0 & \\
\hline FOSDCKDR $\perp$ PRESS & Dillandtap & 625 & 0.03 & 24 & 0.77 & 0.35 & 0.35 & 25 & 13 & 0.98 \\
\hline MWAUKEIMI & Milsot & 83.5 & 0.05 & 24 & 0.78 & 0.36 & 0.36 & 25 & 15 & 0.70 \\
\hline 巴NOH & Inspect & 100 & 0.04 & 24 & 1 & 0.22 & 022 & 25 & 7 & 0.43 \\
\hline DEIREXWASFR & Degrease & 143 & 0 & 24 & 1 & 0.13 & 0.13 & $\mathbf{2 5}$ & 8 & 029 \\
\hline
\end{tabular}




\begin{tabular}{|c|c|c|c|c|c|c|c|c|c|c|}
\hline \multirow{2}{*}{\multicolumn{11}{|c|}{ PN }} \\
\hline & & & & & & & & & & \\
\hline \multirow{2}{*}{ ळाषR61 } & atof & 1000 & 0.03 & 24 & 0.8 & 0.43 & 0.43 & 25 & 15 & 0.06 \\
\hline & Chamfr & & 006 & 0 & 0 & 0 & 0 & 0 & 0 & \\
\hline & & & & & & & & & & \\
\hline \multicolumn{11}{|l|}{ FESSAFPAD } \\
\hline \multirow{3}{*}{ WAFNR\&SWAFYY } & Bae, & 40 & 0.04 & 24 & 0.83 & 024 & 024 & 25 & 15 & 159 \\
\hline & Faœ & & 0.04 & 0 & 0 & 0 & 0 & 0 & 0 & \\
\hline & dhamfr & & 0.06 & 0 & 0 & 0 & 0 & 0 & 0 & \\
\hline BRONN\&SHAFEML & Mistot & 120 & 005 & 24 & 0.85 & 025 & 025 & 25 & 18 & 0.45 \\
\hline ENOH & Inspect & 100 & 0.04 & 24 & 1 & 022 & 022 & 25 & 7 & 0.43 \\
\hline DEIREXWAGGR & Degrease & 60 & 0 & 24 & 1 & 0.13 & 0.13 & 25 & 8 & 0.07 \\
\hline \multicolumn{11}{|l|}{ BALSMME } \\
\hline \multirow{4}{*}{ WAFNR\&SWAEYY } & Tun & 30.3 & 002 & 24 & 0.83 & 0.4 & 0.4 & $\mathbf{2 5}$ & 15 & 223 \\
\hline & Shark & & 0,02 & 0 & 0 & 0 & 0 & 0 & 0 & \\
\hline & autof & & 0.03 & 0 & 0 & 0 & 0 & 0 & 0 & \\
\hline & formbel & & 003 & 0 & 0 & 0 & 0 & 0 & 0 & \\
\hline LANDSGRDER & Gindbal & $\mathbf{2 5}$ & 0.05 & 24 & 089 & 027 & 027 & 25 & 19 & 227 \\
\hline SMPEXML & Mishank & 90 & 0.05 & 24 & 0.92 & 025 & 025 & 25 & 17 & 0.58 \\
\hline \multirow{2}{*}{ FOSDCKDR丩FESS } & Drill & 625 & 003 & 24 & 0.9 & 0.35 & 035 & $\mathbf{2 5}$ & 13 & 081 \\
\hline & Tap & & 0,02 & 0 & 0 & 0 & 0 & 0 & 0 & \\
\hline BNOH & Inspect & 833 & 0.04 & 24 & 1 & 0.22 & 022 & 25 & 7 & 0.52 \\
\hline DEIREXWASGR & Dergease & 600 & 0 & 24 & 1 & 0.13 & 0.13 & 25 & 8 & 0.07 \\
\hline
\end{tabular}

Table 0.1 Model Excel Spreadsheet

Figure 0.1 gives the details of the different parts that go into the final assembly of the Powerarm [22]. The chart gives the different machines used in the manufacture of these parts, the manufacturing parameters involved and the costs for the different machines and operators. Each of these parameters was carefully considered to arrive at the final number of machines and operators and cost of the product. All the data used is published data from [22].

\begin{tabular}{|c|c|}
\hline \multicolumn{2}{|c|}{ SPACE ALLOCATION FOR DIFFERENT MACHINES } \\
\hline Machine Name & Machine Space (Sq.ft) \\
\hline LeBLOND LATHE & 101 \\
\hline WARNER \& SWASEY LATHE & 123 \\
\hline CLEEREMAN DRILL PRESS & 78 \\
\hline DELTA DRILL PRESS & 99 \\
\hline FOSDICK DRILL PRESS & 120 \\
\hline BENCH & 66 \\
\hline DETREX WASHER & 77 \\
\hline OSTER & 134 \\
\hline BROWN \& SHARPE MILL & 99 \\
\hline MILWAUKEE MILL & 113 \\
\hline LANDIS GRINDER & 124 \\
\hline SIMPLEX MILL & 101 \\
\hline OTHERS & 103 \\
\hline
\end{tabular}

Table 0.2 Space Allocation for different machines 


\begin{tabular}{|c|c|}
\hline \multicolumn{2}{|c|}{ Lathe Department } \\
\hline Total Number of Machines & 14 \\
\hline Total Number of Operators & 7 \\
\hline Machine and Operator Space & 1759.87 \\
\hline Aisle Space and Plant Services & 42.522 \\
\hline Total Space for Lathe Department & 1802.392 \\
\hline Lathe Machine Activity Cost & $\$$ \\
\hline
\end{tabular}

\begin{tabular}{|c|c|}
\hline \multicolumn{2}{|c|}{ Drilling Department } \\
\hline Total Number of Machines & 5 \\
\hline Total Number of Operators & 5 \\
\hline Machine and Operator Space & 547.17 \\
\hline Aisle Space and Plant Services & 6.102 \\
\hline Total Space for Drilling Department & 553.272 \\
\hline Drilling Machine Activity Cost & $\$$ \\
\hline
\end{tabular}

\begin{tabular}{|c|c|}
\hline \multicolumn{2}{|c|}{ Milling Department } \\
\hline Total Number of Machines & 3 \\
\hline Total Number of Operators & 3 \\
\hline Machine and Operator Space & 316.13 \\
\hline Aisle Space and Plant Services & 1.878 \\
\hline Total Space for Milling Department & 318.008 \\
\hline Milling Machine Activity Cost & $\$$ \\
\hline
\end{tabular}

\begin{tabular}{|c|c|}
\hline \multicolumn{2}{|c|}{ Grinding Department } \\
\hline Total Number of Machines & 3 \\
\hline Total Number of Operators & 2 \\
\hline Machine and Operator Space & 379.44 \\
\hline Aisle Space and Plant Services & 4.464 \\
\hline Total Space for Grinding Department & 383.904 \\
\hline Grinding Machine Activity Cost & $\$$ \\
\hline
\end{tabular}

\begin{tabular}{|c|c|}
\hline \multicolumn{2}{|c|}{ Inspection Department } \\
\hline Total Number of Machines & 3 \\
\hline Total Number of Operators & 3 \\
\hline Machine and Operator Space & 203.94 \\
\hline Aisle Space and Plant Services & 3.564 \\
\hline Total Space for Inspection Department & 207.504 \\
\hline Inspection Machine Activity Cost & $\$$ \\
\hline
\end{tabular}

\begin{tabular}{|c|c|}
\hline \multicolumn{2}{|c|}{ Washing Department } \\
\hline Total Number of Machines & 2 \\
\hline Total Number of Operators & 2 \\
\hline Machine and Operator Space & 157.08 \\
\hline Aisle Space and Plant Services & 1.848 \\
\hline Total Space for Inspection Department & 158.928 \\
\hline Inspection Machine Activity Cost & $\$$ \\
\hline
\end{tabular}

Table 0.3 Individual Department Calculations 


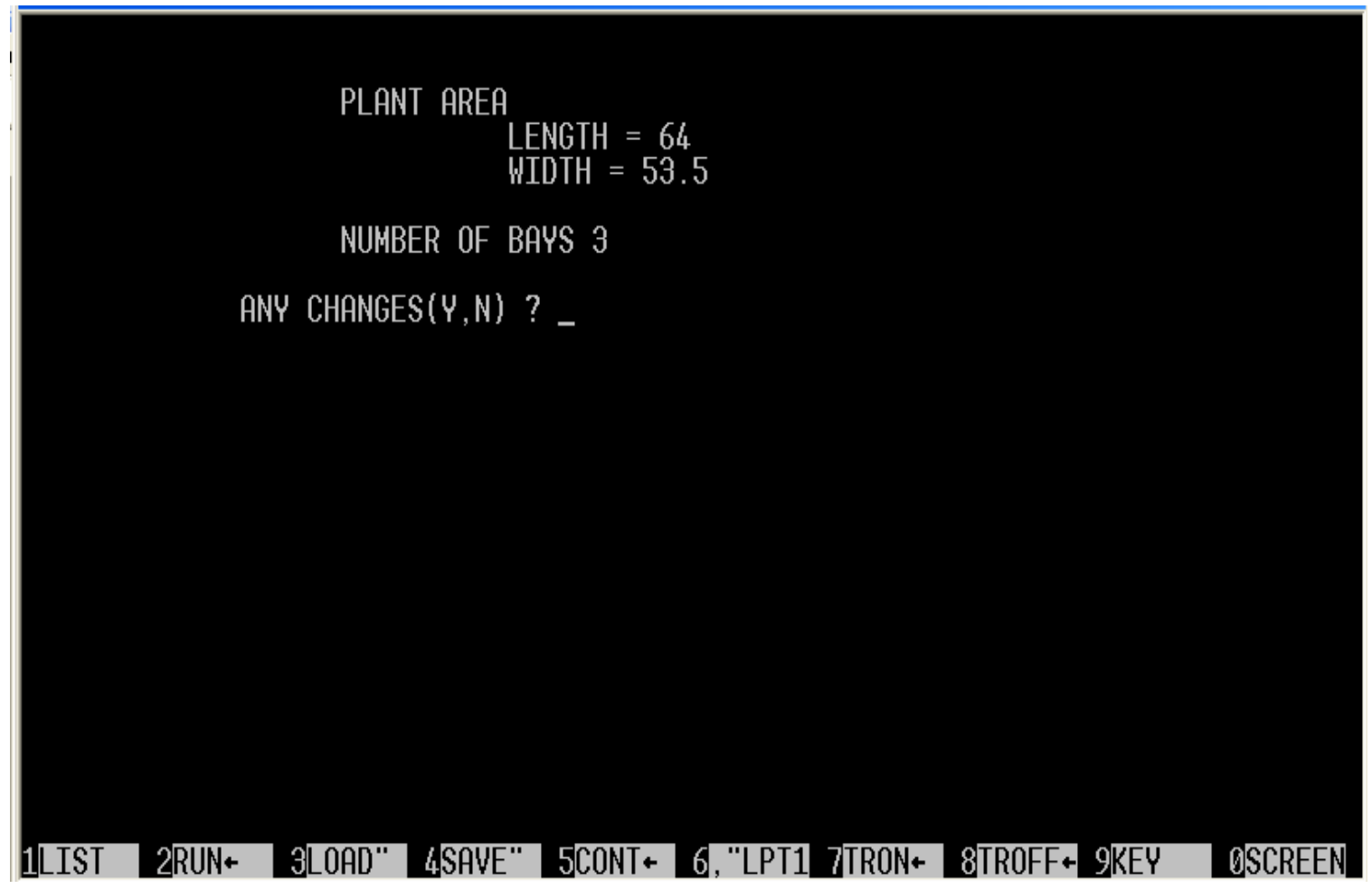

Figure 0.1 M-CRAFT Input Screen 1

SUMMARY OF DEPARTMENTAL AREA

\begin{tabular}{cccccccc} 
DEPT.\# & AREA & DEPT.\# & AREA & DEPT.\# & AREA & DEPT.\# & AREA \\
\hline 1 & 1802 & 2 & 553 & 3 & 318 & 4 & 384 \\
5 & 208 & 6 & 159 & & & &
\end{tabular}

\# OF DEPARTMENT TO CHANGE, O TO CONTINUE ?

1LIST_2RUN+ 3 LOAD" 4 SAVE" 5 CONT+ 6, "LPT1 7TRON+ 8TROFF+ 9KEY QSCREEN

Figure 0.2 M-CRAFT Input Screen 2 
SUMMARY OF

TRAVEL CHART DATA -- FROM DEPARTMENT 1 TO:

\begin{tabular}{|c|c|c|c|c|c|c|c|c|}
\hline $\begin{array}{l}\text { DEP'T } \\
\text { NO. }\end{array}$ & $\begin{array}{l}\text { \# OF } \\
\text { TRIPS }\end{array}$ & $\begin{array}{c}\text { \$/UNIT } \\
\text { DISTANCE }\end{array}$ & $\begin{array}{c}\text { DEP'T } \\
\text { NO. }\end{array}$ & $\begin{array}{l}\text { \# OF } \\
\text { TRIPS }\end{array}$ & $\begin{array}{l}\text { \$/UNIT } \\
\text { DISTANCE }\end{array}$ & $\begin{array}{l}\text { DEP'T } \\
\text { NO. }\end{array}$ & $\begin{array}{l}\text { \# OF } \\
\text { TRIPS }\end{array}$ & $\begin{array}{c}\text { \$/UNIT } \\
\text { DISTANCE }\end{array}$ \\
\hline $\begin{array}{l}2 \\
5\end{array}$ & $\begin{array}{l}49 \\
23\end{array}$ & $\begin{array}{l}\$ 0.50 \\
\$ 0.50\end{array}$ & $\begin{array}{l}3 \\
6\end{array}$ & $\begin{array}{r}11 \\
0\end{array}$ & $\begin{array}{l}\$ 0.50 \\
\$ 0.00\end{array}$ & 4 & 13 & .50 \\
\hline
\end{tabular}

'T0' DEPT.\# TO CHANGE, 0 TO CONTINUE ?

1LIST 2RUN+ 3LOAD" 4SAVE" 5CONT+ 6, "LPT1 7TRON+ 8TROFF+9REY DSCREEN

Figure 0.3 M-CRAFT Input Screen 3

SUMMARY OF

TRAVEL CHART DATA -- FROM DEPARTMENT 2 TO:

DEP'T \# OF \$/UNIT DEP'T \# OF \$/UNIT DEP'T \# OF \$/UNIT

NO. TRIPS DISTANCE NO. TRIPS DISTANCE NO. TRIPS DISTANCE

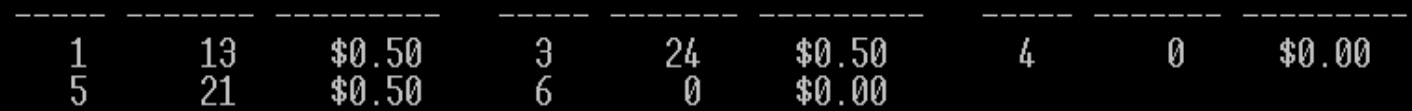

'T0' DEPT.\# TO CHANGE, O TO CONTINUE ?

1LIST 2RUN+ 3LOAD" 4SAVE" 5CONT+ 6,"LPT1 7TRON+ 8TROFF+9REY DSCREEN

Figure 0.4 M-CRAFT Input Screen 4 
SUMMARY OF

TRAVEL CHART DATA -- FROM DEPARTMENT 3 TO:

$\begin{array}{ccccccccc}\text { DEP'T } & \text { \# OF } & \$ \text { \$IUNIT } & \text { DEP'T } & \text { \# OF } & \$ / \text { INIT } & \text { DEP'T } & \text { \# OF } & \$ / \text { UNIT } \\ \text { NO. } & \text { TRIPS } & \text { DISTANCE } & \text { N0. } & \text { TRIPS } & \text { DISTANCE } & \text { N0. } & \text { TRIPS } & \text { DISTANCE } \\ --- & 0 & \$ 0.00 & 2 & 11 & \$ 0.50 & 4 & 0 & \$ 0.00 \\ 1 & 33 & \$ 0.50 & 6 & 0 & \$ 0.00 & & & \end{array}$

'TO' DEPT.\# TO CHANGE, O TO CONTINUE ? -

1LIST 2RUN+ 3LOAD" 4 SAVE" 5CONT+ 6,"LPT1 7TRON+ 8TROFF+ 9REY OSCREEN

Figure 0.5 M-CRAFT Input Screen 5

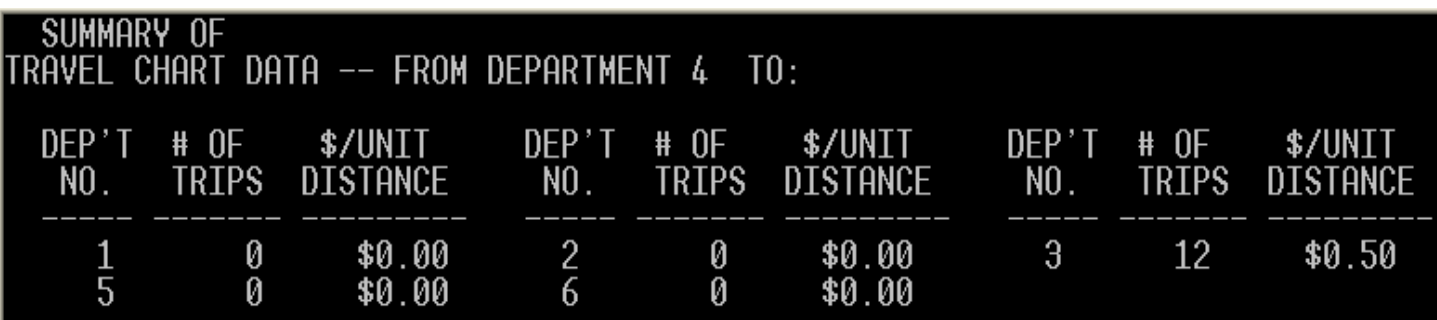

'T0' DEPT.\# TO CHANGE, 0 TO CONTINUE ?

1LIST 2RUN+ 3LOAD" 4 4SAVE" 5CONT+ 6, "LPT1 7TRON+ 8TROFF+ 9REY DSCREEN Figure 0.6 M-CRAFT Input Screen 6 


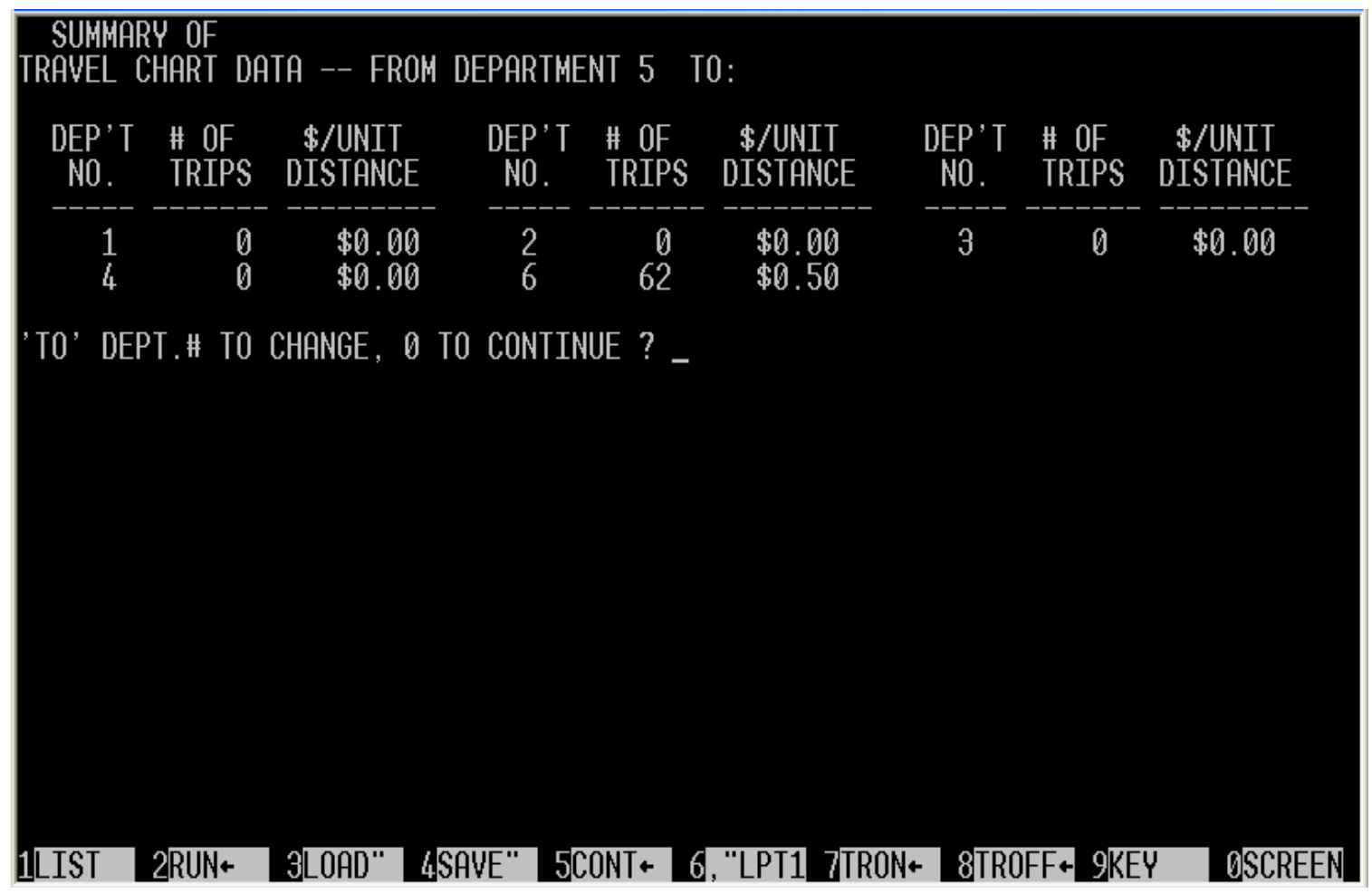

Figure 0.7 M-CRAFT Input Screen 7

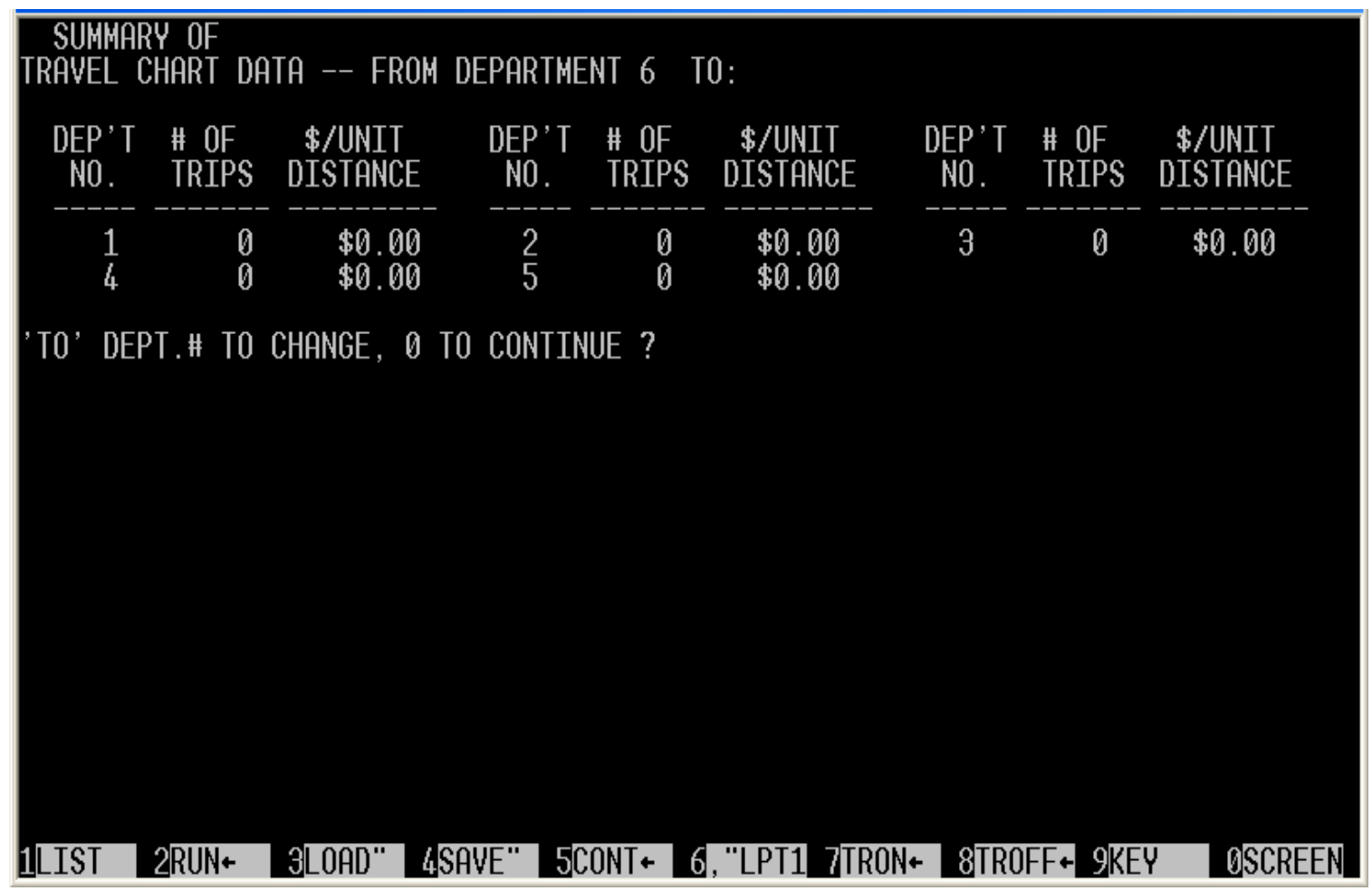

Figure 0.8 M-CRAFT Input Screen 8 


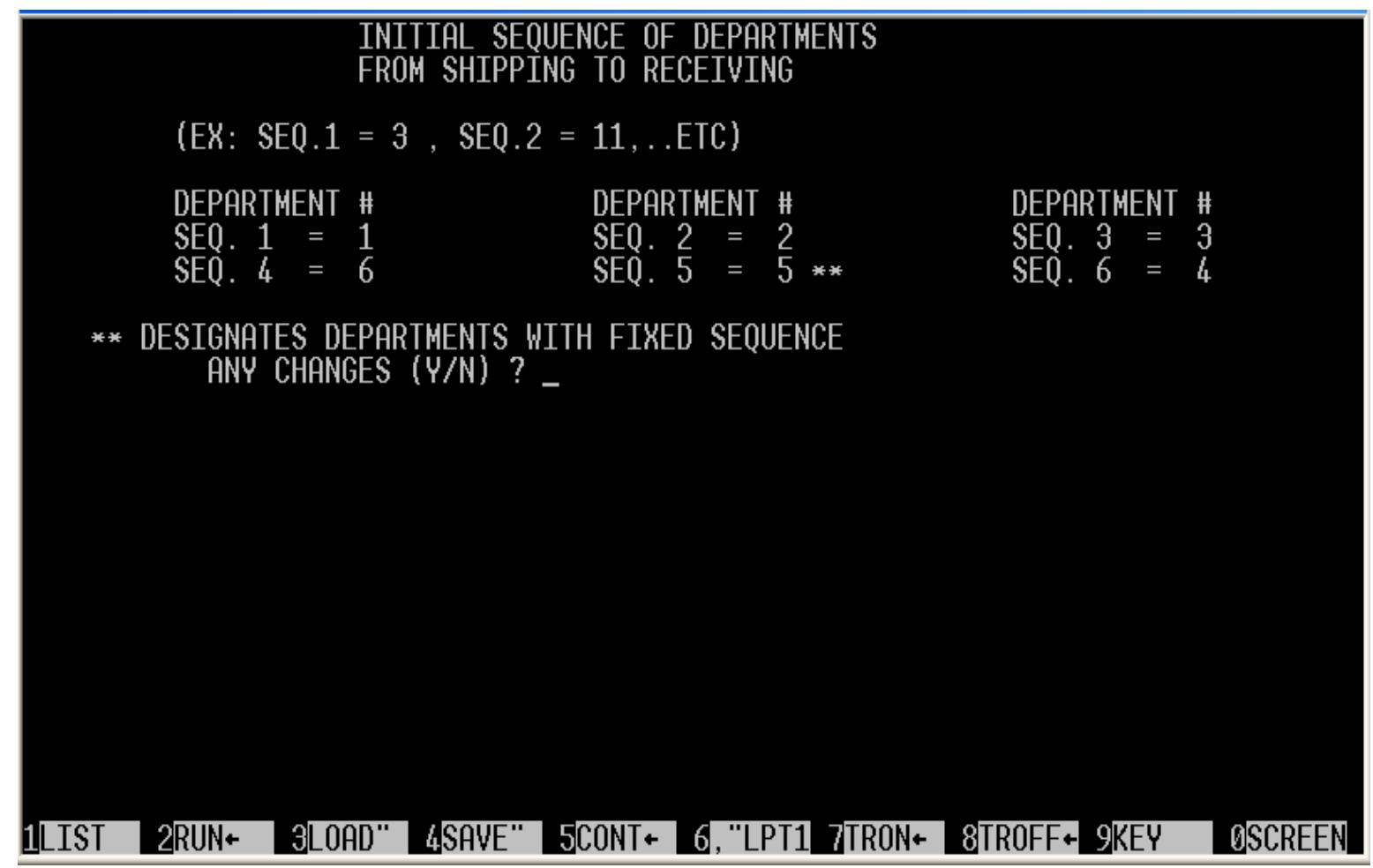

Figure 0.9 M-CRAFT Input Screen 9

DO YOU WANT THE COST TO BE CALCULATED

BY 〈R>ECTILINEAR DISTANCE OR

$B Y<$ E $>$ UCLIDEAN DISTANCE ? R_

1 1LIST 2RUN+ 3LOAD" 4SAVE" 5CONT+ 6, "LPT1 7TRON+ 8TROFF+ 9REY DSCREEN

Figure 0.10 M-CRAFT Input Screen 10 


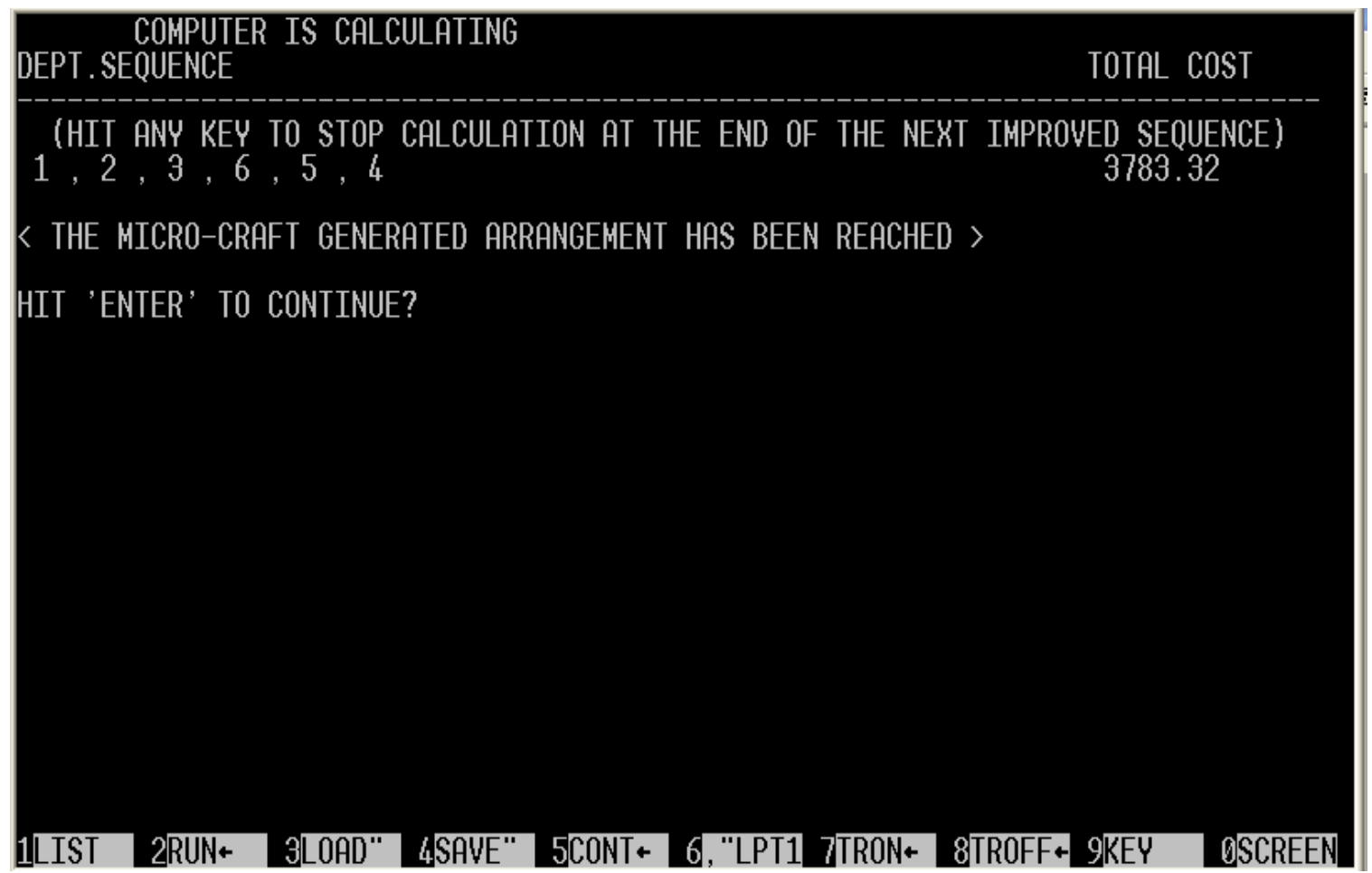

Figure 0.11 M-CRAFT Output Screen 1

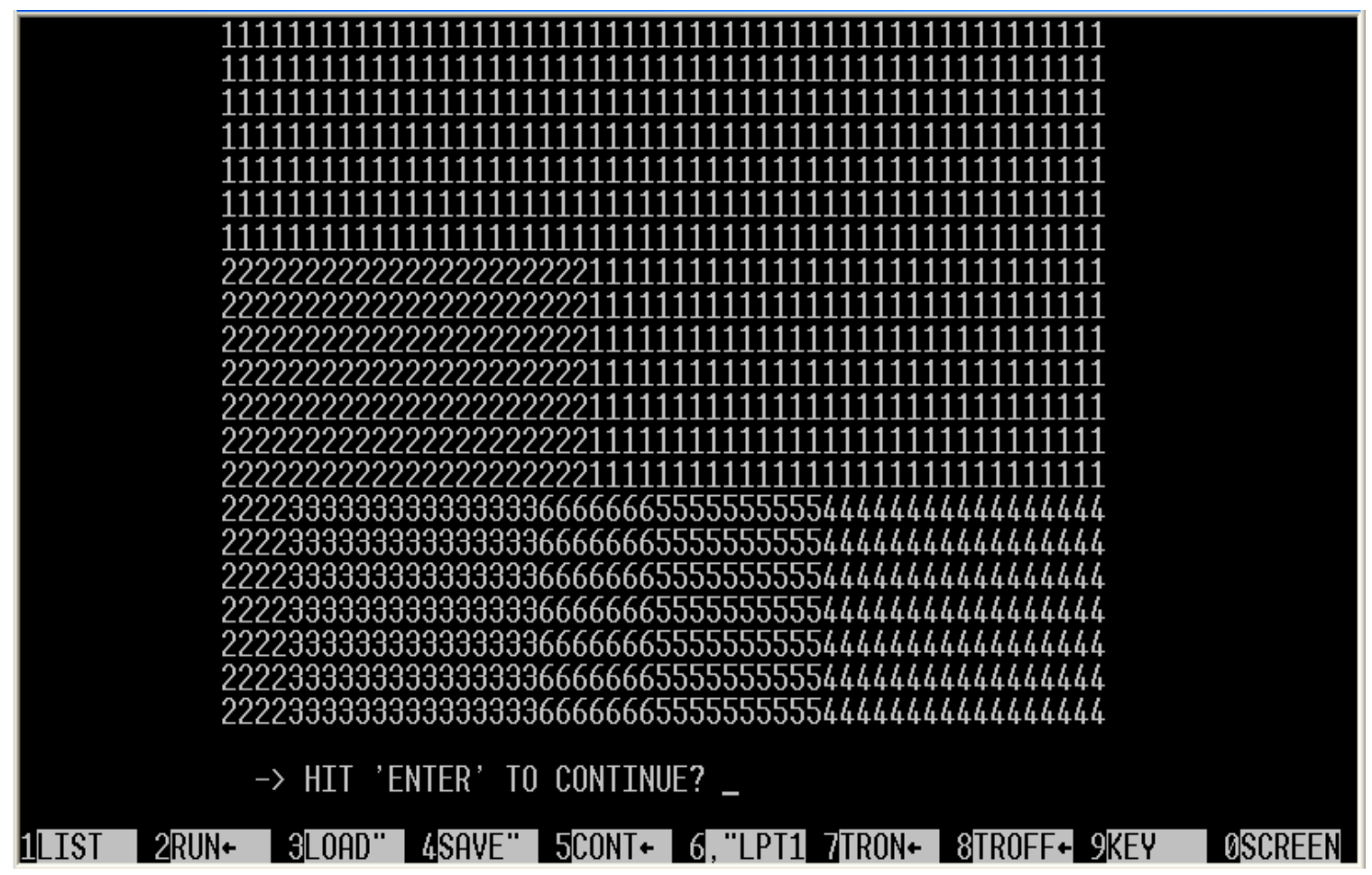

Figure 0.12 M-CRAFT Output Screen 2 
PLANT LENGTH: 64

PLANT WIDTH : 53.5

NUMBER OF BAYS: 3

NUMBER OF DEPARTMENTS: 6

DEPT SEQUENCE:

$1-2-3-6-5 * *-4$

** DESIGNATES DEPARTHENTS WITH FIXED SEQUENCE

DEPT AREA

$1802-553-318-384-208-159$

TOTAL COST : \$ 3783.324

BASED UPON RECTILINEAR DISTANCE

$\rightarrow$ HIT 'ENTER' TO CONTINUE?

1LIST 2RUN+ 3LOAD" 4 SAVE" 5 CONT+ 6,"LPT1 7TRON+ 8TROFF+ 9KEY OSCREEN

Figure 0.13 M-CRAFT Output Screen 3

\section{A1. MCRAFT Results after Scrap Rate was reduced by $50 \%$}

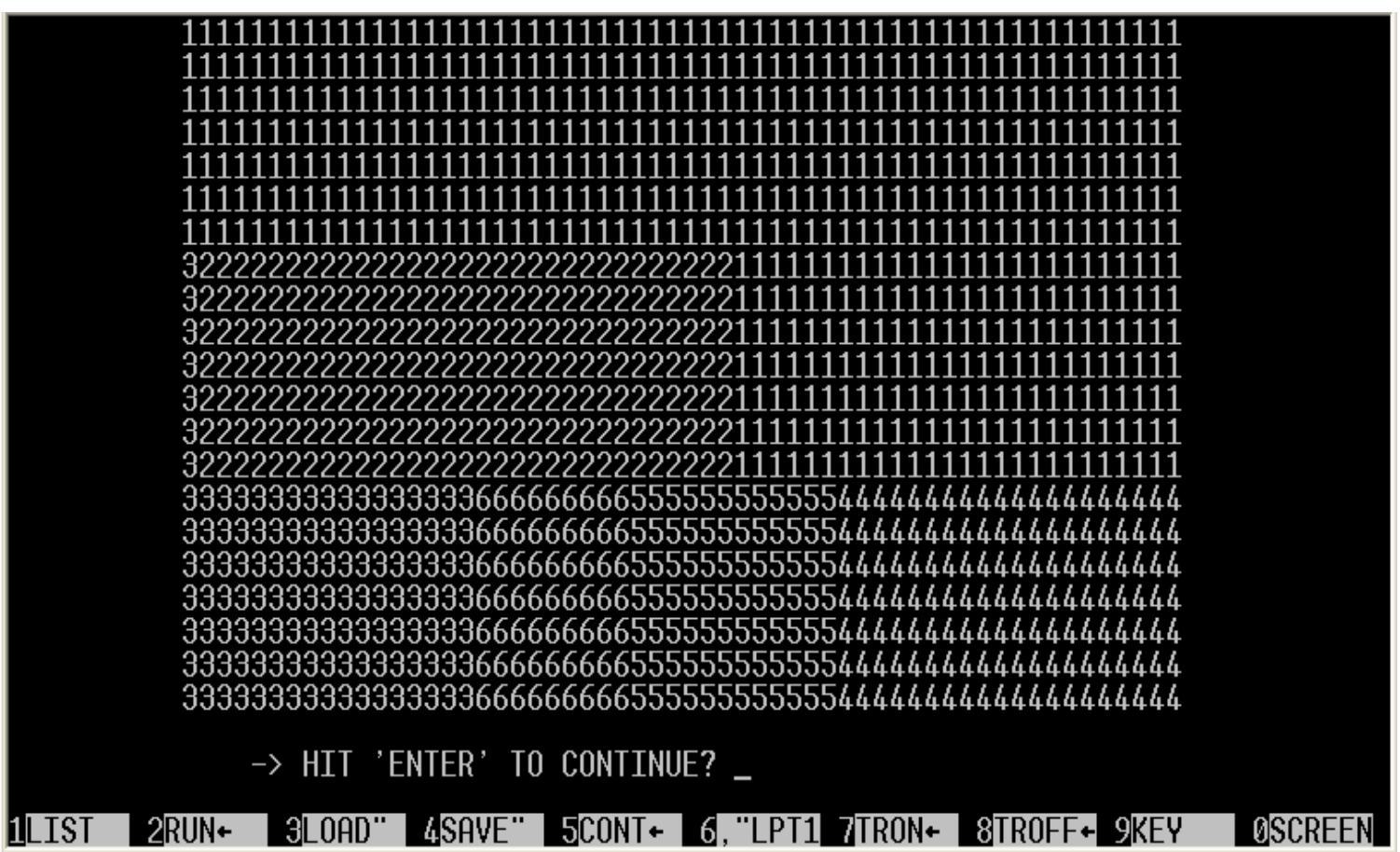

Figure 0.14 M-CRAFT Output Screen 1 when Scrap Rate was reduced by $50 \%$ 
PLANT LENGTH: 64

PLANT WIDTH : 49

NUMBER OF BAYS: 3

NUMBER OF DEPARTMENTS: 6

DEPT SEQUENCE:

$1-2-3-6-5 * *-4$

** DESIGNATES DEPARTMENTS WITH FIXED SEQUENCE

DEPT AREA

$1509-553-318-384-208-159$

TOTAL COST : \$3505.816

BASED UPON RECTILINEAR DISTANCE

$\rightarrow$ HIT 'ENTER' TO CONTINUE? _

1LIST 2RUN+ 3LOAD" 4SAVE" 5CONT+6,"LPT1 7TRON+ 8TROFF+ 9KEY DSCREEN

Figure 0.15 M-CRAFT Output Screen 2 when Scrap Rate was reduced by $50 \%$

\section{A2. MCRAFT Results after Scrap Rate was increased by $50 \%$}

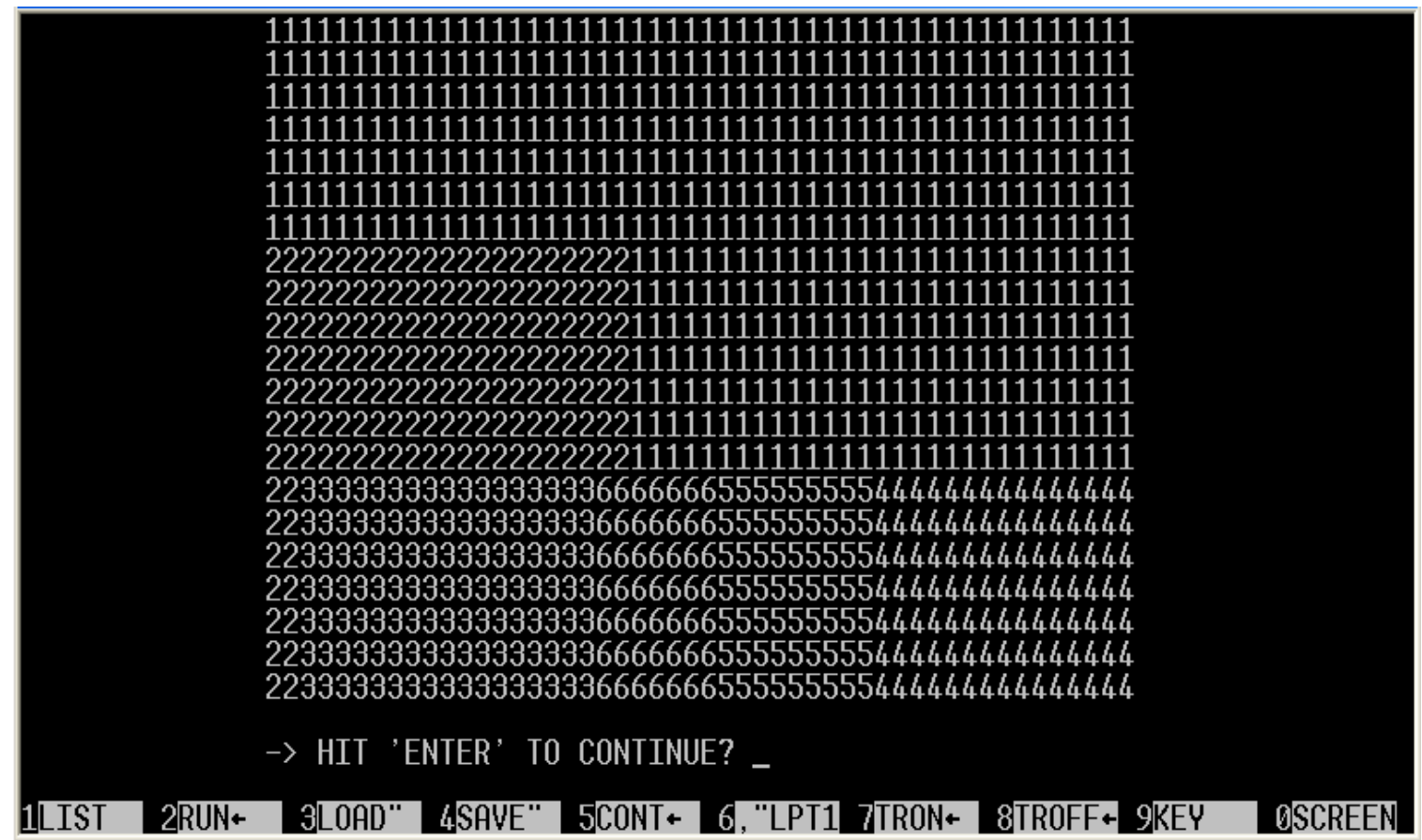

Figure 0.16 M-CRAFT Output Screen 1 when Scrap Rate was increased by $50 \%$ 
PLANT LENGTH: 64

PLANT WIDTH : 57.15

NUMBER OF BAYS: 3

NUMBER OF DEPARTMENTS: 6

DEPT SEQUENCE:

$1-2-3-6-5 * *-4$

** DESIGNATES DEPARTMENTS WITH FIXED SEQUENCE

DEPT AREA

$1936-553-418-384-208-159$

TOTAL COST : \$4180.857

BASED UPON RECTILINEAR DISTANCE

$\rightarrow$ HIT 'ENTER' TO CONTINUE? _

1LIST 2RUN+ 3LOAD" 4SAVE" 5CONT+ 6,"LPT1 7TRON+ 8TROFF+9REY OSCREEN

Figure 0.17 M-CRAFT Output Screen 2 when Scrap Rate was increased by $50 \%$

\section{A3. M-CRAFT Results after Reliability of Machines was reduced by $25 \%$}

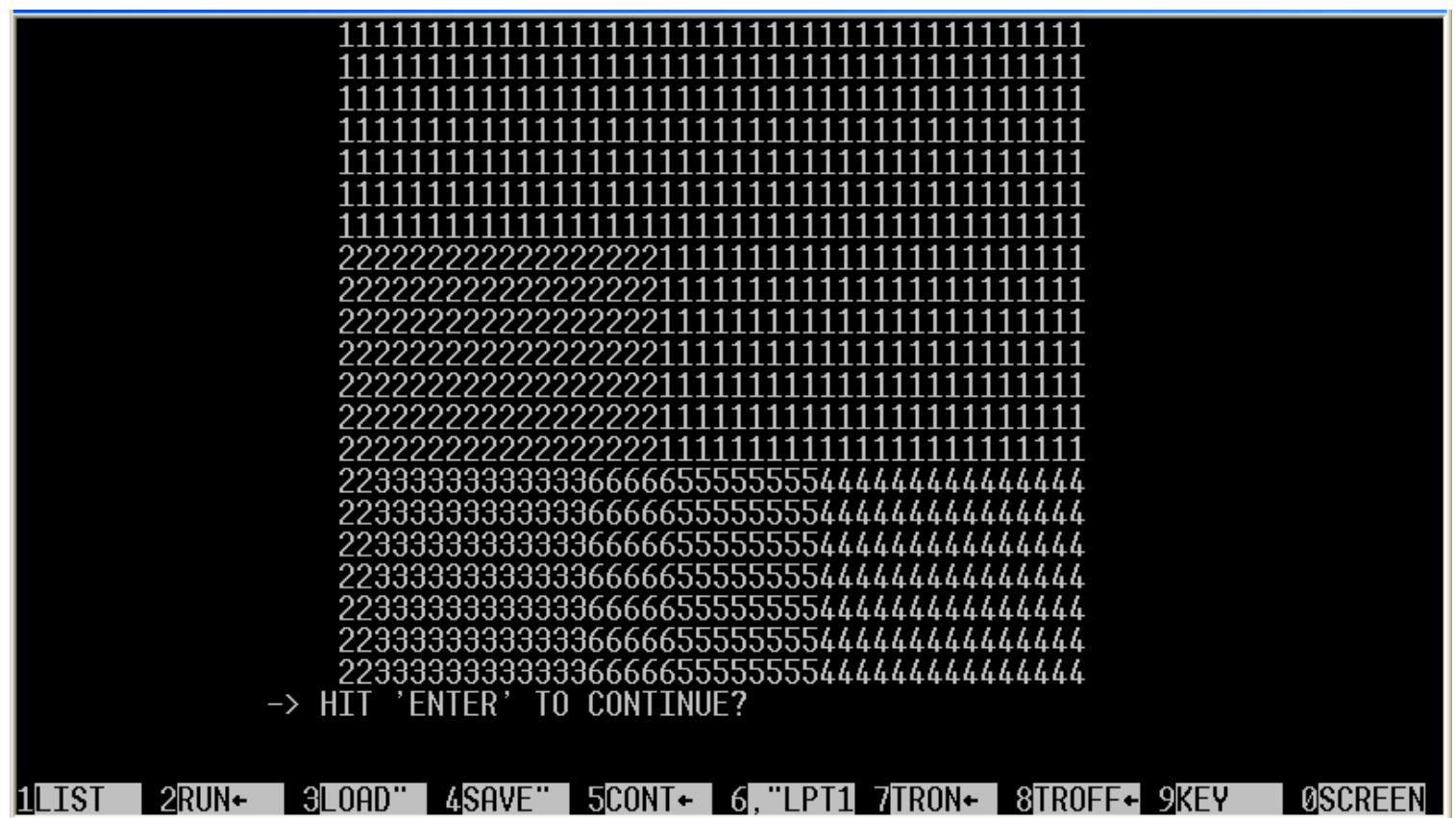

Figure 0.18 M-CRAFT Output Screen 1 when Reliability of Machines was reduced by $25 \%$ 
PLANT LENGTH: 64
PLANT WIDTH : 66.95

NUMBER OF BAYS: 3

NUMBER OF DEPARTMENTS: 6

DEPT SEQUENCE :

$1-2-3-6-5 * *-4$

** DESIGNATES DEPARTMENTS WITH FIXED SEQUENCE

DEPT AREA

$2230-685-418-512-281-159$

TOTAL COST : \$4116.573

BASED UPON RECTILINEAR DISTANCE

$\rightarrow$ HIT 'ENTER' TO CONTINUE? -

1LIST 2RUN+ 3 LOAD" 4 SAVE" 5CONT+ 6,"LPT1 7TRON+ 8TROFF+ 9REY 0 OSCREEN

Figure 0.19 M-CRAFT Output Screen 2 when Reliability of Machines was reduced by 25\%

\section{A4. M-CRAFT Results after Availability of Machines was reduced by $25 \%$}

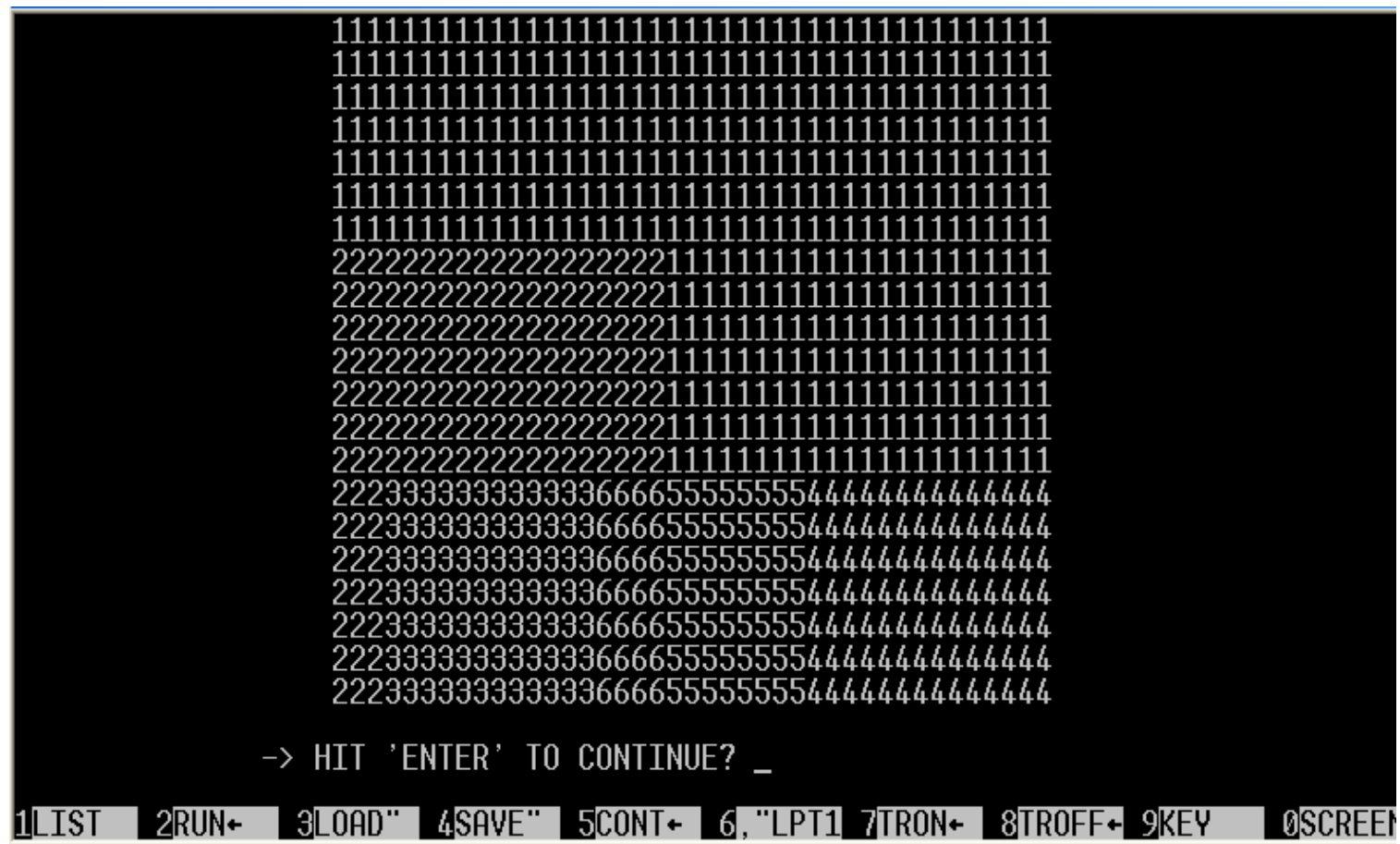

Figure 0.20 M-CRAFT Output Screen 1 when Availability of Machines was reduced by $25 \%$ 


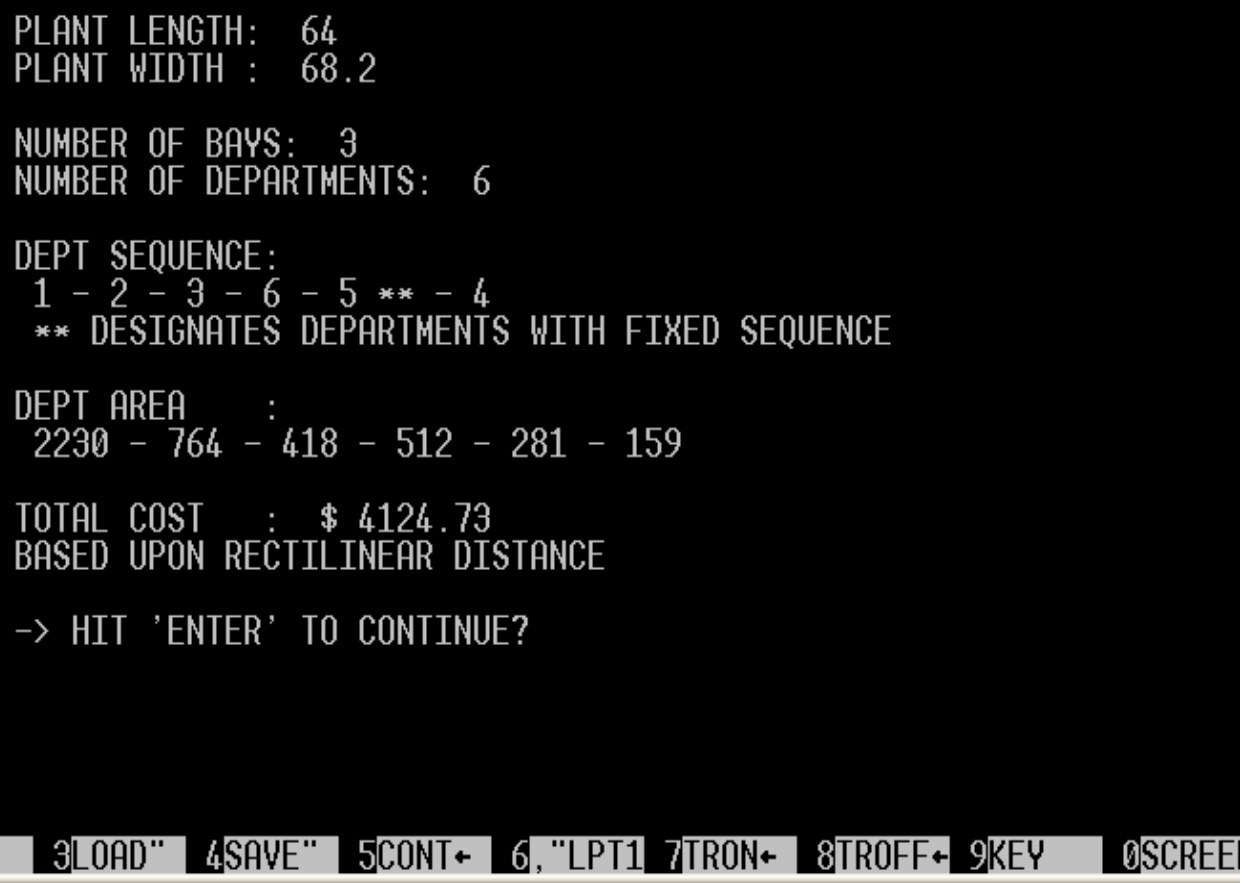

1LIST 2RUN+ 3LOAD" 4 SAVE" 5 CCONT+ 6, "LPT1 7TRON+ 8TROFF+9REY DSCREEl

Figure 0.21 M-CRAFT Output Screen 2 when Availability of Machines was reduced by $25 \%$ 